\section{Unclassified}

Organisation de Coopération et de Développement Economiques

Organisation for Economic Co-operation and Development
ENV/JM/MONO(2000)2

OLIS : 03-Mar-2000

Dist. : 07-Mar-2000

English text only JOINT MEETING OF THE CHEMICALS COMMITTEE AND THE WORKING PARTY ON CHEMICALS

\title{
OECD SERIES ON TESTING AND ASSESSMENT
}

Number 18

Report of the OECD Workshop on Improving the Use of Monitoring Data in the Exposure Assessment of Industrial Chemicals 
ENV/JM/MONO(2000)2 
OECD Environmental Health and Safety Publications

Series on Testing and Assessment

No. 18

\section{REPORT OF THE OECD WORKSHOP ON IMPROVING THE USE OF MONITORING DATA IN THE EXPOSURE ASSESSMENT OF INDUSTRIAL CHEMICALS}

Environment Directorate

ORGANISATION FOR ECONOMIC CO-OPERATION AND DEVELOPMENT

Paris 2000 
ENV/JM/MONO(2000)2 


\section{Also published in the Series on Testing and Assessment:}

No. 1, Guidance Document for the Development of OECD Guidelines for Testing of Chemicals (1993; reformatted 1995)

No. 2, Detailed Review Paper on Biodegradability Testing (1995)

No. 3, Guidance Document for Aquatic Effects Assessment (1995)

No. 4, Report of the OECD Workshop on Environmental Hazard/Risk Assessment (1995)

No. 5, Report of the SETAC/OECD Workshop on Avian Toxicity Testing (1996)

No. 6, Report of the Final Ring-test of the Daphnia magna Reproduction Test (1997)

No. 7, Guidance Document on Direct Phototransformation of Chemicals in Water (1997)

No. 8, Report of the OECD Workshop on Sharing Information about New Industrial Chemicals Assessment (1997)

No. 9, Guidance Document for the Conduct of Studies of Occupational Exposure to Pesticides During Agricultural Application (1997)

No. 10, Report of the OECD Workshop on Statistical Analysis of Aquatic Toxicity Data (1998)

No. 11, Detailed Review Paper on Aquatic Testing methods for Pesticides and industrial Chemicals (1998)

No. 12, Detailed Review Document on Classification Systems for Germ Cell Mutagenicity in OECD Member Countries (1999)

No. 13, Detailed Review Document on Classification Systems for Sensitizing Substances in OECD Member Countries (1999) 
No. 14, Detailed Review Document on Classification Systems for Eye Irritation/Corrosion in OECD Member Countries (1999)

No. 15, Detailed Review Document on Classification Systems for Reproductive Toxicity in OECD Member Countries (1999)

No 16, Detailed Review Document on Classification Systems for Skin Irritation/Corrosion in OECD Member Countries (1999)

No 17, Environmental Exposure Assessment Strategies for Existing Industrial Chemicals in OECD Member Countries (1999)

\section{(C) OECD 2000}

Applications for permission to reproduce or translate all or part of this material should be made to: Head of Publications Service, OECD, 2 rue André-Pascal, 75775 Paris Cedex 16, France. 


\section{ABOUT THE OECD}

The Organisation for Economic Co-operation and Development (OECD) is an intergovernmental organisation in which representatives of 29 industrialised countries in North America, Europe and the Pacific, as well as the European Commission, meet to co-ordinate and harmonize policies, discuss issues of mutual concern, and work together to respond to international problems. Most of the OECD's work is carried out by more than 200 specialised Committees and subsidiary groups composed of Member country delegates. Observers from several countries with special status at the OECD, and from interested international organisations, attend many of the OECD's Workshops and other meetings. Committees and subsidiary groups are served by the OECD Secretariat, located in Paris, France, which is organised into Directorates and Divisions.

The work of the OECD related to chemical safety is carried out in the Environmental Health and Safety Programme. As part of its work on chemical testing, the OECD has issued several Council Decisions and Recommendations (the former legally binding on Member countries), as well as numerous Guidance Documents and technical reports. The best known of these publications, the OECD Test Guidelines, is a collection of methods used to assess the hazards of chemicals and of chemical preparations such as pesticides and pharmaceuticals. These methods cover tests for physical and chemical properties, effects on human health and wildlife, and accumulation and degradation in the environment. The OECD Test Guidelines are recognised worldwide as the standard reference tool for chemical testing.

More information about the Environmental Health and Safety Programme and its publications (including the Test Guidelines) is available on the OECD's World Wide Web site (see page 8).

The Environmental Health and Safety Programme co-operates closely with other international organisations. This document was produced within the framework of the Inter-Organization Programme for the Sound Management of Chemicals (IOMC).

The Inter-Organization Programme for the Sound Management of Chemicals (IOMC) was established in 1995 by UNEP, ILO, FAO, WHO, UNIDO and the OECD (the Participating Organizations), following recommendations made by the 1992 UN Conference on Environment and Development to strengthen co-operation and increase international co-ordination in the field of chemical safety. UNITAR joined the IOMC in 1997 to become the seventh Participating Organization. The purpose of the IOMC is to promote co-ordination of the policies and activities pursued by the Participating Organizations, jointly or separately, to achieve the sound management of chemicals in relation to human health and the environment. 
This publication is available electronically, at no charge.

For the complete text of this and many other Environmental

Health and Safety publications, consult the OECD's

World Wide Web site (http://www.oecd.org/ehs/)

or contact:

OECD Environment Directorate, Environmental Health and Safety Division

2 rue André-Pascal

75775 Paris Cedex 16

France

Fax: (33-1) 45241675

E-mail: ehscont@oecd.org 


\section{Foreword}

This document contains the report of the OECD Workshop on Improving the Use of Monitoring Data in the Exposure Assessment of Industrial Chemicals, which took place in Berlin, Germany on 13th15th May 1998. The Workshop was co-sponsored by the Federal Environment Ministry and Unweltbundesamt. Included in this report are the Workshop's conclusions and recommendations, as well as texts from speakers at the opening plenary session and reports of working group discussions. 


\section{Table of Contents}

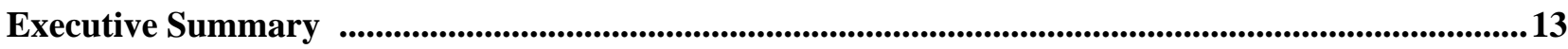

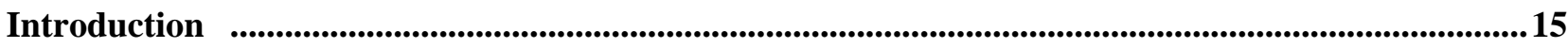

Purpose and Objectives

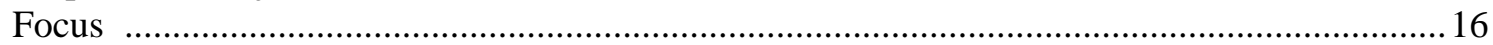

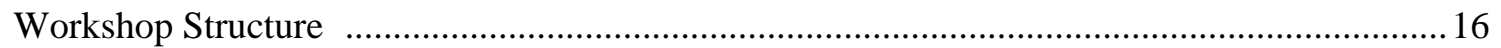

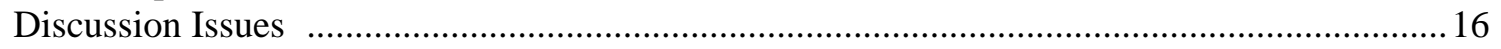

Overview of the Workshop

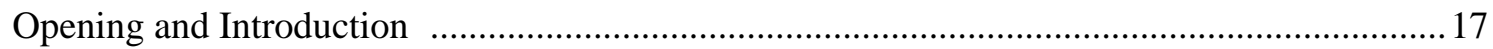

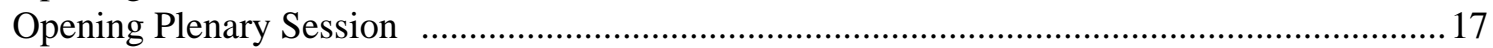

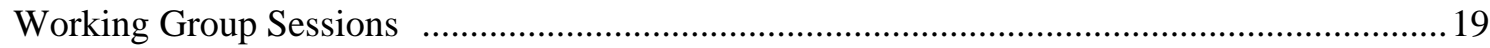

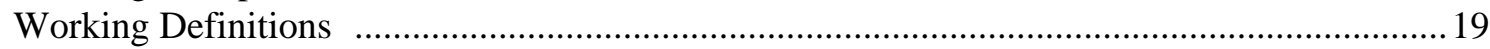

Summary Conclusions

Issue 1: Criteria for Quality and representativeness of Monitoring Data .................................20

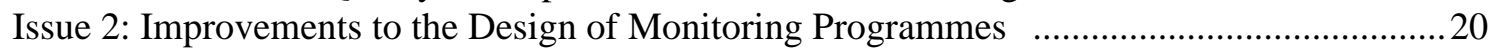

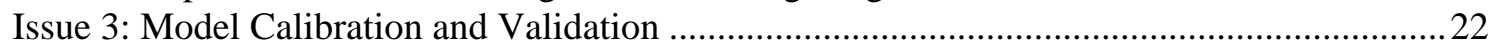

Issue 4: Use of Models in the Design of New Monitoring Initiatives …................................23

Recommendations

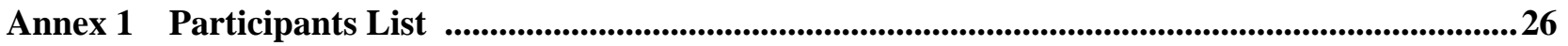

Annex 2 Background Document: Environmental Exposure Assessment Strategies for Existing Industrial Chemicals in OECD Member Countries (Final) ....................................34

Annex 3 Opening Plenary Session Presentations ..............................................................................................42

Monitoring Programmes and Chemical Risk Assessment ....................................................43

Environmental Monitoring, Modelling and Risk Assessment of Industrial Chemicals

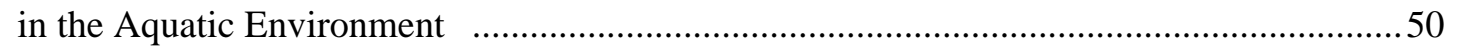

Development of Chemical-Physical Monitoring by the International Commission for the Protection of the Rhine against Pollution ……......................................................59

Two Examples of Japan's Environmental Monitoring Programmes on Chemicals .................64

Monitoring Contaminants in the Hydrological Environment - A Multi Tiered Approach …....70

The European Environment Agency (EEA) and the Monitoring of Chemicals in Europe ........75

Development of a Geography Referenced Regional Exposure Assessment Tool for

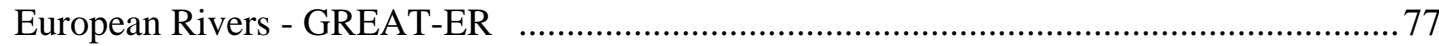

Use of Existing Monitoring Data in Marine Risk Assessment ………………........................ 89

Annex 4 Composition of the Working Groups $\quad$................................................................................................... 98 


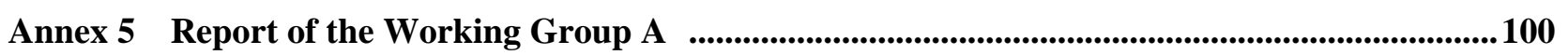

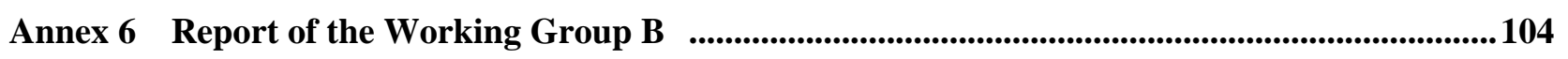

Annex 7 Report of the Working Group C ........................................................................................... 107

Annex 8 Report of the Working Group D ............................................................................................ 114

Annex 9 Members of the Working Group on Environmental Exposure Assessment ..................... 121

Annex 10 Members of the Steering Group for the Workshop ............................................................. 123

Annex 11 References 
ENV/JM/MONO(2000)2 


\section{Executive Summary}

As part of OECD's Risk Assessment Programme, a Workshop on Improving the Use of Monitoring Data in the Exposure Assessment of Industrial Chemicals was held in Berlin, Germany on 13th-15th May 1998. It was co-sponsored by the Federal Environment Ministry and Unweltbundesamt and chaired by $\mathrm{Mr}$ Burkhard Wagner of Unweltbundesamt. The Workshop was attended by 56 people from 17 Member countries, the Slovak Republic, Slovenia, the European Commission, the European Environment Agency (EEA), the Environmental Programme for the DANUBE River Basin (EPDRB), the Global Environment Monitoring System (GEMS)'s GEMS/Water, the Helsinki Commission (HELCOM), the United Nations Economic Commission for Europe (UNECE), the United Nations Environment Programme (UNEP) and several industry groups.

The purpose of the workshop was to improve the use of monitoring data in environmental exposure assessment of industrial chemicals by bringing together people who have different backgrounds, e.g., environmental monitoring, exposure modelling and exposure/risk assessment. The Workshop objectives were to;

(i) share information about different types of chemical monitoring programmes conducted by countries and international bodies;

(ii) share experiences of using measured data in environmental exposure assessment;

(iii) identify ways to improve monitoring programmes so that data from them are of high quality and are appropriate for use in exposure assessment;

(iv) identify ways that existing monitoring data can be used to calibrate and validate exposure models; and

(v) recommend further work for OECD and/or others, as appropriate.

The Workshop focused on the environmental monitoring and exposure assessment of industrial organic chemicals in the aquatic environment (water/sediment systems and biota), because the greatest amount of experience has been gained for this compartment.

The Workshop was organized around a series of plenary sessions and four working groups (i.e., A, B, C and D). Working Groups A and B each addressed (i) the development of criteria for quality and representativeness of monitoring data and (ii) recommendations for improving the design of monitoring programmes. Working Groups $\mathrm{C}$ and $\mathrm{D}$ each discussed (iii) model calibration and validation and (iv) how models can be used to design new monitoring initiatives.

\section{Summary of Discussions}

\section{Criteria for quality and representativeness of monitoring data}

Participants reached consensus on the criteria which could be used to evaluate if monitoring data can be used in exposure assessment. It was stressed, however, that these criteria should be applied in a flexible manner, according to risk assessor's experience and expertise. It was also recognized that applicability of monitoring data is dependent on the scale of the exposure assessment being performed (i.e., local, regional or continental). High priority was given to improving accessibility to monitoring data. 
Improvements to the design of monitoring programmes

A number of recommendations for improvements to the design and performance of monitoring programmes were made. Participants recognized that monitoring programmes should be made more flexible with regard to the choice of substances to monitor so that they could more easily accommodate needs from exposure/risk assessors and that a tiered approach to using monitoring data needs to be incorporated into environmental exposure assessment. To that end, a sustainable dialogue between risk assessors and the monitoring community should be established.

\section{Model calibration and validation}

It was pointed out that calibration and validation of environmental exposure models requires chemicals property data, environmental data, and emission/source data, but, that the last two types of data, particularly geo-referenced ones, are not readily available. Participants recognized that the limitations with the use of monitoring data for model calibration and validation arise mainly from (i) design of monitoring programmes which do not provide for collection of all information required for calibration and validation, (ii) uncertainty of monitoring data and (iii) limited access to monitoring data. It was a general view that most models are not yet adequately validated although a number of validation activities are taking place.

\section{Use of models in the design of new monitoring initiatives}

There was an observation that environmental fate and distribution models had not yet been incorporated into the design stage of monitoring programmes and it was agreed that awareness of the benefits of using these models for this purpose should be promoted amongst the monitoring community. A number of benefits of the use of models were identified. The type of model to help design monitoring programmes should be decided on a case by case, considering the objectives of the monitoring programme and the environmental processes operating in the system so that monitoring programmes can be tailored according to the characteristics of the system of interest.

\section{Recommendations}

There were seven major recommendations:

1) Improve availability of existing and future monitoring data.

2) Improve access to information on chemical emissions.

3) Include considerations of exposure assessment requirements in the design of monitoring programmes.

4) Increase the number of model validation studies.

5) Harmonize monitoring and modelling terminology.

6) Improve the awareness of funding bodies regarding the importance of monitoring activities in human health and environmental protection.

7) Continue the dialogue among the monitoring, modelling and exposure/risk assessment communities initiated by this workshop. 


\section{Introduction}

One of the key elements in the risk assessment of chemicals is estimating the concentrations that are likely to occur in the environment, i.e., the Predicted Environmental Concentration (PEC). PECs can be derived using either measured data from environmental monitoring studies, or predictions from exposure models.

Some countries (e.g., Japan, Canada and the US) rely more heavily on monitoring data to derive PECs and have a wealth of experience in designing and conducting monitoring programmes. Other countries, such as those of the European Union, tend to rely more on model predictions for exposure assessment. Both approaches have their advantages and disadvantages. Good monitoring data directly reflect real concentrations in the environment but can be very expensive to obtain. The use of models to predict PECs is much less expensive than monitoring programmes, but the accuracy of their predictions is more uncertain. For new chemicals, however, the use of models is the only option available for exposure assessment.

Improvements can be made to both approaches used to derive PECs. For example, the design of new monitoring initiatives could be improved such that they would provide data more appropriate for use in the exposure assessment of chemicals. Criteria could be developed to help exposure assessors decide whether existing monitoring data are suitable, and better use could be made of monitoring data to calibrate and validate exposure models.

In order to make these improvements possible, as part of OECD's Risk Assessment Programme, a Workshop on Improving the Use of Monitoring Data in the Exposure Assessment of Industrial Chemicals was held in Berlin, Germany on 13th-15th May 1998, co-sponsored by the Federal Environment Ministry and Unweltbundesamt.

\section{Purpose and Objectives}

The purpose of the Workshop was to improve use of monitoring data in environmental exposure assessment by bringing together people experienced in environmental monitoring programmes with those involved in exposure models and risk assessments. The workshop objectives were to:

(i) share information about different types of chemical monitoring programmes conducted by countries and international bodies;

(ii) share experiences of using measured data in environmental exposure assessment;

(iii) identify ways to improve monitoring programmes such that data are of high quality and are appropriate for use in exposure assessment;

(iv) identify ways that existing monitoring data can be used to calibrate and validate exposure models; and

(v) recommend further work for OECD and/or others, as appropriate. 


\section{Focus}

The workshop focused on the environmental monitoring and exposure assessment of industrial organic chemicals in the aquatic environment (water/sediment systems and biota), because the greatest amount of experience has been gained for this compartment.

\section{Workshop Structure}

Discussions at the workshop were organised around a series of plenary and working group sessions. It began with an opening plenary to review the workshop's objectives, to share information about different types of chemical monitoring programmes conducted by countries and international bodies, and to set the scene for more detailed discussion on various aspects of environmental monitoring, exposure modelling and exposure/risk assessment. After the opening plenary session, the workshop participants broke out into four working groups (i.e., A, B, C and D), to address specific issues and, at regular intervals, to present their conclusions in plenary. The workshop ended with a Closing Plenary Session to agree on the workshop's conclusions and recommendations.

\section{Discussion Issues}

\section{Issue 1: Criteria for quality and representativeness of monitoring data}

The purpose of these discussions was to develop a series of criteria for quality (sampling and analysis), representativeness and coverage (in relation to exposure assessment scenarios) of monitoring data that exposure assessors can use when deciding whether the data can be used in exposure assessment. Discussions focused on the representativeness and coverage of monitoring data, since much work has already been done on quality criteria for monitoring studies and data.

\section{Issue 2: Improvements to the design of monitoring programmes}

The goal was to develop a list of recommendations to the monitoring community (i.e. government, industry, international bodies) describing the minimum requirements for monitoring programmes, including a strategy of how to proceed (e.g., a tiered approach). The objective in doing this is to ensure that future chemical monitoring programmes will provide the exposure endpoints required for exposure assessment in the context of risk assessment.

\section{Issue 3: Model calibration and validation}

The objective of discussion issue 3 was to (1) develop guidance on which monitoring data can be used to calibrate or validate models, (2) develop guidance on how data gaps for calibration and validation can be filled, (3) identify criteria that can be used to decide if a model has been validated, and (4) develop guidance on what to do when monitoring data and model predictions give different results.

\section{Issue 4: Use of models in the design of new monitoring initiatives}

The goal was to recommend and give examples of how risk and exposure assessment models could be used to help design new monitoring initiatives. For example, (1) multi-media fate models may be useful in identifying which compartments should be monitored and (2) predicted environmental concentrations can be used to help decide the level of detection needed for analytical techniques. 


\section{Overview of the Workshop}

The Workshop was attended by 56 people from 17 Member countries, the Slovak Republic, Slovenia, the European Commission, the European Environment Agency (EEA), the Environmental Programme for the Danube River Basin (EPDRB), GEMS/Water, the Helsinki Commission (HELCOM), the United Nations Economic Commission for Europe (UNECE), the United Nations Environment Programme (UNEP) and several industry groups (see the list of participants in Annex 1).

\section{Opening and Introduction}

Mr Klaus-G. Steinhäuser (Umweltbundesamt, Germany) opened the Workshop and welcomed all participants. Mr Steinhäuser noted that since the OECD Workshop on Exposure Assessment held in Berlin in 1991, exposure assessment had become a fully recognized component of the risk assessment of chemicals, and added that the discipline of exposure assessment, particularly the use of monitoring data is in rapid development. He explained that this 1998 Workshop might prove to be a landmark by initiating sustainable dialogue between experts of risk assessment, exposure modelling and monitoring.

Ms Nicky Grandy (OECD Secretariat) gave a presentation about the context of the workshop within the OECD Chemicals Programme. She explained that the OECD's Chemicals Programme focuses on two aspects; (i) tools to assess and manage risks, and (ii) co-operative assessment of chemicals by Member countries. Better use of monitoring data in exposure assessment will help to improve tools for estimating Predicted Environmental Concentrations (PECs) of chemicals in the environment, which can be applied, for example, within the Existing Chemicals Programme.

Mr Burkhard Wagner (Umweltbundesamt, Germany) outlined the objectives of the workshop and introduced the Workshop structure. Mr Wagner chaired the Workshop plenary sessions.

\section{Opening Plenary Session}

The opening plenary session was designed to increase mutual understanding among exposure/risk assessors, modellers and monitoring experts. Ten topics in total were presented by experts from different fields. The first three topics set the scene for working group discussions, the next four gave examples of successful monitoring programmes, and the last three introduced practical lessons, using examples of specific chemicals. All texts provided by the speakers are provided in Annex 3.

\section{Setting the Scene}

Firstly, Mr Patrick Doyle (Environment Canada) gave a talk on "Risk Assessment and Use of Monitoring Data". He provided monitoring people with information regarding environmental exposure assessment, referring to the Background Document "Environmental Exposure Assessment Strategies for Existing Industrial Chemicals in OECD Member Countries", which he had developed in consultation with the OECD Working Group on Environmental Exposure Assessment (see Annex 2). He also explained how monitoring data are used when available, and introduced the problems which the environmental exposure assessors are facing, e.g., quality of monitoring data, data representativeness, data availability.

Mr Jos Timmerman (RIZA, the Netherlands) delivered a talk on "Monitoring Programmes and Chemical Risk Assessment". This presentation was made from the viewpoint of people involved in environmental monitoring. He introduced different types of monitoring programmes and explained how the monitoring 
data are used. Data quality and quantity from monitoring programmes were also discussed. "State-of-the art" monitoring programmes, including their cost effective design and communication between monitoring people and exposure assessors were mentioned.

Mr Tom Feijtel (Procter \& Gamble, ECETOC) talked about "Environmental Monitoring, Modelling and Risk Assessment of Industrial Chemicals in the Aquatic Environment". The objective of this presentation was to focus on contradictions, issues, and where we had learnt from each other, particularly the interplay between models and monitoring data.

\section{Overviews of Successful Monitoring Programmes}

Mr Klaus Vogt (State Environment Agency North Rhine - Westphalia, Germany) spoke about "Development of Chemical-Physical Monitoring by the International Commission for the Protection of the Rhine against Pollution". He gave an overview and historical perspective of chemical loading in Rhine river and their trends over time. What data had been measured, how those data had been evaluated and what actions had been taken were highlighted, taking into consideration the interaction of modelling and monitoring.

Mr Kiyoshi Tanabae (National Institute for Environmental Studies, Japan) presented "Two Examples of Japan's Environmental Monitoring Programmes on Chemicals" He described two environmental programmes; (i) general inspection survey (surface water, sediment, biota etc.) and (ii) monitoring of hazardous air pollutants (HAPs). He reported that the general inspection survey provided information on the concentration of chemicals in multi-compartments which was evaluated and used for the early warning of pollution. Comparisons of measured concentrations and predicted concentrations by using models were also discussed. With respect to the HAPs monitoring programme, how the monitoring system had been designed following a tiered approach in risk/exposure assessment and how the obtained data had been used in the environmental exposure assessment were introduced.

Mr Larry B. Barber (Unites States Geological Survey, US) delivered a talk on "Monitoring Contaminants in the Hydrological Environment - A Multi Tiered Approach". The United States Geological Survey (USGS) has a long history of monitoring the water quality of the surface and ground waters of the U.S. Mr Barber described the approach which the USGS had used to design monitoring programmes of varying scale and detail, to develop appropriate sampling and analytical methodologies, and to evaluate the water quality data from a hydrogeochemical perspective. Utilization of the scientific information derived from the monitoring programmes by water resource managers was also discussed.

Mr Bo Jansson (Stockholm University, Scientific Committee of EEA) spoke about "The European Environment Agency (EEA) and the Monitoring of Chemicals in Europe". He reported that the European programmes for monitoring chemicals in the environment are mainly focused on compounds that are already banned or restricted which enable the effects of the measures taken to be followed. However, he suggested that different programmes are needed to support the risk assessment work for existing

chemicals. He recognised that this is a huge task that should be shared between several countries. EEA could be a co-ordinator of the European efforts within this field.

\section{Practical Lessons for Specific Chemicals}

Practical lessons for specific chemicals were highlighted by three speakers.

Mr Walter Giger (Swiss Federal Institute for Environmental Science and Technology, Switzerland) made a presentation of "Micropollutants in the Environment: from Environmental Monitoring to Process- 
oriented Field Studies". his presentation discussed several chemicals which had been discharged to the aquatic environment from municipal and industrial wastewaters including the organic complexing agents NTA and EDTA, fluorescent whitening agents, nonylphenol and nonylphenolethoxylates. It was reported that monitoring data revealed the impact of risk reduction measures on specific emissions. He noted that these process-oriented field studies combined measured data with the results of mathematical modelling and aimed at providing information on the fate-determining transport, transfer and transformation processes. (Note: His papers are not included in this report. See more details in "EAWAG news 40 E, July 1996".)

Mr Martin Holt (ECETOC) delivered a talk about "Development of a Geography Referenced Regional Exposure Assessment Tool for European Rivers - Great-ER". The Geography-Referenced Regional Exposure Assessment Tool for European Rivers (GREAT-ER) is a computer software system which can be used to calculate a realistic distribution of environmental concentrations of down-the-drain chemicals in European surface water. He introduced the concept of GREAT-ER and how monitoring data had been used for validation of this modelling approach, referring to linear alkylbenzene sulphonate (LAS) as a case-study for detergents.

Mr André Lecloux (EuroChlor, Brussels) made a presentation of "Use of Existing Monitoring Data in Marine Risk Assessment". This presentation described the collation, evaluation and use of existing monitoring data for rivers, estuaries and seas to assess exposure levels in the marine environment. Practical examples were presented and discussed to assess the risk for the marine environment in the case of chlorinated organic compounds.

\section{Working Group Sessions}

Working Groups A and B each addressed Issues 1 and 2 and Working Groups C and D each discussed Issues 3 and 4. The composition of the Working Groups are shown in Annex 4.

Summary reports of working group discussions are attached as Annexes 5 to 8 for Working Groups A to D respectively.

\section{Working Definitions}

The following working definitions were used at the Workshop:

\section{- Calibration}

The process in which the initial parameter estimates are refined to improve agreement between model predictions and observed data to fall within criteria.

\section{- Validation}

Process of confirming that the model accurately represents the process it is designed to mimic. Validation requires applying a calibrated model to a new scenario and then evaluating the agreement between model predictions and observed data.

\section{- Verification}

Test of the internal logic of the model. This includes scientific acceptance that 1) the model includes all major and salient processes, 2) the process are formulated correctly, and 3 ) the model suitably describes observed phenomena for the use intended. 


\section{Summary Conclusions}

\section{Issue 1: Criteria for Quality and Repesentativeness of Monitoring Data}

Participants reached consensus on the criteria which could be used to justify if monitoring data can be used in exposure assessment (see Table 1). It was stressed, however, that these criteria should be applied in a flexible manner. For example, data should not always be discounted simply because they do not meet the criteria. Risk assessors can make a decision to use the data or not, on a case by case basis, according to their experience and expertise and the needs of the risk assessment. In general it was felt that more recent monitoring data may be most useful for exposure assessments. However, when looking at concentration trends over time, older monitoring data may also be useful.

It was agreed that the applicability of monitoring data is dependent on the scale of the exposure assessment being performed (i.e., local, regional or continental). Traditional monitoring programmes, such as those for water quality, have been designed to avoid too much influence from point sources.

High priority was given to improving accessibility to monitoring data so that opportunities for their use in exposure assessment could be increased. Both working groups A and B made recommendations about how accessibility could be improved (see Annexes 5 and 6). For the purposes of risk assessment, aggregated data (e.g., 90 percentile, number of samples and ranges) are preferred rather than basic (raw) data.

\section{Issue 2: Improvements to the Design of Monitoring Programmes}

A number of recommendations for improvements to the design and performance of monitoring programmes were made. These included:

- decreasing monitoring activities for banned or severely restricted chemicals - especially when concentrations are below levels of concern and where they have been steadily falling in recent years;

- making monitoring programmes more flexible so that additional chemicals can be added more easily (e.g., chemicals appearing on new priority substance lists);

- using geo-reference models to help identify potential areas of concern;

- increasing efficiency of chemical analysis, e.g., (1) sharing the cost and burden of the development of new analytical methods where possible (when several bodies/organisations are involved in a monitoring programme) and (2) adding further substances that can be analysed in the same way/using the same method;

- improving the reporting of information, i.e. to include items listed in Table 1, parameters that can influence bioavailability (e.g., organic carbon, $\mathrm{pH}$ ) and maximum, minimum and percentile concentrations of chemicals reflecting spatial and temporal variation;

- creating a sustainable dialogue between risk assessors and the monitoring community to increase the understanding of why particular substances are on priority lists, to improve awareness of and access to existing monitoring data, and to discuss and compare methods for deriving quality objectives and PNECs, and

- applying a tiered approach to using monitoring data in risk assessments in a similar way as practised in Japan and used in the UN/ECE Guidelines on Water Quality Monitoring of Transboundary Rivers. Considering the large number of substances in use, it is not possible to monitor them all. Priorities should be set based on potential hazard and exposure. High priority substances should then be monitored in the environment. 
For monitoring in the vicinity of industrial facilities, a number of general recommendations were made, i.e. that a description of the site, the emission controls in place, the identity of the compartment of concern and the dilution of the discharge be developed and that measurements during high and low receiving water flows should be taken.

Table 1: Minimum Information to Justify Use of Existing Ambient Monitoring Data

\begin{tabular}{|c|c|c|}
\hline Criteria & Ideal Set & $\begin{array}{c}\text { Minimum Set for } \\
\text { Exposure Assessment }\end{array}$ \\
\hline Objective of the programme & $\checkmark$ & \\
\hline What has been analysed ? ${ }^{1)}$ (e.g., pore water, bulk, water column) & $\checkmark$ & $\checkmark$ \\
\hline Analytical method $^{2)}$ & $\checkmark$ & $\checkmark$ \\
\hline Unit & $\checkmark$ & $\checkmark$ \\
\hline Limit of quantification (LOQ) $)^{3)}$ & $\checkmark$ & $\checkmark$ \\
\hline Blank concentration $^{4)}$ & $\checkmark$ & \\
\hline Recovery $^{5)}$ & $\checkmark$ & \\
\hline Accuracy $^{6}$ & $\checkmark$ & \\
\hline Reproducibility $^{7}$ & $\checkmark$ & \\
\hline $\begin{array}{l}\text { Sampling protocol (e.g., grab samples, continuous sampling, } \\
\text { duration, filtered/unfiltered, sampling frequency and pattern }{ }^{8} \text { ) }\end{array}$ & $\checkmark$ & $\begin{array}{l}\text { (see statistical evaluation } \\
\text { below) }\end{array}$ \\
\hline One shot or mean ${ }^{9)}$ & & $\checkmark$ \\
\hline Location $^{10)}$ & $\checkmark$ & $\checkmark$ \\
\hline Date $\mathrm{dd} / \mathrm{mm} / \mathrm{yy}^{11)}$ & $\checkmark$ & $\begin{array}{l}\text { Minimum is } \\
\text { knowledge of year }\end{array}$ \\
\hline Time & $\checkmark$ & \\
\hline $\begin{array}{l}\text { Matrix characteristics (e.g., OC-content, size and age of } \\
\text { organisms) }\end{array}$ & $\checkmark$ & \\
\hline Proximity and influence of sources ${ }^{12)}$ & $\checkmark$ & $\checkmark$ \\
\hline Discharge emission pattern and volume ${ }^{13)}$ & $\checkmark$ & \\
\hline Flow and dilution or application rate of water body sampled & $\checkmark$ & $\checkmark$ \\
\hline Explanation of value assigned to non-detects if used in a mean & $\checkmark$ & $\checkmark$ \\
\hline Description of statistical evaluation of results & $\checkmark$ & $\begin{array}{l}\text { Minimum required is whether } \\
\text { one-shot or mean }\end{array}$ \\
\hline
\end{tabular}

Notes

1. Precisely what has been analysed should be clear. Details of the sample preparation, including for example whether the analysis was of the dissolved fraction, the suspended matter (i.e., adsorbed fraction) or the total (aqueous and adsorbed) should be given.

2. The analytical method should be given in detail or the scientific publication (e.g., the relevant ISO/DIN method or standard operating procedure) should be referenced.

3. The limit of detection (LOD) and details of possible interfering substances should be quoted. There is normally a fixed relation between LOD and LOQ, so LOQ may be calculated from the LOD.

4. Concentrations in system blanks should be given to support the minimum level of detection.

5. Recovery of laboratory and field standard additions (spikes) should be quoted.

6. The relationship between the measured concentration and the LOD should be given. Results of analysis of standard "reference samples", containing a known quantity if the substance. Accuracy is connected to analytical method and the matrix.

7. The degree of confidence and standard deviation in the results from repeat analyses should be given. Reproducibility is also connected to analytical method and the matrix.

8. Whether the sampling frequency and pattern relate to the emission pattern, or whether they allow for effects such seasonal variations need to be considered.

9. The assessor needs to know how the data have been treated, e.g., are the values reported single values, means, $90 \%$-ile, etc.

10. The monitoring site should be representative of the location and scenario chosen. If data represent temporal means, the time over which concentrations were averaged should be given too. 
11. The time, day, month and year may all be important depending upon the release pattern of the chemicals. For some modelling and trend analysis, the year of sampling will be the minimum requirement.

12. For the aqueous environment, detailed information on the distance from and influence of other sources in addition to qualitative information on flow and dilution (see "Flow and dilution or application rate of water body sampled") are needed.

13. Whether there is a constant and continuous discharge, or whether the chemical under study is released as a discontinuous emission showing variations in both volume and concentration with time need to be considered.

\section{Issue 3: Model Calibration and Validation}

The calibration and validation of environmental exposure models requires (i) chemical property data (e.g., physico-chemical properties, biodegradability), (ii) environmental data (e.g., controlling variables such as $\mathrm{pH}$, etc.; hydrological data; geographic data; population data) and (iii) emission/source data (e.g., point source location, emission scenarios, emission volume). It was agreed that environmental monitoring data can be used to calibrate and validate models, but only to a limited extent at present. Reasons for this include the following:

- Monitoring programmes are usually designed for other purposes (e.g. surveillance, setting environmental quality objectives and consents for industrial emissions, and improving our understanding of river systems and processes) and therefore do not provide all the data required for model calibration and validation. For example, monitoring programmes do not provide data for model parameterisation of rates and processes. However, it was recognised that these type of data are usually determined in laboratory experiments and confirmed in research-orientated field studies.

- Uncertainty concerning the 'quality' of monitoring data, e.g. reliability, representativeness. Improved reporting, such as recommended in Table 1 would improve confidence in the data.

- Limited access to monitoring and ancillary data. In addition, it is often difficult to find out where the monitoring databases are held. For example, it is important to have emission data for the chemical of interest, but these are often considered confidential by business.

Filling data gaps for calibration and validation can be done in a number of ways, e.g. using literature searches, using QSARs, using emission source data such as emission scenario documents. The groups agreed however, that it would be useful to 'flag' those data which have been 'filled in'. Furthermore, before using the data, it is important to consider how many parameters were estimated relative to how many are measured and the effect this could have on the final conclusions.

It was stressed that calibration/validation should focus on exposure time-frames consistent with the type of effects caused by the chemical in question (e.g. acute, chronic). "Hand-tuning" appeared to be the most common technique for calibration. Potentially, calibration/validation could be easier on a local scale rather than on a regional scale since there could be better and more complete understanding of the site. For regional scales, it is necessary to determine if the monitoring sample is representative of the regional situation.

During calibration/validation, measured data and predicted data are compared qualitatively or quantitatively to determine if there is a significant difference. It should be noted that the scale of resolution for calibration and validation depends on the models, the chemicals, the environment and intended or required accuracy. 
When measured data and model predictions are different, it is necessary to check the measured data, the model parameters and model assumptions for any errors in a pragmatic way. This should be an iterative process including the use of expert judgement. Cost/benefit should be considered before making a decision on whether or the extent to which further checking or fine tuning is necessary. For example, if predicted and measured concentrations differ, but both are below effect concentrations, then absolute agreement between models and monitoring data is less important.

The current situation is that most models are not yet adequately validated, although a number of validation activities are taking place (e.g., with the EUSES models).

\section{Issue 4: Use of Models in the Design of New Monitoring Initiatives}

There was an observation that environmental fate and distribution models had not yet been incorporated into the design stage of monitoring programmes and it was agreed that awareness of the advantages of using these models for this purpose should be promoted amongst the monitoring community.

The use of models could contribute to:

- increased understanding of the fate and distribution of chemicals;

- selecting chemicals to be monitored;

- identifying which parts of the environment to monitor;

- estimating the level of detection needed for analytical techniques;

- helping to estimate concentrations, if analytical techniques are not available;

- reducing the number of samples taken (i.e., optimising sampling);

- determining the sources of chemicals (e.g., location, emission rates).

The type of model to use in designing monitoring programmes should be decided on a case by case basis, considering the objectives of the monitoring programme and the environmental processes operating in the system. Because the environmental system is not the same everywhere, there is no single way to design monitoring programmes and they must be tailored according to the characteristics of the system of interest. 


\section{Recommendations}

\section{Improve availability of existing and future monitoring data}

Two possibilities were proposed at the workshop:

- Develop a meta-database (possibly on Internet) which summarises "who is doing what monitoring' and who can be contacted in order to get more information. To keep such a database manageable, it will be necessary to limit the scope in some way (e.g., aquatic environment, size of the programme, type of data collected).

- Develop a database or series of databases (on CD ROM/Internet?) through which actual monitoring data (from governments, industry, international organisations, etc.) could be accessed.

$\Rightarrow$ data on chemical pollutants and other data (hydrology, geographic, environmental, etc.) should be included;

$\Rightarrow$ would need to agree on the form of the data needed, e.g. aggregated rather than raw data, and if aggregated, in what way (mean, $90 \%$ ile, etc.)

$\Rightarrow$ would need to explore impediments to making data available (i.e., confidentiality and ownership issues).

It was agreed that the OECD should establish a small working group comprising some participants from the workshop to recommend what data and how data could be made more available. In doing so, close attention should be paid to relevant activities of organisations outside the OECD (e.g., UNEP/GEMS, EEA, US Geological Survey, EUROSTAT, industry).

This activity was given high priority.

\section{Improve access to information on chemical emissions}

It was proposed that emission data could be made more accessible via:

- Emission Scenario Documents (ESDs);

- effluent monitoring and Integrated Pollution Prevention Control (IPPC) data;

- Pollutant Release and Transfer Registries (PRTRs);

- other geo referenced emission data;

- Life Cycle Inventories (LCI).

The OECD Environmental Exposure Working Group is working on and already mandated to develop further ESDs, building on those already developed within the EU. The workshop recommended that the Working Group also be asked to consider how the other four areas could be used to provide information on emissions at their next meeting in early 1999. 


\section{Improve considerations of exposure assessment requirments in the design of monitoring programmes}

It was agreed that the use of guidance for good monitoring practice such as that being developed or planned by organisations such as UNECE and GEMS/Water should be promoted and possibly harmonized. Such guidance should:

- include advice on how to use screening or preliminary risk assessment to identify priority substances for monitoring;

- promote flexibility in design so that investigation of additional aspects (e.g., substances, processes) can be added when necessary;

- promote communication between monitoring, modelling and risk assessment communities.

It was agreed that the UNECE and UNEP/GEMS guidance documents should be circulated to workshop participants.

\section{Increase the number of model validation studies}

It was proposed that recommendations for (1) how existing monitoring data should be used in model validation and (2) how new monitoring studies should be designed so that they provide data suitable for model validation should be developed. It was also agreed that more scientific activities are need. At the 9th Annual Meeting of the Society for Environmental Toxicology and Chemistry (SETAC) Europe, 25th29th May 1999 in Leipzig, a session on "Modelling and Monitoring" should be organised to discuss the scientific issues.

\section{Harmonize monitoring and modelling terminology}

It was recommended that terms related to monitoring and modelling be included in the existing OECD/IPCS project on harmonization of terminology used in the hazard/risk assessment of chemicals.

6. Improve awareness of funding bodies (governments) regarding the importance of monitoring activities in human health and environmental protection

The workshop participants felt that this was an important recommendation, but were not sure how it could be achieved, other than participants themselves spreading the word. One important point made was that when developing budgets for monitoring programmes, costs for communicating the data should be included.

7. Continue the dialogue among the monitoring, modelling and exposure/risk assessment communities initiated by this workshop 


\section{Annex 1}

\section{Participants List}

\section{MEMBER COUNTRIES}

\begin{tabular}{|c|c|}
\hline AUSTRALIA & \\
\hline $\begin{array}{l}\text { Jack HOLLAND } \\
\text { Manager, Risk Assessment and Policy Section } \\
\text { Environment Australia } \\
\text { P.O. Box E } 305 \\
\text { KINGSTON ACT } 2604\end{array}$ & $\begin{array}{r}\text { Tel: } 6162741643 \\
\text { Fax: } 6162741610 \\
\text { E-mail: jholland@dest.gov.au }\end{array}$ \\
\hline AUSTRIA & \\
\hline $\begin{array}{l}\text { Aline BERTHOLD } \\
\text { Federal Environment Agency } \\
\text { Spittelaur Lände } 5 \\
\text { A-1090 Vienna }\end{array}$ & $\begin{array}{r}\text { Tel: } 43131304661 \\
\text { Fax: } 43131304655 \\
\text { E-mail: berthold@uba.ubavie.gv.at }\end{array}$ \\
\hline CANADA & \\
\hline $\begin{array}{l}\text { Patrick DOYLE } \\
\text { Commercial Chemical Evaluation Branch } \\
\text { Environment Canada } \\
\text { 351 St.Joseph Blvd. } \\
\text { Hull, Quebec, Canada, K1A 0H3 }\end{array}$ & $\begin{array}{r}\text { Tel: } 18199531590 \\
\text { Fax: } 18199534936 \\
\text { E-mail: Pat.Doyle@ec.gc.ca }\end{array}$ \\
\hline $\begin{array}{l}\text { Yves DE LAFONTAINE } \\
\text { Aquatic Contaminants, St. Lawrence Centre } \\
\text { Environment Canada } \\
105 \text { McGill St., Suite } 400 \\
\text { Montreal, Quebec, Canada, H2Y 2E7 } \\
\end{array}$ & $\begin{array}{r}\text { Tel: } 15144965025 \\
\text { Fax: } 15144967398 \\
\text { E-mail: Yves.delafontaine@ @ec.gc.ca }\end{array}$ \\
\hline CZECH REPUBLIC & \\
\hline $\begin{array}{l}\text { Hana CULÍKOVÁ } \\
\text { Department of Ecological Risk and Monitoring } \\
\text { Ministry of Environment } \\
\text { Vrsovicka } 65 \\
\text { CZ-100 } 10 \text { Prague } 10\end{array}$ & $\begin{array}{c}\text { Tel: } 420267122025 \\
\text { Fax: } 420267310013\end{array}$ \\
\hline DENMARK & \\
\hline $\begin{array}{l}\text { Ole Christian HANSEN } \\
\text { Danish Technological Institute } \\
\text { Environment Gregersensvej } \\
\text { Postbox } 141 \\
\text { DK-2630 Tåstrup } \\
\end{array}$ & $\begin{array}{r}\text { Tel: } 4543504350 \\
\text { Fax: } 4543507150 \\
\text { E-mail: ole.christian.hansen@ dti.dk }\end{array}$ \\
\hline $\begin{array}{l}\text { Henrik Søren LARSEN } \\
\text { Chemicals Division } \\
\text { Danish Environmental Protection Agency } \\
\text { Strandgade } 29 \\
\text { DK- } 1401 \text { Københaven K }\end{array}$ & $\begin{array}{l}\text { Tel: } 4532660100 \\
\text { Fax: } 4532660261 \\
\text { E-mail: hel@ mst.dk }\end{array}$ \\
\hline
\end{tabular}




\begin{tabular}{|c|c|}
\hline FINLAND & \\
\hline Arto KULTAMAA & Tel: 358940300527 \\
\hline Chemicals Division & Fax: 358940300591 \\
\hline Finnish Environmental Institute & E-mail: arto.kultamaa@vyh.fi \\
\hline FIN-140 00251 Helsinki & \\
\hline FRANCE & \\
\hline Marc BABUT & Tel: 33387344731 \\
\hline Agence de l'eau Rhine-Meuse & Fax: 33387604985 \\
\hline BP3019 & E-mail: babut@franceNet.fr \\
\hline F-57161 Moulins-lès-Metz Cedex & \\
\hline Robert DIDERICH & Tel: 33344556216 \\
\hline Institute National de l'Environnement Industrial & Fax: 33344556767 \\
\hline et des Risques (INERIS) & E-mail: robert.diderich@ineris.fr \\
\hline Parc Technologique ALATA - BP 2 & \\
\hline F-60550 Verneuil-en-Halatte & \\
\hline GERMANY & \\
\hline Karlheinz BALLSCHMITER & Tel: 49-7119063130 \\
\hline Center of Technology Assessment in Baden-Wuerttemberg & Fax: 497119063269 \\
\hline Industriestrasse 5 & E-mail: ballsch@afta_bw.de \\
\hline D-70565 Stuttgart & \\
\hline Tessa BEULSHAUSEN & Tel: $49-3089033123$ \\
\hline Umweltbundesamt & Fax: 49-30 89033129 \\
\hline PO-Box: 330022 & E-mail: tessa.beulshausen@uba.de \\
\hline D-14191 Berlin & \\
\hline Hartmut HEINRICH & Tel: $49-40-3190.3513$ \\
\hline Bundesamt für Seeschiffahrt und Hydrographie - M5 & Fax: 49-30-3190.5035 \\
\hline Postfach 301220 & E-mail: hartmut.heinrich@bsh.d400.de \\
\hline D-20305 Hamburg & \\
\hline Michael KLEIN & Tel: 49-2972-302.317 \\
\hline Fraunhofer Institut für Umweltchemie und Ökotoxikologie & Fax: $49-2972-302.319$ \\
\hline Environmental Information and Evaluation Systems & E-mail: klein@iuct.fhg.de \\
\hline Auf dem Aberg 1 & \\
\hline D-57392 Schmallenberg & \\
\hline Michael MATTHIES & Tel: 49-541-969.2576 \\
\hline Institute of Environmental Systems Research & Fax: 49-541-969.2599 \\
\hline University of Osnabrück & E-mail: matthies@usf.uni-osnabrueck.de \\
\hline Artilleriestr. 34 & URL: http//www.usf.uni-osnabrueck.de \\
\hline D-49069 Osnabrück & \\
\hline Jürgen MÜLLER & Tel: 49-69-82988.149 \\
\hline Umweltbundesamt, Pilotstation Frankfurt & Fax: $49-69-800.38 .73$ \\
\hline Frankfurter Strasse 135 & \\
\hline D-63067 Offenbach & \\
\hline Bernd SCHARENBERG & Tel: 493089033224 \\
\hline Umweltbundesamt & Fax: 493089033900 \\
\hline Postfach 330022 & E-mail: bernd.scharenberg@uba.de \\
\hline D-14191 Berlin & \\
\hline Klaus VOGT & Tel: $49-211-1590.2255$ \\
\hline Landesumweltamt Nordrhein-Westfalen & Fax: 49-211-1590.2415 \\
\hline Postfach 102363 & E-mail:vogt@ duesseldorf.lua.nrw.de \\
\hline D-45023 Essen & \\
\hline Burkhard WAGNER & Tel: $49-30-8903.3220$ \\
\hline Umweltbundesamt & Fax: 49-30-8903.3900 \\
\hline Postfach 330022 & E-mail: burkhard.wagner@uba.de \\
\hline D-14191 Berlin & \\
\hline
\end{tabular}




\begin{tabular}{|c|c|}
\hline ITALY & \\
\hline $\begin{array}{l}\text { Alessandro DI DOMENICO } \\
\text { Instituto Superiore di Sanità - Laboratorio di Tossicologia } \\
\text { Comparata ed Ecotossicologia } \\
\text { Viale Regina Elena } 299 \\
\text { I - 00161 Rome }\end{array}$ & $\begin{array}{r}\text { Tel: 39-6-4990-2826 or } 2077 \\
\text { Fax: 39-6-4938-7139 } \\
\text { E-mail: addeke@iss.it }\end{array}$ \\
\hline JAPAN & \\
\hline $\begin{array}{l}\text { Takao KOWATA } \\
\text { National Institute of Technology and Evaluation } \\
\text { Ministry of International Trade and Industry } \\
\text { 2-49-10 Nishihara, Shibuya-ku } \\
\text { Tokyo }\end{array}$ & $\begin{array}{r}\text { Tel: 81-3-3481-1812 } \\
\text { Fax: 81-3-3481-1950 } \\
\text { E-mail: ktaa4257@ miti.go.jp }\end{array}$ \\
\hline $\begin{array}{l}\text { Kiyoshi TANABE } \\
\text { National Institute for Environmental Studies } \\
\text { 16-2 Onogawa, Tsukuba, Ibaraki } 305 \\
\end{array}$ & $\begin{array}{r}\text { Tel: } 81-298-50-2478 \\
\text { Fax: } 81-298-50-2570 \\
\text { E-mail: tanabe@ @nies.go.jp }\end{array}$ \\
\hline THE NETHERLANDS & \\
\hline $\begin{array}{l}\text { Charles BODAR } \\
\text { RIVM } \\
\text { P.O. Box } 1 \\
\text { NL-3720 BA Bilthoven }\end{array}$ & $\begin{array}{r}\text { Tel: } 31302743000 \\
\text { Fax: } 31302744401 \\
\text { E-mail: charles.bodar@rivm.nl }\end{array}$ \\
\hline $\begin{array}{l}\text { Jos TIMMERMAN } \\
\text { RIZA } \\
\text { P.O. Box } 17 \\
\text { NL-8200 AA Lelystad }\end{array}$ & $\begin{array}{r}\text { Tel: } 31320298779 \\
\text { Fax: } 31320249218 \\
\text { E-mail: j.g.timmerman@ riza.rws.minvenw.nl }\end{array}$ \\
\hline NORWAY & \\
\hline $\begin{array}{l}\text { Beryl C. NYGREEN } \\
\text { Norwegian Pollution Control Authority (SET) } \\
\text { P.O. Box } 8100 \text { Dep. } \\
\text { N-0032 Oslo }\end{array}$ & $\begin{array}{r}\text { Tel: } 4722573649(4722573400) \\
\text { Fax: } 4722676706 \\
\text { beryl-c.nygreen@ sftospost.md.dep.telemax.no }\end{array}$ \\
\hline POLAND & \\
\hline $\begin{array}{l}\text { Janusz SWIATCZAK } \\
\text { Department of Environmental Health Hazards } \\
\text { Nofer Institute of Occupational Medicine ul. } \\
\text { Sw. Teresy } 8 \\
\text { P.O.Box } 199 \\
\text { PL-90-950 Lodz }\end{array}$ & $\begin{array}{r}\text { Tel: } 4842314575 \\
\text { Fax: } 4842314562 \\
\text { E-mail: } \text { jsw@a.imp.lodz.pl }\end{array}$ \\
\hline $\begin{array}{l}\text { Stanislaw TARKOWSKI } \\
\text { Department of Environmental Health Hazards } \\
\text { The Nofer Institute of Occupational Medicine } \\
8 \text { Sw. Teresy Str. } \\
\text { PO Box } 199 \\
\text { PL-90-950 Lodz }\end{array}$ & $\begin{array}{r}\text { Tel: } 4842314842 \\
\text { Fax: } 4842568331 \\
\text { E-mail: tarko@porta.imp.lodz.pl }\end{array}$ \\
\hline
\end{tabular}




\begin{tabular}{|c|c|}
\hline SWEDEN & \\
\hline Britta HEDLUND & Tel: 4686981208 \\
\hline Swedish Environmental Protection Agency & Fax: 4686981585 \\
\hline S-106 48 Stockholm & E-mail: britta.hedlund@environ.se \\
\hline Ivar LUNDBERGH & Tel: 4687306803 \\
\hline Hazard and Risk Assessment Division & Fax: 4687357698 \\
\hline KemI & E-mail: ivarl@kemi.se \\
\hline P.O. Box 1384 & \\
\hline S-17127 Solna & \\
\hline Alf LUNDGREN & Tel: 4687306742 \\
\hline National Chemicals Inspectorate & Fax: 4687356798 \\
\hline KemI & E-mail: alfl@kemi.se \\
\hline P.O. Box 1384 & \\
\hline S-171 27 Solna & \\
\hline Sten-Âke SVENSSON & Tel: 4687306776 \\
\hline National Chemicals Inspectorate & Fax: 4687356798 \\
\hline KemI & E-mail: stenake@kemi.se \\
\hline P.O. Box 1384 & \\
\hline S-171 27 Solna & \\
\hline SWITZERLAND & \\
\hline Christof STUDER & Tel: 41313226860 \\
\hline Swiss Agency for the Environment, Forests and & Fax: 41313247879 \\
\hline Landscape & E-mail: christof.studer@buwal.admin.ch \\
\hline CH-3003 Bern & \\
\hline Walter GIGER & Tel: 4118235475 \\
\hline Swiss Federal Institute for Water Resources & Fax: 4118235028 \\
\hline Ueberland str.133 & E-mail: giger@eawag.ch \\
\hline CH-8600, Dürendorf & \\
\hline UNITED KINGDOM & \\
\hline David BROOKE & Tel: 441923664862 \\
\hline Building Research Establishment & Fax: 441923664609 \\
\hline Bucknalls Lane, Garston & E-mail: brookedn@bre.co.uk \\
\hline GB-Watford WD2 7RJ & \\
\hline Colin NEAL & Tel: 441491692256 \\
\hline Institute of Hydrology & Fax: 441491692424 \\
\hline Crowmarsh Gifford & E-mail: c.neal@mail.nerc-wallingford.ac.uk \\
\hline GB-Wallingford Oxfordshire OX10 8BB & or c.neal@ua.nwl.ac.uk \\
\hline UNITED STATES & \\
\hline Larry BARBER & Tel: 13035413039 \\
\hline Unites States Geological Survey & Fax: 13034472505 \\
\hline 3215 Marine Street & E-mail: lbbarber@usgs.gov \\
\hline Boulder, CO 80303 & \\
\hline Patrick KENNEDY & Tel: 12022603916 \\
\hline Exposure Assessment Branch & Fax: 12022600981 \\
\hline Economics, Exposure, and Technology Division & E-mail: kennedy.patrick@epamail.epa.gov \\
\hline Office of Pollution Prevention and Toxics (7406) & \\
\hline U.S. Environmental Protection Agency & \\
\hline 401 M Street SW & \\
\hline Washington D.C. 20460 & \\
\hline
\end{tabular}


ENV/JM/MONO(2000)2

\section{NON-MEMBER COUNTRIES}

\section{SLOVAK REPUBLIC}

Milan TATARA

Tel: 042174379330

Institute of Preventive and Clinical Medicine

Fax: 04217373906

Limbova 14

83301 Bratislava

\section{SLOVENIA}

Slavko LAPAJNE

Zavod za zdravstveno varstvo Maribor

Institut za varstvo okolja

Tel: 62 4500-100

Prvomajska 1, 2000 Maribor 


\section{INTERNATIONAL BODIES}

\section{EUROPEAN COMMISION}

Ferdinand KASER

European Chemicals Bureau

Tel: 39332789088

Environment Institute - JRC

Fax: 39332789963

I-21020 Ispra, Italy

\section{EUROPEAN ENVIRONMENT AGENCY (EEA)}

Bo JANSSON

Scientific Committee of EEA

Institute of Applied Environmental Research (ITM)

Stockholm University

S-10691 Stockholm, Sweden

W. Eberhard FALCK

Consultant to EEA

Tel: 49304951128 (answering machine)

Reginhardstr. 149

Fax 49304951128 (on request)

E-mail: wefalck@berlin.snafu.de

D-13409 Berlin, Germany

\section{ENVIRONMENTAL PROGRAMME FOR DANUBE RIVER BASIN (EPDRB)}

Liviu N. POPESCU

Chairman of the Monitoring Laboratory and Information

Management Expert Group Meeting (MLIM/EG)

Spl. Independentei Street, No. 294, sect. 6

ROM-77703 Bucharest, Romania

\section{GEMS/Water}

Andrew FRASER

GEMS/Water Programme Manager

UNEP/WHO GEMS/Water Collaborating Centre

Tel: 4686747220

Fax: 468287829

E-mail: bo.jansson@itm.su.se

National Water Research Institute

867 Lakeshore Rd.

Burlington, Ontario

Canada L7R 4A6

\section{HELSINKI COMMISION (HELCOM)}

Heike HERATA

Chairman, Working Group on Inputs to the Environment

Tel: 493089032053

(TCINPUT), HELCOM Technological Committee

Fax: 493089032285

Federal Environmental Agency

Bismarckplatz 1

P.O. Box 330022

D-14193 Berlin, Germany

\section{UNECE}

Peter RONCAK

Task Force for UNECE's Workshop on Risk

Tel: 42173785296

Assessment, Monitoring and Inventories

Slovak Hydrometeorological Institute

eseniova 17

83315 Bratislava, Slovakia

\section{UNEP CHEMICALS}

Agneta Sundén-Byléhn

Tel: 19053364919

Fax: 19053364582

E-mail: Andy.Fraser@cciw.ca

UNEP Chemicals

United Nations Environment Programme

15, Chemin des Anémones

CH-1219 Châtelaine,

Geneva, Switzerland

Tel: 41-22 9178193

Fax: 41-22 7973460

E-mail: asunden@unep.ch 


\section{INDUSTRY}

\begin{tabular}{|c|c|}
\hline BIAC & \\
\hline $\begin{array}{l}\text { Christina E. COWAN } \\
\text { Proctor \& Gamble Company } \\
\text { Environmental Sciences Department } \\
5299 \text { Spring Grove Ave. } \\
\text { Cincinatti, Ohio 45217, USA }\end{array}$ & $\begin{array}{r}\text { Tel: } 15136278216 \\
\text { Fax: } 15136275526 \\
\text { E-mail: cowance@pg.com }\end{array}$ \\
\hline $\begin{array}{l}\text { Roland SCHRÖDER } \\
\text { Henkel KgaA } \\
\text { TTB-Ökologie } \\
\text { D-40191 Düsseldorf, Germany }\end{array}$ & $\begin{array}{r}\text { Tel: } 492117979558 \\
\text { Fax: } 492117981279 \\
\text { E-mail: Roland.Schroeder@ Henkel.De }\end{array}$ \\
\hline $\begin{array}{l}\text { Ralph G. STAHL, Jr. } \\
\text { E.I. DuPont de Nemours \& Company } \\
\text { P.O. Box 80027, BMP-27 } \\
\text { Wilmington, Delaware 19805, USA }\end{array}$ & $\begin{array}{c:cccc}\text { Tel: } & 1 & 302892 & 1369 \\
\text { Fax: } & 1 & 302892 & 7641\end{array}$ \\
\hline ECETOC & \\
\hline $\begin{array}{l}\text { Tom FEIJTEL } \\
\text { Proctor \& Gamble } \\
\text { European Technical Center } \\
\text { Temselaan } 100 \\
\text { B-1820 Strombeek-Bever, Belgium }\end{array}$ & $\begin{array}{r}\text { Tel: } 3224562329 \\
\text { Fax: } 3224562845 \\
\text { E-mail: feijtelt@pg.com }\end{array}$ \\
\hline $\begin{array}{l}\text { Katharine Kay FOX } \\
\text { UNILEVER RESEARCH } \\
\text { Port Sunlight Laboratory, } \\
\text { Quarry Road East } \\
\text { Bebington, Wirral, } \\
\text { GB-Merseyside L } 633 \mathrm{JW} \\
\end{array}$ & $\begin{array}{r}\text { Tel: } 441514713935 \\
\text { Fax: } 441514711853 \\
\text { E-mail: } \text { kay.fox@ unilever.com }\end{array}$ \\
\hline $\begin{array}{l}\text { Martin HOLT } \\
\text { ECETOC } \\
\text { Av. E. van Nieuwenhuyse } 4 \text { BTE } 6 \\
\text { B-1160, Brussels, Belgium }\end{array}$ & $\begin{array}{r}\text { Tel: } 3226633812 \\
\text { Fax: } 3226753625 \\
\text { E-mail: martin.holt@ecetoc.org }\end{array}$ \\
\hline $\begin{array}{l}\text { Jouko KINNUNEN } \\
\text { NESTE, Environmental and Industrial Hygiene } \\
\text { P.O. Box } 320 \\
\text { FIN-009 } 80, \text { Helsinki, Finland }\end{array}$ & $\begin{array}{r}\text { Tel: } 358204502297 \\
\text { Fax: } 358204507658 \\
\text { E-mail: jouko.kinnunen@ neste.com }\end{array}$ \\
\hline $\begin{array}{l}\text { Richard MURRAY-SMITH } \\
\text { ZENECA } \\
\text { Environmental Laboratories } \\
\text { GB-Brixham, Devon, TQ5 } 8 \text { BA, United Kingdom }\end{array}$ & $\begin{array}{c}\text { Tel: } 441803882882 \\
\text { Fax: } 441803882974\end{array}$ \\
\hline EUROCHLOR & \\
\hline $\begin{array}{l}\text { André LECLOUX } \\
\text { EuroChlor } \\
\text { Av. Nieuwenhuyse } 4 \\
\text { Box } 2 \\
\text { B-1160 Brussels, Belgium }\end{array}$ & $\begin{array}{r}\text { Tel: } 3226767306 \\
\text { Fax: } 3226767241 \\
\text { E-mail: ale @ cefic.be }\end{array}$ \\
\hline
\end{tabular}




\section{OECD SECRETARIAT}

Ms. N. GRANDY

2, rue André-Pascal

75775 Paris Cedex 16, France

Mr. S. MORISHITA

2, rue André-Pascal

75775 Paris Cedex 16, France
Tel: 33145241676

Fax: 33145241675

E-mail: nicola.grandy@oecd.org

Tel: 33145247907

Fax: 33145241675

E-mail: satoru.morishita@oecd.org

\section{UBA SECRETARIAT}

\section{Rita DÄHN}

Umweltbundesamt

P.O. Box 330022

Tel: 493089032261

Fax: 493089032285

D-14191 Berlin, Germany

Dagmar LARWS

Umweltbundesamt

P.O. Box 330022

E-mail: rita.daehn@uba.de

D-14191 Berlin, Germany

Gabriele VORWERG

Tel: 493089032152

Fax: 493089032920

Umweltbundesamt

Tel: 493089033167

P.O. Box 330022

Fax: 493089033900

D-14191 Berlin, Germany 


\section{Annex 2}

\section{Background Document}

OECD Environmental Health and Safety Publications

Series on Testing and Assessment

No. 17

Environmental Exposure Assessment Strategies for Existing Industrial Chemicals in OECD Member Countries

Note: Annex of this document is not attached. 


\section{Environmental Exposure Assessment Strategies for Existing Industrial Chemicals in OECD Member Countries}

\subsection{SCOPE}

This paper reviews some general strategies used by OECD Member countries when assessing exposure in the context of risk assessments for existing industrial chemicals. It is intended as an initial overview, not as a comprehensive review. Strategies for source assessment, one of the elements of environmental exposure assessment, are in particular not fully described.

The principal documents consulted are listed in the Bibliography. Additional information on the practice of environmental exposure assessment in OECD Member countries is provided in the attached Annex.

\subsection{BACKGROUND}

\subsection{Objective of Exposure Assessment}

Environmental exposure assessments are intended either to describe the exposure of one or more populations of organisms to a chemical stressor (e.g., Environment Canada, 1997; US EPA, 1992a and 1996), or as in the European Union, to describe the concentration of a chemical in various environmental compartments which has the potential to effect organisms (European Commission, 1996). Exposure data are compared to effects data to characterize risk.

\subsection{Representation of Exposure Values}

Exposure is usually estimated as either calculated or measured concentrations - often called "Predicted Environmental Concentrations" or "PECs" - for impacted environmental compartments. In some cases (e.g., for bioaccumulative substances), calculated or measured environmental concentrations are used to estimate doses (e.g., PECoral), especially to top predators (Cowan et al., 1995a; Environment Canada, 1997; European Commission, 1996).

\subsection{Representation of Variability}

Concentrations of chemicals in environmental compartments vary in both space and time. PECs typically attempt to describe different aspects of the variability of concentrations to which populations of organisms are exposed. As noted in US EPA (1992a), for a given set of exposure conditions (e.g., near an identified point source), or for a given exposure scenario (if a model is used), exposure values may be intended to represent: 
(i) a value that likely exceeds actual exposures (a "bounding" or "worst-case" estimate),

(ii) a value that is representative of the "high end" of actual exposures (a "reasonable worst-case" estimate),

(iii) a value that is representative of "typical" exposures, or

(iv) the complete set of actual exposure values resulting from those conditions.

Type (i), (ii) and (iii) PECs are point estimates which can be used in risk quotient (e.g., PEC/PNEC) calculations. Type (iv) PECs are represented as frequency distributions, which can be incorporated into risk analyses graphically (e.g., US EPA, 1996). For a given exposure scenario, PECs may vary depending upon nature and behavior of receptor organisms. Thus one population's typical exposure may be another population's high end exposure.

Often exposures associated with several different exposure scenarios (or sets of exposure conditions) are examined in one assessment. For example, in large scale regional or national assessments, several geographically distinct point sources may be of interest. In such cases PECs may represent, for example, a bounding value for all possible exposure conditions, or several "typical" or "high end" values for a range of exposure conditions (e.g., near several different sources).

\subsection{OVERALL ASSESSMENT STRATEGIES}

\subsection{Fate and Pathways Analysis}

Before exposure concentrations are estimated, environmental fate and pathways should be examined, taking into account information on the:

- physical/chemical properties of the substance, including its degradation and transformation, and bioaccumulation potential (see Section 4.10);

- nature of degradation or transformation products;

- nature of commercial uses, and amounts used;

- nature and location of principal sources of releases (taking into account the life-cycle of the substance);

- amounts, forms and timing of releases; and the

- nature of the receiving compartments.

Whenever possible this should be done quantitatively, using appropriate mathematical models (e.g., a generic fugacity model). Otherwise a qualitative analysis should be undertaken, using a conceptual fate model.

The fate and pathways analysis is intended to identify important fate processes affecting a substance, to determine the environmental compartments (air, surface or ground water, soil, sediment, biota) in which the substance is most likely to accumulate, and to define the appropriate spatial and temporal dimensions (e.g., local, regional, continental) for the assessment.

\subsection{Iterative or Tiered Approach}

Assessments are normally done in an iterative or "tiered" fashion. The tiers may be thought of as benchmarks, in the more-or-less continuous process of refining assessments.

The quality of an initial exposure assessment is usually driven by the quality of available information. To conserve resources when data are limited, a bounding PEC may be estimated first, with 
successive iterations adding more realism and detail (e.g., US EPA 1992a; Cowan et al, 1995a; Environment Canada, 1997; European Commission, 1996; ECETOC 1994; Wagner, 1997). When better quality information is readily available, however, the bounding step may be omitted. Although tiered systems vary, other steps often involve estimation of realistic "high end" or typical PECs for a particular exposure scenario, and finally estimation of an entire distribution of PECs (see Annex, Sections 4.2.1 and 4.3.1).

\subsubsection{Bounding Point Estimates}

The output from this screening may be described as a "bounding" (US EPA 1992a), "worstcase", or "hyperconservative" (Environment Canada, 1997) point estimate of exposure. Such PECs are intended to exceed maximum exposure values under the exposure condition(s) of interest (US EPA, 1992a).

A bounding estimate is usually determined by assuming that several factors that influence concentration or dose are at their maximum. For example, when exposures are calculated, concentrations are often estimated at the point of entry, assuming that releases are as high as possible, that dilution is zero, and that none of the substance is lost from the receiving compartment. In circumstances where bioavailability is expected to be limited, a bounding exposure estimate may also be based on a maximum total measured concentration (e.g., of a metal in a soil), by making the unrealistic assumption that all of the total measured concentration is available to biota (Environment Canada, 1997).

The purpose of the hyperconservative screening is usually to identify the receptors and/or exposure pathways of most concern and to eliminate others. For example, if a bounding PEC is less than the predicted no effect concentration (PNEC) for a particular receptor organism (risk quotient <1), no further investigation of effects to this receptor is usually required. However, if a hyperconservative PEC exceeds the corresponding PNEC, such PECs should usually be estimated in a more realistic fashion.

\subsubsection{Realistic Point Estimates}

\section{Screening}

The first step in refining a bounding PEC may be to estimate the maximum exposure values likely to actually occur under the exposure condition(s) of interest (Environment Canada, 1997). Such estimates may be called "conservative", "reasonable worst-case" or "high end" exposure values. When data on variability are available, "high end" exposure estimates may be defined to fall within the 90th and 99.9th percentiles of the expected variability (US EPA, 1992a). If a bounding PEC has not been estimated, this realistic screening is usually the first step in the assessment process.

When calculating "high end" exposures, a limited number (sometimes only one) of the most sensitive exposure variables are maximized (US EPA, 1992a). For example, dissolved concentrations in receiving waters could be calculated assuming that releases are as high as possible, dilution is low (but not zero), and a typical value for removal during wastewater treatment. Alternatively, "high end" PECs could be based on a maximum bioavailable concentrations measured in receiving waters (e.g., Environment Canada, 1997).

\section{Typical Values}

Individual PECs may also be intended to represent 'typical' exposure values (US EPA 1992a). When PECs are measured, usually arithmetic average or median values are used. When exposures are 
calculated, an average PEC may be estimated using average values for all input variables. When exposure distributions are expected to be skewed, it is also helpful to estimate median or geometric mean exposure values (US EPA, 1992a).

\subsubsection{Realistic Exposure Distributions}

When exposure estimates are based on ambient monitoring data or on Monte Carlo simulations, the complete range of PECs associated with a given set of exposure conditions may be estimated and represented as frequency distributions (e.g., Environment Canada, 1997; US EPA, 1996).

\subsection{ESTIMATION OF PECs}

\subsection{Use of 'Weight or Multiple Lines of Evidence' Approach}

In view of the uncertainty associated with exposure estimates, whenever possible PECs should be determined using more than one method. Most jurisdictions recommend basing PECs on both monitoring data and model calculations, although it is recognized that this is not always possible (e.g., US EPA, 1992a; European Commission, 1996; Environment Canada, 1997; Hayamizu 1997). When both estimates agree, at least within an order of magnitude, confidence in the derived PECs is increased. When there is disagreement, particularly when making realistic (higher tier) exposure estimates, analysis and critical discussion of divergences are important steps. If the measured values have passed the procedure of critical statistical and geographical evaluation, a high degree of confidence can be attributed to those data and they are given preference (European Commission, 1996).

\subsection{Use of Ambient Monitoring Data}

Empirical data on concentrations of substances in receiving media may be used both at a screening level and in higher tier assessments (see Section 3.2). Monitoring data are generally preferred when making realistic (higher tier) exposure estimates. However, such data should be evaluated for both reliability and representativeness. This is particularly true when measured concentrations are low - near the method detection limits - as is the case for some highly toxic chemicals. Criteria for evaluating existing monitoring data are described, for example, in US EPA (1992a). If the uncertainties associated with existing monitoring data are unacceptable, additional monitoring data may be collected or confirmatory modeling data may be sought.

\subsection{Use of Models}

Models may be used to calculate PECs for both screening level and more realistic (higher tier) assessments (see Section 3.2). In the European Union, for example, initial PECs for surface waters may be calculated using models that account for removal of substances during sewage treatment, and for dilution and adsorption in receiving waters (European Commission, 1996; see Annex, Section 4.2.3). Models used may be either generic or site-specific (see Annex, Sections 4.2.1 and 4.3.1). Strategies for selecting and validating exposure models are discussed, for example by Cowan et al. (1995b), and are reviewed by US EPA (1992a).

Limitations on the amount and quality of emission data are major sources of uncertainty in model calculations. In an attempt to standardizing approaches and reduce uncertainties associated with calculated PECs, generic emission scenario documents are being developed in the European Union and the United States for specific combinations of chemical use and industry categories (European Commission, 1996; see Annex, Section 3). 
Because the uncertainties associated with model outputs may be large, uncertainty should be evaluated with particular care when realistic PECs are calculated using models. If the uncertainties are too large, model input data may be refined or confirmatory monitoring data may be sought.

\subsection{Spatial Scales}

As indicated in the Section 4.1 of the Annex, assessments may be conducted at local, regional, national, or continental scales (European Commission, 1996; OECD, 1996). Releases from point sources have largest impacts on environmental concentrations locally, but can also contribute to environmental concentrations on a larger scale. Assessments of releases from point sources should therefore include at least a local and possibly a larger (e.g., regional) component. When releases are from diffuse sources, generally only larger scale (e.g., regional) assessments are required (European Commission, 1996).

\subsection{Temporal Scales}

PECs for a particular location are usually estimated as arithmetic average concentrations for a specified time interval. Averaging periods may be as short as a day, or as long as a year or more. PECs representing steady state concentrations are considered to represent long-term average exposure levels.

Exposure assessors should consult with effects assessors when determining the most appropriate averaging times. Short-term averages may be used when releases are episodic, particularly when determining PECs on a local scale (EC, 1996) and chemicals have short half-lives in environmental media. Longer-term averages are normally used when releases are continuous, especially when assessing persistent contaminants. PECs calculated as short-term averages should be compared to PNECs representing short-term toxicity; long-term PECs should be compared to PNECs representing long-term toxicity (Environment Canada, 1997; EC, 1996).

\subsection{Environmental Compartments}

PECs may be determined separately for water, sediment, air, soil and biota (see Annex, Sections 4.2.1 and 4.3.1). The compartments of primary concern are typically identified during fate and pathways analysis.

\subsection{Background Exposure}

Both natural and ambient background concentrations may contribute to local exposures. Generally such background concentrations are deliberately incorporated into exposure estimates (e.g., European Commission, 1996). This is straightforward when PECs are based on monitoring data. When PECs are calculated, ambient background concentrations may be estimated using regional models, and added to PECs determined using local models (European Commission, 1996; see Annex, Section 4.4).

\subsection{Connecting Measured PECs to Source(s) of Interest}

Although monitoring data are often limited, this is not always so. In cases when monitoring data are abundant and PECs are based primarily on such data, the connection between observed PECs and releases from a particular source of interest may be unclear - especially for heavily industrialized areas. The most straightforward method of connecting exposure values to particular sources of interest is to calculate PECs by modeling emissions from those sources (US EPA, 1992a). If measured concentrations exceed calculated PECs, the "excess" may represent accumulations from sources other than those of 
interest. Other approaches, based for example application of statistical methods to empirical data, have been reviewed by Gordon (1988).

\subsection{Bioavailability of Measured PECs}

PECs and PNECs are compared directly in risk analysis. Effects studies are frequently conducted under conditions that optimize bioavailability, while bioavailability under field conditions can range widely. For realistic exposure estimates, the bioavailability of PECs should therefore be similar to that of PNECs estimated from key toxicity tests (Environment Canada, 1997).

When a substance can occur in different chemical and/or physical forms but only one is usually bioavailable, PECs (and PNECs) should ideally be expressed in terms of concentrations of the bioavailable form. In the case of an organic compound, for example, that is often the un-ionized freely dissolved aqueous form (Environment Canada, 1997). For some substances, bioavailability is controlled by a particular chemical component of an exposure medium. For such substances bioavailability should, whenever possible, be adjusted or normalized to the controlling variable. For example, concentrations of a non-ionic organic chemical in a sediment could be normalized to the sediment's organic carbon content (Environment Canada, 1997).

\subsection{Persistence and Bioaccumulation}

For organic substances persistence and bioaccumulation are key parameters determining potential to cause long-term harmful effects. Information on persistence and bioaccumulation may be used when identifying candidate substances for risk assessment or management initiatives (Environment Canada, 1995; Government of Canada, 1995)

Information on persistence and bioaccumulation is considered when scoping the fate of the substance - particularly when identifying the media in which it is most likely to accumulate and when selecting assessment endpoints (see Section 3.1). Because of the importance of these parameters Cowan et al. (1995a) have proposed special persistence and bioaccumulation assessment schemes. Their persistence assessment determines the potential for increased exposure concentration as a result of repeated additions of the substance. Their tiered bioaccumulation assessment evaluates the potential for direct and indirect effects on the species of interest due to bioaccumulation.

\subsection{Uncertainty and Variability}

The uncertainty of realistic PECs, should be analyzed quantitatively, but if this is not possible, uncertainty should at least be characterized qualitatively. Sources of uncertainty in exposure characterization, and strategies for quantifying the uncertainty of PECs are reviewed by US EPA (1992a). When analyzing uncertainty of PECs associated with a particular set of exposure conditions, an attempt should be made to distinguish uncertainty - understood as the lack of knowledge of the correct value for a particular PEC (e.g., an average value) - from natural variability - defined as real differences in PECs over space and/or time under the conditions of interest (US EPA, 1992a and 1996). Approaches to uncertainty analysis used in OECD member countries are summarized in the Annex (Section 5.0).

\subsection{BIBLIOGRAPHY}

Cowan, C.E., D. J. Versteeg, R. J. Larson, P. J. Kloepper-Sams. 1995a. Integrated approach for environmental assessment of new and existing chemicals. Regulatory Toxicology and Pharmacology 21: 3-31. 
Cowan, C.E., D. Mackay, T.C.J. Feijtel, D. van de Meent, A. DiGuardo, J. Davies and N. Mackay (Eds.) 1995b. The Multi-media fate model: A vital tool for predicting the fate of chemicals. Society for Environmental Toxicology and Chemistry, Pensacola, Fl.

EC. 1996. EUSES, the European System for the Evaluation of Substances. National Institute for Public Health and the Environment (RIVM), the Netherlands, European Chemicals Bureau, Ispra Italy.

ECETOC. 1994. Environmental exposure assessment. Tech. Rept. No. 61, European Centre for Ecotoxicology and Toxicology of Chemicals. Brussels, Belgium. 109p.

Environment Canada, 1995. Report of the Ministers' Expert Advisory Panel on the second Priority Substances List, under the Canadian Environmental Protection Act., Environment Canada, Hull Quebec, 26p.

Environment Canada. 1997. Environmental assessments of priority substances under the Canadian Environmental Protection Act, Guidance manual version 1.0. March 1997, EPS/2/CC/3E, Environmental Canada, Hull, Canada.

European Commission, 1996. Technical guidance documents in support of the Commission directive 93/67/EEC on risk assessment for new notified substances and the Commission regulation (EC) 1488/94 on risk assessment for existing substances - Part II, Chapter 3 and Part IV, Chapter 7. European Commission, Luxembourg.

Gordon, G.E. 1988. Receptor models. Environ. Sci. Technol. 22(10): 1132-1142.

Government of Canada, 1995. Toxic substances management policy. Government of Canada and Environment Canada, June 1995, Ottawa, Canada, 10p.

Hayamizu, T. 1997. Strategy for environmental exposure assessment used by member countries in the SIDS initial assessments (Draft). Personal communication. February 1997, 2p.

OECD. 1996. Draft interim summary of responses to the questionnaire on environmental exposure assessment. Organization for Economic Cooperation and Development, October 1996. Paris, France. 93p.

Tanabe, K. 1997. The system of investigation of persistence in the environment concerning chemical substances. Personal communication. February 1997. 4p.

US EPA. 1992a. Guidelines for Environment Exposure Assessment. Federal Register 57: 22888-22936.

US EPA. 1992b. Potential approaches to developing screening quality estimates of releases of chemicals; Estimates of releases of new chemicals. United States Environmental Protection Agency, Office of Pollution prevention and Toxics. 9p.

US EPA. 1996. Proposed Guidelines for Ecological Risk Assessment. Federal Register 61: 47552-47631.

Wagner, B. 1997. Environmental exposure assessment strategies; Position paper of Germany. German Federal Environmental Agency (Umweltbundesamt), Berlin, 17p. 
ENV/JM/MONO(2000)2

Annex 3

Opening Plenary Session Presentations 


\title{
Monitoring Programmes and Chemical Risk Assessment
}

\author{
Jos G. Timmerman and Cees Van de Guchte \\ Institute for Inland Water Management and Waste Water Treatment RIZA, \\ P.O. box 17, 8200 AA Lelystad, The Netherlands.
}

\section{INTRODUCTION}

Monitoring programmes generate a huge amount of data on actual environmental concentrations of hazardous chemicals, which can be very useful in risk assessment procedures. These 'real world' monitoring data may be used directly to estimate the so-called Predicted Environmental Concentration, or can be used to calibrate and verify exposure models that predict PECs.

Since obtaining good monitoring data reflecting actual concentrations can be very expensive, it is essential to design efficient and cost-effective monitoring programmes.

However, much of the efforts to optimise monitoring programmes mainly focus on their role in evaluating generic environmental policies and management at the national level, rather then on describing the environmental fate of chemicals of concern for the benefit of risk assessment protocols. As a consequence, the present aggregation of data, international reporting and international accessibility of data offer risk assessors only limited tools to improve their assessments of environmental exposure. The same trends can be discerned in regional and local monitoring programmes, but on a smaller scale. Nevertheless, the risk assessment process might benefit more from these programmes. However, there is hardly any awareness of the interest of international bodies for their data and standardisation and accessibility are rather poor.

Existing monitoring programmes may be modified in such a way that the resulting data are better suitable for risk assessment purposes. Therefore risk assessors should be aware of current practices in the design of monitoring programmes. In this document, a framework for the design of (chemical) surface water monitoring programmes is presented and the application of the framework in routine monitoring programmes will be described. The framework applies to national, regional as well as local scales.

\section{THE MONITORING CYCLE}

To define information programmes that provide suitable information, there has to be a mutual understanding of the issue at hand. Therefore, information producers and information users should jointly specify the information that is needed. To provide a common basis for this discussion, the monitoring cycle (figure 1) as a shared framework has been developed (ECE, 1996). 


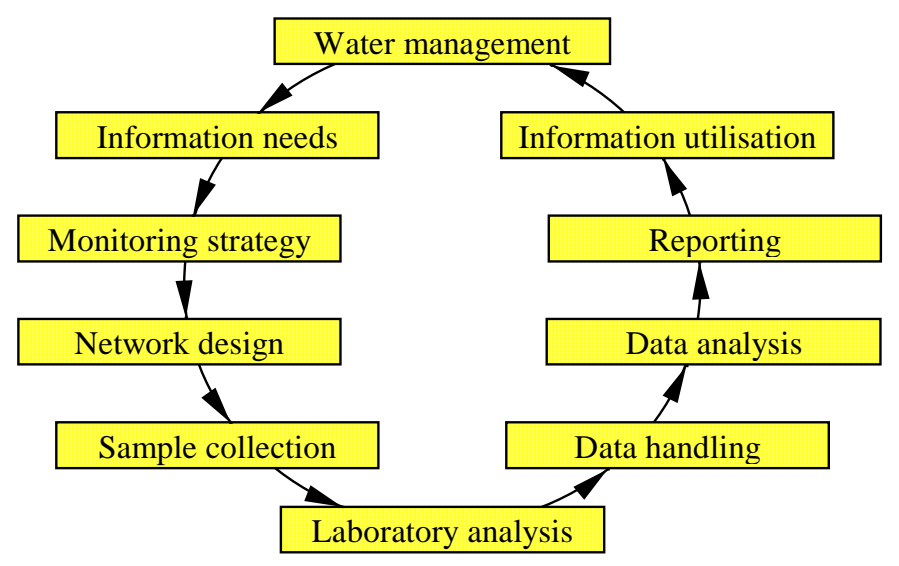

Figure 1 Monitoring cycle (ECE TFMA, 1996)

The monitoring cycle describes the process of information production. Going from information required to information obtained, the following steps can be distinguished:

- information users, as part of the monitoring cycle, should, in co-operation with information producers, decide upon the characteristics of the information that is needed;

- information producers will, in co-operation with information users, decide upon the best way (i.e. strategy) to collect information;

- the actual measurements, after network design through sample collection, laboratory analysis and data storage, form the next step in the monitoring cycle;

- the data collected are analysed statistically, the results are aggregated and interpreted relative to the information sought, and information statements are made;

- the resulting information is presented and transferred to the information users in a proactive manner.

Each step in the monitoring cycle puts requirements on the previous step of the cycle. If, for example, a trend with a defined reliability has to be calculated, sampling has to take place with a certain frequency, depending on the variability of the data. Thus data analysis puts requirements on data collection. Also, each step limits the possibilities in following steps. For example, if the sampling frequency is too low, no reliable trend can be calculated. By going through the information cycle both clockwise and counterclockwise, in an interactive way, these requirements and limitations may be made explicit (Timmerman et al., in press).

\section{INFORMATION NEEDS FOR MONITORING PROGRAMMES}

The first and most critical step in the design of monitoring programmes is to specify the information need. Monitoring programmes are usually designed to provide information for water management. This information should support operational water management but also policy development and evaluation. In water management many interests have to be considered. Surface waters do support many functions and uses, like recreation, transport, drinking water supply and ecological quality, with often conflicting requirements. Next to this, many different issues pose problems on the use of water bodies (figure 2). Water management has to find a balance between these different functions and current issues. Monitoring for water management should provide sufficient information on water quality and quantity related to these functions and issues. 


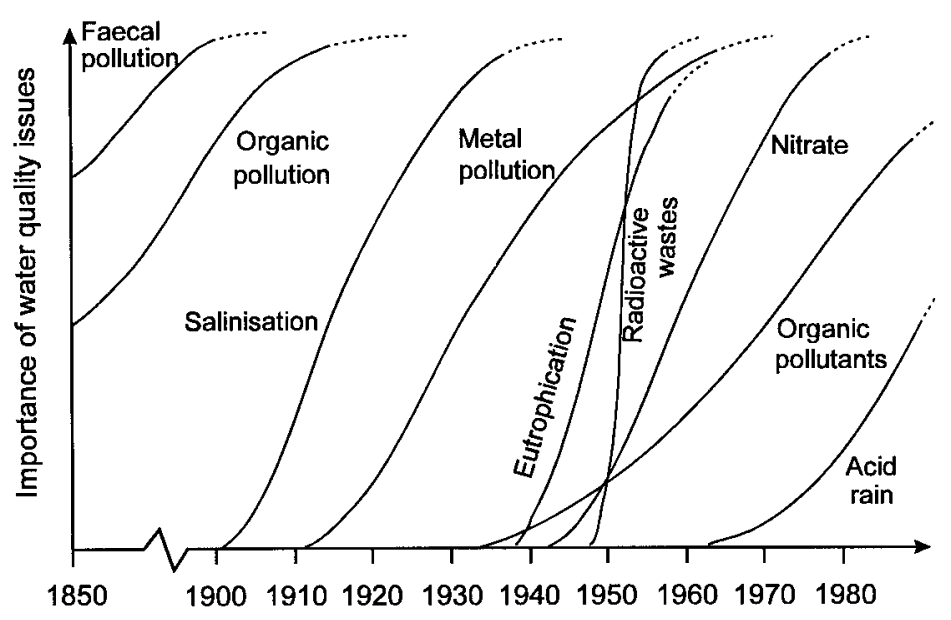

Figure 2 The sequence of water quality issues arising in industrialised countries (Meybeck and Helmer, 1989)

Monitoring takes place at different levels of detail. A distinction will be made here between local, regional, national and supra-national scales. Local monitoring usually is related to effluent discharge monitoring, or for specific research purposes. Regional and national monitoring is generally executed to support water management. These monitoring programmes usually provide information on the actual status of water bodies (often combined with compliance testing), and on trends and loads of chemical substances. Next to this, regional and national monitoring programmes support alarm and early warning systems for, for instance, calamities and floodforecasting. Supra-national monitoring is mostly done for the purpose of describing the status of international or transboundary waters, or for compliance testing of international agreements, and is often related to specific issues (Zabel, 1997).

The type of information needed may be selected on the basis of different perspectives. Van Harten and others (1995) distinguish indicators on the pressure, state of, and impact on a water body and the response of the socio-economic system (figure 3). A pressure indicator describes the intensity of human activities that cause changes in quality and/or quantity of the water. The state indicator describes the status of the quality and/or quantity of the water. A pressure may result in a new state. The impact indicator describes the influence of the state of the water on functions and uses of that water. When functions or uses are affected, a societal response may be expected. This is described by the response indicator. The response aims at a new balance between the water body as it is or might be, and the protection of its functions and uses. 


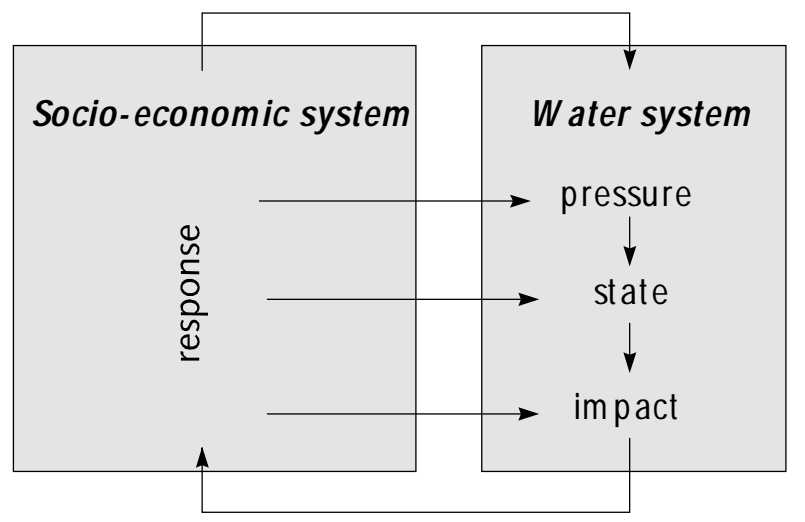

Figure 3 PSIR-concept (after Van Harten et al., 1995)

As an example, for information on a pesticide, an indication of the pressure may be the amount of pesticide that is being used. For status, the concentration in water is of interest. To look at impact, bioassays are a promising toool, while for response, information may be wanted on, for instance, compliance with the restrictions in the use of the pesticide.

\section{WHAT MONITORING STRATEGY IS TO BE USED?}

After defining the information need, a strategy for collecting this information has to be specified. The monitoring strategy chosen is a mixture of the information need and the best practical way to collect this information. For policy development and evaluation of environmental management, in general, information is wanted on what is coming in and what is going out, and on the general status of the water body in the area under administration. This leads to load calculation at the borders of administrative units, and to measurements at as little as possible sampling sites in the respective waters. Such sampling sites should be representative for the water body as a whole, and therefore not directly influenced by, for instance, industrial discharges. At a local scale more emphasis might be put in describing gradients in space and time.

\section{COLLECTING DATA}

From the information need and the monitoring strategy, the monitoring network may be designed. The determinants are fixed and sampling sites are chosen, often on the basis of historical knowledge on hydrology and ecology of the water body. Sampling frequencies have to be chosen depending on the variability of the water quality to obtain a desired level of confidence (Bartram and Ballance, 1996). After sampling, the samples are analysed and the analysed data are stored. Some analytical methods, like GCMS, provide many extra data in one analysis-run compared to the dataset required. In many cases these extra data are stored as raw data, but are not analysed.

In the Netherlands, optimisation of the monitoring networks was carried out for both inland water and coastal zone monitoring networks (Adriaanse, 1995; Swertz et al., 1997). On the basis of the information needs defined, the existing networks were analysed statistically. It appeared that, among others, water quality data at different sites were often correlating, several parameters had lost their importance, and trends could not be detected with the existing frequencies. Optimisation of these networks resulted in a 
reduction of the number of sampling sites from 130 to 25 in inland water and from 70 to 13 in the coastal zone (figure 4), deletion of several parameters and adding of others to the network, and changing and often increasing of frequencies. The resulting information from these new networks showed a better fit to the information need, while the budget was decreased.
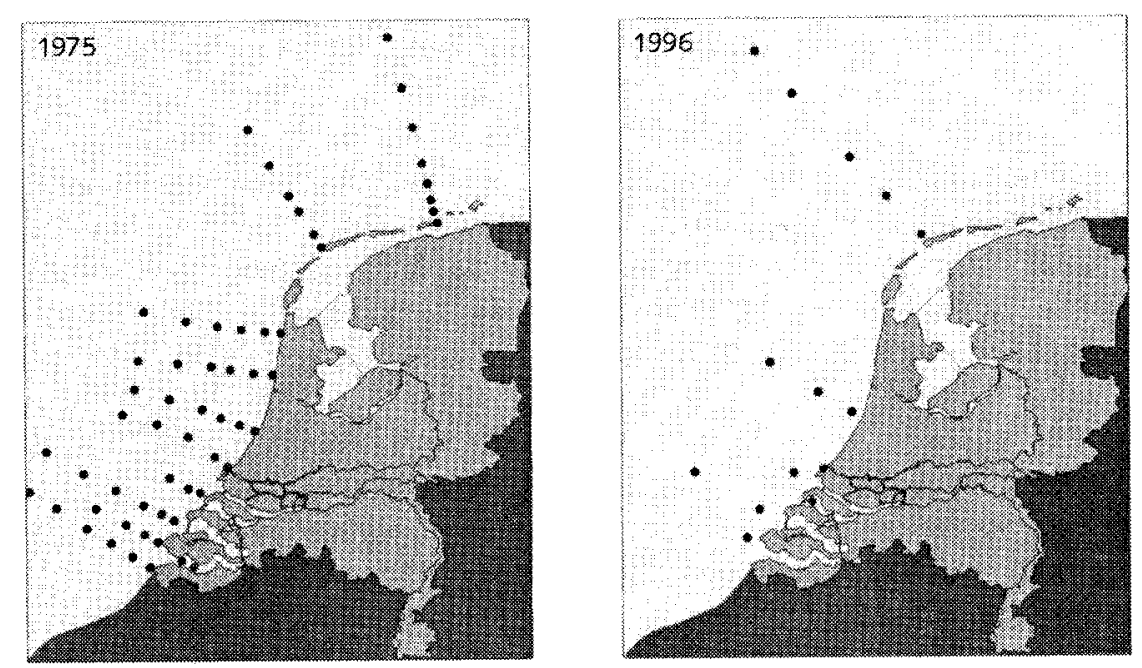

Figure 4 National water quality monitoring sites in the Dutch coastal zone (1975/1996) (Swertz et al., 1997)

\section{DATA ANALYSIS AND REPORTING}

Data from different databases often have different qualifiers. Therefore, information on the dimensions and appearance (e.g. phosphate in $\mathrm{mg} \mathrm{P} / \mathrm{l}$ or $\mu \mathrm{g} \mathrm{PO}_{4} / \mathrm{l}$ ) should be stored. Next to this, a sufficient amount of secondary data ('meta-information'), necessary to interpret the data, has to be stored such as characteristics regarding time and place of sampling, type of sample, pre-conditioning and analytical techniques (ECE TFMA, 1996). Comparability of data can best be achieved through harmonisation with the use of meta-information.

Monitoring data are in many cases reported in yearbooks. This may be a yearly overview of general statistics, like mean or median value, standard deviation, minimum and maximum value (Chapman, 1996), of all or a subset of determinants per sampling site or group of sampling sites. Trend plots are sometimes included as well as compliance testing. In some cases this information is also made available in digitised form, sometimes through internet. The basic data are seldom directly accessible.

\section{DISCUSSION}

Routine monitoring aims at getting a good overview of the general status of surface waters related to the use of the water and the issues at hand. If there are few major issues, much of the monitoring effort is put into these issues. In many industrialised countries, however, there are no major issues, but a diversity of smaller issues that may affect the use of the water body. This implies that the choice of determinants, sampling sites and sampling frequency is such that with relatively little costs as much relevant information is gathered as possible (Ministry of Housing, 1995). Since the number of chemical substances potentially present in water is overwhelming, there is a tendency to shift from monitoring individual 
chemicals to indicative screening of the water quality with the use of ecotoxicological methods. The resulting information will be less suitable for risk assessment.

On the other hand there is much information being produced and stored that is not direct accessible. As stated, often not all available data are reported, or reported in a way that is not applicable. However the raw data are usually stored and may be obtained from the monitoring organisation. Also, several specific research projects collect data, that are not reported officially. These sources may prove to be suitable for supporting risk assessment procedures.

In conclusion it can be stated that

- the monitoring cycle offers a basic framework to improve the interaction between monitoring and risk assessment of chemicals, which is useful at national, regional as well as local levels of detail;

- quality assurance, international reporting and accessibility of data is best harmonised at the national and supra-national level; however, the risk assessment procedures might benefit most from a better accessibility of monitoring programmes at regional and local scales.

- concerted action is needed to further bridge the gaps between trends in designing cost-effective monitoring programmes and the specific needs of international bodies dealing with the risk assessment of hazardous chemicals. Here interactive communication, primarily focusing on the different scales of interest, is of utmost importance.

\section{REFERENCES}

Adriaanse, M., 1995. Information requirements as design criteria for surface water monitoring. Pages 126 - 133 in: M. Adriaanse, J. Van de Kraats, P.G. Stoks, and R.C. Ward (eds.) Proceedings of the international workshop Monitoring Tailor-made. Beekbergen, The Netherlands.

Bartram, J., and R. Ballance (eds.) 1996. Water quality monitoring. A practical guide to the design and implementation of freshwater quality studies and monitoring programmes. UNEP/WHO, London. 383 pp.

Chapman, D. (Ed.) 1996. Water quality assessment - A guide to the use of biota, sediments and water in environmental monitoring. Chapman, and Hall, London, UK. 626 pp.

ECE Task Force on Monitoring and Assessment, 1996. Guidelines on water-quality monitoring and assessment of transboundary rivers. RIZA report nr. 96.034.

Meybeck, M. and R. Helmer, 1989. The quality of rivers: from pristine state to global pollution. Paleogeog. Paleoclimat. Paleoecol. (Global Planet. Change Sect.), 75, 283 - 309.

Ministry of Housing, Spatial Planning and the Environment, 1995. Monitoring Water Quality in the Future, Volumes: Chemical monitoring, Mixture toxicity parameters, Biomonitoring, Monitoring strategies for complex mixtures, Organizational aspects and Executive summary. Zoetermeer, The Netherlands.

Swertz, O.C., R.W.P.M. Laane and K.J.M. Kramer, 1997. An assessment of water quality monitoring in the Dutch coastal zone: needs, aims and optimisation. Pages 287 - 295 in: J.J. Ottens, F.A.M. Claessen, P.G. Stoks, J.G. Timmerman, and R.C. Ward (eds.) Proceedings of the international workshop Monitoring Tailor-made - II. Nunspeet, The Netherlands.

Timmerman, J.G., J.J. Ottens and R.C. Ward, in press. The information cycle as a framework for defining information goals for water quality monitoring. Environmental Management.

Zabel, T., 1997. EC Directives and their impact on European water policy. Pages 385 - 390 in: J.J. Ottens, F.A.M. Claessen, P.G. Stoks, J.G. Timmerman, and R.C. Ward (eds.) Proceedings of the international workshop Monitoring Tailor-made - II. Nunspeet, The Netherlands. 
Van Harten, H.A. J., G.M. Van Dijk and H.A.M. De Kruijf. 1995. Waterkwaliteitsindicatoren overzicht, methode-ontwikkeling en toepassing. (Water quality indices, overview, methodologies and application) RIVM report no. 733004001 (In Dutch). 


\title{
Environmental Monitoring, Modelling and Risk Assessment of Industrial Chemicals in the Aquatic Environment
}

\author{
Feijtel $^{1}$, T., K. Fox ${ }^{2}$; M. Holt ${ }^{3}$, E. Grießbach ${ }^{4}$, S. Johnsen ${ }^{5}$, J. Kinnunen ${ }^{6}$, A. Lecloux ${ }^{7}$, R Murray-Smith ${ }^{8}$, \\ D.R. Peterson ${ }^{9}$, R Schröder ${ }^{10}$, M. Silvani ${ }^{11}$, W.F.J. ten Berge ${ }^{12}$, and R.J. Toy ${ }^{13}$ \\ ${ }^{1}$ Procter \& Gamble, Eurocor, Temselaan 100, B-1853 Strombeek-Bever \\ ${ }^{2}$ Unilever Research Port Sunlight Laboratory, Quarry Road East, Bebington, Wirral, U.K. \\ ${ }^{3}$ ECETOC, Avenue E. Van Nieuwenhuyse 4 Box 6, B-1160 Brussels \\ ${ }^{4}$ Dow Corning Europe, 62, rue Général de Gaulle, B-1310 La Hulpe \\ ${ }^{5}$ Statoil, Den Norske Stats Oljeselskap a.s., Arkitekt Ebbells veg 10, Rotvoll, N-7005 Trondheim \\ ${ }^{6}$ Neste Oy, Environment and Industrial Hygiene, P.O.B. 320, FIN-06101 Porvoo \\ ${ }^{7}$ Eurochlor, Avenue E. Van Nieuwenhuyse 4 Box 6, B-1160 Brussels \\ ${ }^{8}$ Zeneca, Brixham Environ Laboratory, Freshwater Quarry, Brixham, Devon, U.K. \\ ${ }^{9}$ Exxon Biomedical Sciences Inc., Mettlers Road, CN 2350, USA-East Millstone, NJ 088752350 \\ ${ }^{10}$ Henkel, TTB/Ökologie, D-40191 Düsseldorf \\ ${ }^{11}$ BASF AG, DUU/O-Geb. Z570, D-67056 Ludwigshafen \\ ${ }^{12}$ DSM, Corporate Staff Safety, Health \& Environment, P.O. Box 6500, NL-6401 JH Heerlen \\ ${ }^{13}$ Shell Chemicals Ltd, , Shell Centre, London, U.K.
}

\section{Introduction:}

In environmental exposure assessment the concentration of a substance in the different environmental compartments is estimated from the amount of the substance released during the production and formulation, the use and disposal patterns and the releases resulting from them, the substance's physicochemical properties and the properties of the environmental compartments into which the substance is released or distributed. The predicted environmental concentration, (PEC), can therefore be calculated from a knowledge of the quantity of the substance that will enter the environment and the distribution and degradation processes occurring in the environment using, generic, representative model environments as specified in the EU Technical Guidance Documents (TGD) for Risk Assessment of New and Existing Chemicals.

An alternative to such calculations is to measure (monitor) concentrations in the relevant environmental compartments. This is only possible for substances which are released in quantities large enough to be detectable by appropriate analytical methods after dilution in the environment. In those cases where reliable high quality monitoring data are available - with proper statistical and temporal evaluation and adequate spatial representation- they should take precedence over the predicted environmental concentrations .

Most often, environmental monitoring is defined as a long-term and standardised measurement, observation, evaluation and reporting of the environment in order to define status and trends. Monitoring may include survey, defined as a sampling programme of finite duration and for a specific purpose or surveillance which is a more continuous, specific measurement or observation with the goal of environmental quality reporting and/or operational activity reporting. 
Monitoring and modelling are integral parts of risk assessment. The principle in the EU Technical Guidance Documents for Risk Assessment is that measured data may take precedence over model results but only after they are judged to be of adequate reliability and to be representative of the particular environmental compartments to which they are applied. In practice, laboratory and field data are used to provide parameters for the models, while monitoring data are used to validate models' predictions. Discrepancies between the results of models and monitoring should be investigated in terms of both the representativeness of the models and the monitoring data. Thus, comprehensive risk assessments require the integration of laboratory and monitoring data with the model predictions. However, this interplay is often overlooked. Certainly in the context of the EU risk assessment of existing chemicals, the specific requirements for monitoring data have not been adequately addressed.

Worst-case assumptions in the exposure scenarios and exposure models have led to the belief that monitoring data are unreliable and/or only represent the best case and therefore can't be representative. There is thus a need to position monitoring data in the context of risk assessment, and specifically $1 /$ to define and position worst-case and reasonable worst case scenarios in a probabilistic exposure and risk assessment; 2 / to recommend a monitoring strategy for collecting new data which is suitable for use in a risk assessment; and 3/ to determine criteria for the acceptability of data already existing in the different environmental compartments, for risk assessment purposes.

To further explore the interplay between monitoring, modelling and risk assessment, the European Centre for Ecotoxicology and Toxicology of Chemicals (ECETOC) formed a Task Force with the following Terms of Reference:

- define the terms observation, monitoring and surveillance as used in the EU Risk Assessment Technical Guidance Document and evaluate how these relate to the risk assessment of substances;

- evaluate environmental settings adopted by the EU Risk Assessment Scheme and develop guidance on the relationship between time and space variable monitoring data and the predictions of exposure models;

- develop guidelines for exposure monitoring strategies resulting in the generation of representative quality data for use in risk assessment and to establish that any risk management is working

The ECETOC report will attempt to address the use of monitoring data in the TGD and to develop guidance on the relationships between generic steady state model predictions and specific monitoring data. Guidance on monitoring strategies (e.g. sampling, analysis techniques, representativeness, etc.) will be provided for validation of the exposure models. In addition the report will also summarize the main findings and recommendations on how to improve the use of monitoring programmes and data, and how to better integrate monitoring data into a risk assessment. The environmental risk assessment of pesticides and related products are addressed in a different directive (91/414/EEC and amendments) and will not be considered in this document.

This note is a summary of the forthcoming ECETOC report. 


\section{Key Conclusions:}

- monitoring and laboratory data have integral roles alongside fate and exposure models in comprehensive risk assessments;

- it is not a foregone conclusion that PECs based upon measured concentrations will take precedence. It must be clearly demonstrated that the monitoring data are representative of the intended scale, setting, scenario, life stage, etc. If this is the case, the monitoring data may be used to derive environmental concentrations, to validate the exposure model and/or be used for improvement in default emission assumptions;

- by using monitoring and laboratory data to calibrate fate and exposure models for the chemical and environment of interest, and monitoring data to verify and validate these models for specific environments and classes of chemicals, greater confidence can be placed in the resulting risk assessment and conclusions based on it;

- there is no one way to do 'good' monitoring. For example, spatial distribution and sampling frequency are key to the quality of a dataset, but the criteria by which to judge these attributes will depend directly on the objectives of the monitoring programme;

- monitoring programmes should be designed to meet the specific objectives of the study e.g. assessment of water quality, $\mathrm{PEC}_{\text {local }}$ or $\mathrm{PEC}_{\text {regional }}$ either targeted or full exposure and risk assessment. The monitoring site or sites should be selected accordingly;

- once a site is identified which is consistent with the goals of the monitoring programme, a sampling protocol which is also consistent needs to be developed.

The key features of a cost-effective monitoring exercise are:

- clearly defined objectives which are focused and have a well defined sampling strategy;

- involvement of all interested parties from the early planning stages to optimise knowledge, and resources and maximize acceptance of study;

- visits to select thoroughly 'characterised' sites;

- a pre-study to confirm suitability of sites and applicability/feasibility of analytical methodology;

- the use of validated sample preservation, quality assurance and control procedures;

- the organisation of an appropriate supporting programme;

- select the monitoring period to be compatible with the scenario in respect of season, weather conditions etc.

- an effectively planned and implemented reporting procedure to deliver the information gathered to all interested parties.

- monitoring data can be used in a straightforward manner to carry out site specific or local risk assessment, provided that sufficient information concerning the chemical and the environment, the release history of the chemical with respect to the monitoring site, and the analytical methods used to determine the concentrations are provided; 
- the use of monitoring data for regional risk assessment will be a possibility in the future, when the data necessary to relate the characteristics of a monitoring site (including distance from and strength of release sources, and the environmental characteristics which will determine the residence time of the chemical in that site), to the distribution of site characteristics for the rest of Europe have been identified, collected, accepted and released for general use.

\section{Recommendations:}

- monitoring objectives should be used to define the sampling strategy which, in turn, should promote efficient, relevant and cost effective monitoring;

- the ultimate goal of monitoring is to provide information to meet well defined objectives. The reliability of the information must be checked in the light of this objective;

- the reliability of the data should be established via appropriate quality assurance/ quality control measures;

- existing monitoring data should be used, whenever possible, for environmental risk assessment and model validation purposes. However, it is essential that the data set contains appropriate information and is shown to be fit for the purpose for which it is to be used;

- monitoring results should be summarized in order to make conclusions about, for instance, the real concentration or how typical the reported numerical values of the total group of samples are;

- both the choice of the site(s) and the monitoring data must be associated with a particular scenario in order to be of use in establishing the realistic risk scenario, the 'reasonable worst case' or 'representative or realistic case';

- an effort should be made to harmonize monitoring programmes across Europe and ensure appropriate data logging and data access. Ideas of how to harmonise monitoring and incorporate the wealth of data that exists into a database should be investigated;

- guidelines should be developed and agreed to ensure ready availability and transparent access of data via standardised procedures. A dedicated data centre whose role is to co-ordinate data acquisition and dissemination may be a cost-effective way of achieving this goal;

- for future programmes, it is recommended that representative areas and sites be developed to represent specific scenarios for river basins as part of the proposed framework for Community action in the field of water quality. Representative regions should also be developed, and used to define local and regional scenarios for the risk assessment of substances under the Risk Assessment Technical Guidance Documents.

\section{Appendix: Monitoring Practicalities}

There are a number of practical considerations when designing a monitoring programme which are generic regardless of the compartment being monitored. Designing a monitoring study to determine $\mathrm{PEC}_{\text {regional }}$ is very difficult and consequently most of the ensuing discussion relates to monitoring to determine the $\mathrm{PEC}_{\text {local }}$. The topics considered are practical, and concern the specifics of study design and implementation. 
Monitoring programmes may have one or more objectives, including confirmation of regulatory compliance, trend analysis, warning of a pollution event, establishment of the concentration of a particular chemical for purposes of risk assessment or risk management. Defining the objectives of the study allows one to define the site or sites which will be needed to meet these objectives. The site and sampling pattern need to be chosen such that they will adequately represent the setting and location which are intended by the study objectives.

To be successful, a monitoring study must be well planned. The goals and objectives of the study need to be well defined as these will determine the site selection, the extent of sampling (both duration and numbers of samples), the types of samples, the data requirements, the analytical methods, etc. Execution of the plan requires co-operation of those on site, adequate training of personnel, and a host of other technical details. Figure 1 illustrates some of the key stages in designing a monitoring programme.

Figure 1: Stages in Planning and Execution of a Monitoring Programme

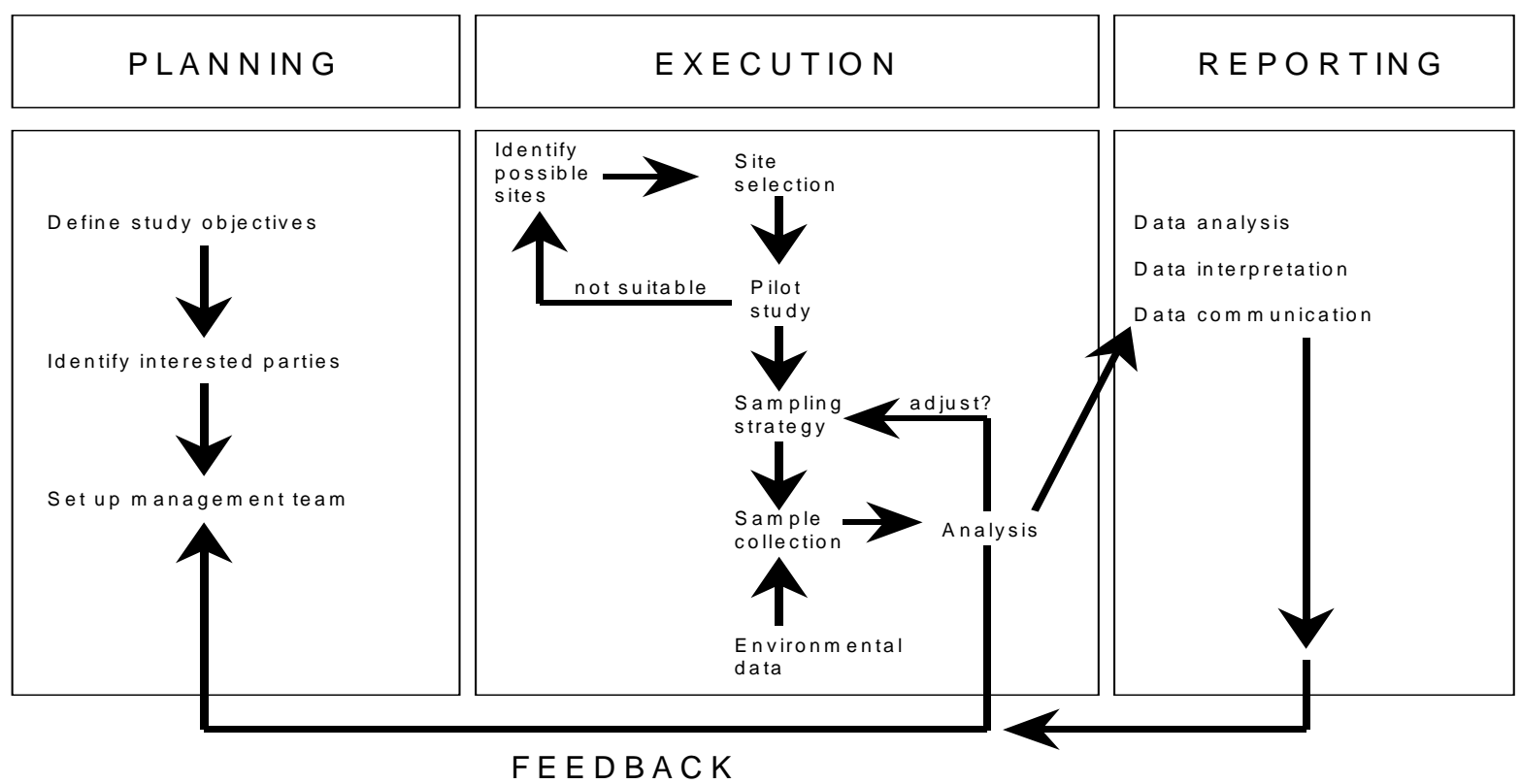

Adequate planning and definition of study objectives will allow an evaluation of the availability of sufficient resources for the programme. Both human and financial resources are needed.

The resources needed to carry out a monitoring programme can be significant. To ensure these resources are effectively utilised it is important that the relevant parties, whose knowledge and practical experience can be used and whose endorsements are necessary for the acceptance of the study, are identified and involved at all stages. Attention should be given to identifying and involving regulatory authorities, local officials, trade organisations, laboratories, and academia. Following initial discussions with interested parties, which should establish a commitment to the study, a management team should be set up. Their team role is to agree to a project protocol which clearly states the aims and objectives, identifies individual responsibilities and allocates resources. 
The major areas to consider when designing a monitoring programme are summarised in Table 1. It is specific for monitoring studies designed to collect chemical concentration data to be used for risk assessment. The table focuses attention on generic areas of importance for the design, execution and reporting of monitoring results but not on the issues specific to different environmental compartments.

The generic areas are subdivided into six categories:

1. the technical details of how the sample was collected, preserved and analysed;

2. the degree of quality assurance and quality control employed in arriving at a final environmental concentration;

3. the location in space and time of the sample(s);

4. the condition and characteristics of the sample and the environment from which it came;

5. the local manufacturing facilities, the characteristics of the facility;

6. the data handling, how many analyses does a concentration represent and how were the numbers composited?

Categories 1 and 2 pertain to data quality issues in sampling and analysis, while categories 3 to 6 relate to issues necessary or useful in establishing the representativeness of the samples and of the site (geographically and within a particular risk assessment scenario.)

Close adherence to the points and principles specified in the table should ensure that the resulting monitoring programme generates results which will be both suitable and applicable for environmental risk assessment.

Table 2 lists the criteria considered important when using existing monitoring data. 


\section{Technical Aspects of Sampling}

a. Necessary sample size, (i.e. volume, weight, etc.)

b. Appropriate sampling techniques: apparatus (type and materials), duration, transfer methods,

c. Appropriate containers (size, composition, type, labelling, cleaning procedures, closures), replication, methods to avoid (cross)contamination

d. Appropriate sample preservation, cooling, transport \& storage times

e. Select sub-sampling techniques: methods to avoid volatile losses, methods to remove sorbed or precipitated chemical from container surfaces, separation of suspended particulates, mixing

\section{Technical Aspects of Analysis}

a. Techniques for sample preparation, concentration or extraction

b. Techniques to correct for losses during the analytical scheme (recoveries of spikes)

c. Techniques to evaluate and account for background interference or contamination

d. Select or develop selective chemical analysis with appropriate sensitivity and reproducibility

e. Assure that analytical method detection limit is low enough for intended purpose

f. Specify method and frequency of calibration/standardisation of the analysis

\section{Quality Control and Quality Assurance}

a. Establish procedures for tracking and documenting sample integrity, transfers, etc.(e.g. inventories, chain of custody, etc.)

b. Establish procedures to assure consistent sampling and analysis methods (protocol, standard operating procedures, personnel training, etc.)

c. Establish procedures to associate final analytical result with original sample (sample coding and unique sample i.d.s, data sheets, transfer forms, etc.)

d. Establish procedures to track and document analytical reliability (e.g. QC charting, sample re-analysis, blind performance samples, etc.)

e. Establish criteria for re-analysed or omission of "'outliers'.

g. Define monitoring or auditing responsibilities for supervisory or independent QA checks on conformance of sampling and analysis with the protocol requirements.

\section{Sample Location in Time and Space}

a. Select sampling durations, frequency and times (of day, month, season, year)

b. Select sample sizes and decide on grab or compositing (flow or time related)

c. For composite samples, select locations or sample intervals to be combined

d. Collect environmental data to establish influence of season and weather on sample representativeness

e. Sample location (macro): Select catchment, country, geographic location (e.g. latitude/longitude), distance from source(s), etc.

f. Sample location (micro): select sampling locations relative to source and surface of environmental compartment and relative to other samples taken (i.e. distance, direction, time interval). Positively identify site for future sampling. 
Table 1: Considerations for the Design of New Monitoring Programmes

\section{Sample Characteristics}

(Sample characteristics depend upon specific compartment being sampled and are treated separately)

\section{Environment Characteristics}

(Environment characteristics generally differ with specific compartment but a few are generic)

a For the specific purpose (scenario) for which the data are intended the following are appropriate:

i. distance from industrial effluents of the same chemical

ii. population (urban, sub-urban, rural)

iii. climate and weather (temperature variations, rainfall, etc.)

iv. physical characteristics (topography, distance inland, etc.)

v. flow (tidal, spring flood, summer drought etc)

b. Presence and location of other sources of pollution in the region of the sampling site

c. Data on the site history regarding physical characteristics and pollution (e.g. BOD; DO, $\mathrm{pH} ; \mathrm{NH} 3$; $\mathrm{SS}$; DOC)

\section{Local Source or Site Characteristics}

a. Site selected representative of the emission source (point source or diffuse source)

b. Site is representative of intended life stages of chemical (production, processing, storage, etc.)

c. Site is typical of the industry in annual production or throughput of the chemical

d. Site selected is used typical processes for the industrial step

e. Site selected is has similar waste disposal and wastewater treatment practices as those which are representative of the industry.

f. Site selected has a stable operational schedule; the time frame for releases of the chemical are known and not likely to change. no changes in schedule, new equipment, or processes changes are likely to occur over the time frame of the study

\section{Reporting}

a. Details of sampling scheme, sample locations and time intervals, sample sizes and numbers, local environment and sample characteristics

b. Available data on site representativeness including direction and magnitude of source and site characteristics regarding industrial activities, tonnage throughput, etc.

c. Details of the sample handling and tracking procedures. Provide results of background or procedure blank analyses

d. Details of the sample preparation procedures including mixing. sub-sampling, extractions or concentration, dilution of extracts, etc.

e. Details of analytical methods and data on selectivity and background interferences. Results of blank/background analyses, sample analytical result.

f. Data on the sensitivity and reproducibility of the sample handling and analysis, including results for spikes, QC samples, QC charting, etc.

g. Statistical summary of the data: number, distribution, mode, mean, std. dev., 90th \%-ile, etc.

h. Description of the value used to incorporate non-detects in the mean and the actual number of non-detects

i. Discussion of the relevance of the data, how concentration compare with background (upstream) data, historical data, data from other similar monitoring studies, etc. 
Table 2: Minimum Information to justify Use of Existing Data

\begin{tabular}{|l|c|c|c|}
\hline \multicolumn{1}{|c|}{ Criteria } & $\begin{array}{c}\text { Highest Quality } \\
\text { Data }\end{array}$ & $\begin{array}{c}\text { Support for Exposure } \\
\text { Assessment (Data } \\
\text { Interpretation Difficult) }\end{array}$ & $\begin{array}{c}\text { Not for Use in Exposure } \\
\text { Assessment but valid for } \\
\text { trend analysis }\end{array}$ \\
\hline What has been analysed? & $\checkmark$ & $\checkmark$ & $\checkmark$ \\
\hline Analytical method & $\checkmark$ & $\checkmark$ & \\
\hline Minimum level of detection & $\checkmark$ & & \\
\hline Blank concentration & $\checkmark$ & & \\
\hline Recovery & $\checkmark$ & & \\
\hline Accuracy & $\checkmark$ & & \\
\hline Reproducibility & $\checkmark$ & & $\checkmark$ \\
\hline Sample collection & $\checkmark$ & & \\
\hline One shot or mean & $\checkmark$ & & \\
\hline Location & $\checkmark$ & Minimum is knowledge of & \\
\hline Date dd/mm/yy & $\checkmark$ & year & \\
\hline Time & $\checkmark$ & & $\checkmark$ \\
\hline Matrix characteristics & $\checkmark$ & $\checkmark$ & \\
\hline $\begin{array}{l}\text { Sampling frequency and } \\
\text { pattern }\end{array}$ & $\checkmark$ & $\checkmark$ & \\
\hline Proximity of discharge points & $\checkmark$ & & \\
\hline $\begin{array}{l}\text { Discharge emission pattern } \\
\text { and volume }\end{array}$ & $\checkmark$ & & \\
\hline Flow and dilution & & & \\
\hline $\begin{array}{l}\text { Explanation of value assigned } \\
\text { to non-detects if used in a } \\
\text { mean }\end{array}$ & $\checkmark$ & & \\
\hline
\end{tabular}




\title{
Development of Chemical-Physical Monitoring by the International Commission for the Protection of the Rhine against Pollution
}

\author{
Dr. Klaus Vogt, State Environment Agency North Rhine - Westphalia, Germany \\ 1. \\ Introduction
}

The central European river Rhine with a length of $1320 \mathrm{~km}$ and an average flow of about $2000 \mathrm{~m}^{3} / \mathrm{s}$ (Nether Rhine) is not the mightiest river within Europe, but considering its importance as a drinking water resource and sewage discharge for 20 million people, it is one of the most important rivers. Due to the high density of industry and population, the river is also a busy waterway for shipping and a source of hydroelectric power generation. Furthermore a lot of beautiful sceneric places have influenced many artists over the centuries, and the Rhine area is still a region of high touristic interest.

Corresponding to the multiple functions, water quality decreased particularly during the reconstruction of towns and industry after World War II. In 1950 the international monitoring and actions by the bordering countries Switzerland, France, Luxembourg, Federal Republic of Germany and Netherlands began, coordinated in the International Commission for the protection of the Rhine against pollution (ICPR). Focusing on chemical-physical monitoring the strategy over the years can be divided in three phases.

\section{Phase I - The Beginning}

Based on the recognition, that transboundary rivers can only be effectively managed in a common international way, the ICPR was founded in 1950, followed 1963 by the signature of a basis on international law for the International Commission (Bern Convention), detailing the tasks assigned to the ICPR: Analyze the state of the Rhine, propose clean-up measures, prepare international conventions and carry out the tasks decided on the Rhine Minister Conferences.

Until the early seventies the ecological measures could not follow the economic development and the Rhine was called "the cloaka of Europe" in order to inforce further protection measures.

In 1976 the European Economic Commission (EEC) joined as contracting party and two additional conventions (against chemical pollution and chloride pollution) were signed, a third against thermal pollution was under development.

The initial monitoring network consists of 7 international stations, where 6 determinands were analyzed regularly in high frequency with spot and mixed samples.

The initial list of determinands consisted mainly of basic parameters regarding oxygen ballance, salts and nutrient state. Furthermore "hazardous substances", especially toxic and/or persistent chemicals were added later to the list. The selection was founded on the expertise at that time, so mainly basic industrial chemicals were chosen.

All monitoring data are published in yearly numeric reports since 1953. 


\section{Phase II - The Rhine Action Programme}

Following the measures based on monitoring results and the general environmental development in Europe in the early eighties, the water quality of the Rhine was on a good way. Due to the construction of an area-covering network of municipial and industrial wastewater treatment plants the biologic quality (analyzed as saprobic index) increased and the self-purification-capacity of the river set in. But in 1986 the Sandoz storehouse fire, when 10 - 30 tons of pesticides and combustion products were released with the fire-extinguishing water in the Rhine with desasterous effects on the aquatic communities, shows the vulnerability of the Rhine ecosystem. As an effective reply in 1987 the "Rhine Action Programme", also known as "Salmon 2000", was adopted by the Minsters of the ICPR member states [1].

Regarding the actions and the monitoring programme the strategy had to be changed significantly to fulfil the ambitious goals of the programme.

A list of "priority substances" was defined. Following a combined (emission plus water quality) approach a bundle of requirements had to be fulfilled by these substances:

- they had to be monitored in the preferable compartiment with sufficient analytical limits,

- quality targets (not imperative values) for all water uses had to be derived,

- until 1995 the inputs of the substances by point sources should be reduced to less than $50 \%$, for some substances to less than $70 \%$ and

- the progress of reduction has to be demonstrated by emission inventories.

In practice the monitoring network consists of 9 international monitoring stations along the Rhine, where at least 13 times a year samples of water and suspended particular matter are collected and analyzed.

Besides the basic parameters the main emphasis was put on priority substances. The list consists of 45 substances or groups of substances (see table 1). 27 were part of the list attached to the above mentioned convention against chemical pollution. Additional 28 substances, mainly pesticides, dioxines, chlortoluenes and arsenic were implemented by the Rhine Ministers, following the results of surveillance programmes within individual member states and the results of the 3. International North Sea Conference. All substances are known to be produced or in use inside the Rhine basin.

In a provisional appraisal 1993 it could be demonstrated, that - as a result of multiple measures - for 35 substances out of 45 the quality targets could be met at every international station. Furthermore the point source inputs have fulfilled or exceeded the required reduction quotas for most of the priority substances (table 1)[2,3]. 
Table 1: Reductions of Point Source Inputs in the Period 1985-1992 in Percent (ICPR 1994)

\begin{tabular}{|c|c|c|c|}
\hline \multirow{2}{*}{$\begin{array}{l}\text { Non-detectable } \\
\text { point source inputs } \\
1990 \text { or } 1992\end{array}$} & \multicolumn{3}{|c|}{ Reduction quotas } \\
\hline & \multicolumn{2}{|c|}{$80-100 \%$} & $70-79 \%$ \\
\hline $\begin{array}{l}\text { Atrazine } \\
\text { Azinphosethyle } \\
\text { Dichlorvos } \\
\text { Fenitrothion } \\
\text { Malathion } \\
\text { Parathion-methyle } \\
\text { Simazine } \\
\text { Trifluraline } \\
\text { DDT } \\
\text { Dioxins }\end{array}$ & $\begin{array}{l}\text { Cadmium } \\
\text { Chromium } \\
\text { 1,2-Dichloroethane } \\
\text { Tetrachloroethene } \\
\text { Trichloromethane } \\
\text { Trichloroethene } \\
\text { Tetrachloromethane } \\
\text { Benzene } \\
\text { Hexachlorobenzene } \\
\text { Hexachlorobutadiene } \\
\text { Chloroanilines }\end{array}$ & $\begin{array}{l}\text { Chloronitrobenzenes } \\
\text { PCB } \\
\text { AOX } \\
\text { Pentachlorophenol } \\
\text { Azinphosmethyle } \\
\text { Fenthion } \\
\text { Drines } \\
\text { Parathion-ethyle } \\
\text { organic Tin compounds }\end{array}$ & $\begin{array}{l}\text { Nickel } \\
\text { Bentazon }\end{array}$ \\
\hline & $60-69 \%$ & $50-59 \%$ & $30-49 \%$ \\
\hline & $\begin{array}{l}\text { Copper } \\
\text { Zinc } \\
\text { Lead } \\
\text { 2-Chlorotoluene }\end{array}$ & \begin{tabular}{|l} 
Mercury \\
$1,1,1$-Trichloroethane \\
Trichlorobenzenes \\
total Phosphorous
\end{tabular} & $\begin{array}{l}\text { Ammonium } \\
\text { Endosulfan } \\
\text { 4-Chlorotoluene }\end{array}$ \\
\hline
\end{tabular}

\section{A bit on the side - The Rhine Alarm Model}

The desasterous fire at Sandoz - Schweizerhalle has also highlighted the insufficient knowledge about a wave of pollution moving downstreams. So the Rhine Minister Conference in 1986 asked the ICPR for a quick but reliable method for predicting the time of arrival and the expected concentrations at the different monitoring sites. This should support the work within the alarm monitoring, which beside the regular long term monitoring was established earlier and - after the accident - increased rapidly. Today most of the international stations are equipped with continuously or semi-continuously working analyzers including a range of continuous biomonitors.

The ICPR, together with the International Commission for the Hydrology of the Rhine Area (CHR), special departments and universities of the member states established and tested a prediction model [4]. The first uncalibrated version was available in 1988, now version 2.1 with calibration, improvements and amendments is a permanent component of the international alarm and warning system "Rhine", which incorporates 8 warning centres and the attached agencies.

Based on 6 tracer tests the prediction model is able to calculate with flow velocity, cross-section of the river bed, water level and quantity, extension and breakdown of substances as the most influencing factors. With the fundamental information of water levels at 18 stations -ready available by a phone call and further information on the accident the transit time of a pollution wave can be predicted with about 95 $\%$ accuracy. 
Restrictions are caused

- in downstream stations near the scene of the accident by incomplete mixture of the substance in the cross profile of the river,

- in places near the Dutch estuary area by different tides and

- by floating pollution like oil.

Future work includes the most important tributaries like Moselle and Aare.

\section{Phase III - The modern List 2000 of Rhine - relevant Substances}

Considering the success of the Rhine Action Porgramme and the renewal of the Rhine Agreement on the agenda the Rhine Ministers have asked the expert groups inside the ICPR to develop a new list of relevant substances in the catchment [5].

As a first step the list of priority substances could be diminished by those, which over the last years fell short the quality targets and reached the required emission reduction quotas.

The list of remaining substances was complemented by proposals on new substances, which are suspected to be harmful, are handled in the Rhine catchment (production and / or use) and where positive analytical findings confirms their occurence in the river. Within the proposals the results of the 4. North Sea Conference were taken into account.

For a lot of new substances a selection scheme for identification of relevant substances [6] was applied. This tiered approach allows a ranking of harmful substances. In a first step, substances occuring in surface waters were identified by comparison with substances in international lists (e.g. list I and II of the directive 76/464/EEC and annexes of the 3. International North Sea Conference). With emphasis on detected substances they were ranked according to their hazard for aquatic organisms using a scoring system, which is based on exposure assessment (validated monitoring data) and effect assessment (physical properties, ecotoxicological data, bioconcentration).

The difference between the "priority substances" and the "relevant substances" is the different status. For priority substances the monitoring, the derivation of quality targets, an emission reduction programme and an emission inventory was obligatory, for relevant substances a pragmatic and tiered approach is proposed: Based on the comparison between the concentration (in general annual 90 percentile) in the river and a preliminary quality target it has to be decided, wether

- the substance should be monitored

- a quality target should to be derived and / or

- reduction quotas for emissions should be determined.

As yet the new list is not totally completed and the recent considerations within the development of the European Water Framework Directive have to be taken into account. 


\section{Summary}

Though the results of actions and measures, done or influenced by the ICPR in almost every field of river basin management, could not be shown in detail, it can be stated, that the restoration of the Rhine is a good example of successful international catchment management.

Regular monitoring, completed by specialized surveys (assessment of sediments, biota and morphologic structure) in a fixed time schedule is an indisputable fundament for actions and measures.

With growing ecotoxicological expertise objective, reliable and quantitative considerations, particularly the derivation of quality targets could be completed.

The shift over the years in ICPR monitoring strategies shows, that intelligent monitoring is able to give the information needed and can be a flexible and operational tool in the dynamic development of water management.

\section{References}

[1] ICPR (1987): Rhine Action Programme technical-scientific secretariat, Koblenz, Germany

[2] ICPR (1994): Rhine Action Programme, inventory of point source inputs of priority substances technical-scientific secretariat, Koblenz, Germany

[3] ICPR (1994): Rhine Action Programme, comparison of water quality of the Rhine with quality targets 1990 - 1993, technical-scientific secretariat, Koblenz, Germany

[4] ICPR (1993): Topic Rhine No. 8, April 1993 technical-scientific secretariat, Koblenz, Germany

[5] ICPR (1998): Agreements, follow-up and state of play concerning the list of Rhine-relevant substances, internal document AC 8/98 technical-scientific secretariat, Koblenz, Germany

[6] UBA (1995): Application of a selection scheme for the identification of substances hazardous to the aquatic system,

UBA-Texte 50/95

Umweltbundesamt Berlin, Germany. 


\title{
Two Examples of Japan's Environmental Monitoring Programmes on Chemicals
}

\author{
Kiyoshi Tanabe \\ National Institute for Environmental Studies, Environment Agency, Japan \\ Onogawa 16-2, Tsukuba, Ibaraki, 305-0053
}

\begin{abstract}
Among varieties of environmental monitoring programmes, there are two different type monitoring programmes on chemicals in Japan. One, "General Inspection Survey", which is designed to provide early warning on chemical pollution, was introduced under Chemical Substances Control Law (CSCL) in 1974 ${ }^{1}$. The other one, "Monitoring of Hazardous Air Pollutants (HAPs)", which is designed to provide both screening and quantitative level information on HAPs pollution, has been introduced under amended Air Pollution Control Law (APCL) in 1997. Environmental monitoring of chemicals is expanding following recent movement of chemical regulations based on exposure/risk assessment. Necessity of systematic approach is under discussion, which may efficiently link various regulations, monitorings, databases, PRTR, etc.
\end{abstract}

\section{General Inspection Survey (environmental survey on existing and examined chemicals)}

CSCL was enacted in 1973 following serious troubles caused by problematic chemicals such as PCBs. It requires 1) various evaluation of chemicals and 2) classification of chemicals by persistence, bioaccumulation and toxicity, which results in regulations on classified chemicals. New chemicals are to be tested by manufacturer or importer, and existing chemicals are under examination by government. Biodegradation and accumulation are tested by Ministry of International Trade and Industry, toxicity is examined by Ministry of Health and Welfare, and Environment Agency (EA) is responsible for environmental persistence and monitoring.

EA initiated monitorings for checking and early warning of chemical pollution in 1974 . The monitorings consist of environmental survey on existing and examined chemicals and monitorings of classified chemicals such as PCBs, DDTs, PCDDs, etc. The survey is a screening system for chemicals in environment, so that it is carried out systematically as shown in Figure 1. A list of priority chemicals had been selected from thousands of chemicals based on production volume, use pattern, persistence, toxicity, etc. Since the survey is 10 years plan (now in 2nd phase from 1989 to 1998), about 110 chemicals are picked up every year from the list. Based on the prediction by a non-steady state equilibrium model, 20 30 chemicals including about 5 key chemicals are selected for the survey. Environmental media are also selected based on the prediction. Prior to the survey, detailed analytical protocols are developed for the selected compounds and media.

In 1995, 3 surface water and sediment samples were collected in 56 areas, 3 fish samples were collected in 52 areas, 3 consecutive 24 hour air samples were collected in 18 areas. For efficient data collection, survey is carried out as shown in Figure 2. For surface water samples, 4 key compounds were analyzed for all samples, and all 30 compounds were analyzed for $11 \mathrm{key}$ area samples. Analysis of non-key compounds in non-key areas were carried out case by case. In the case of air, 5 key compounds were analysed for all samples and 1 key compound was analyzed for 16 area samples. All 18 compounds were analyzed for 6 key area samples. Actual survey, i.e., sampling, analysis, etc., are carried out under cooperation with local research/testing institutions. The survey covers Japanese islands as shown in Figure 3. Sampling areas/sites were selected to reflect varieties of types and sizes of urban areas, where most of people are living.

1. Chemicals in the Environment - Report on Environmental Survey and Wildlife Monitoring of Chemicals in F.Y. 1995. Environmental Health and Safety Division, Environment Agency, Japan (1997). 


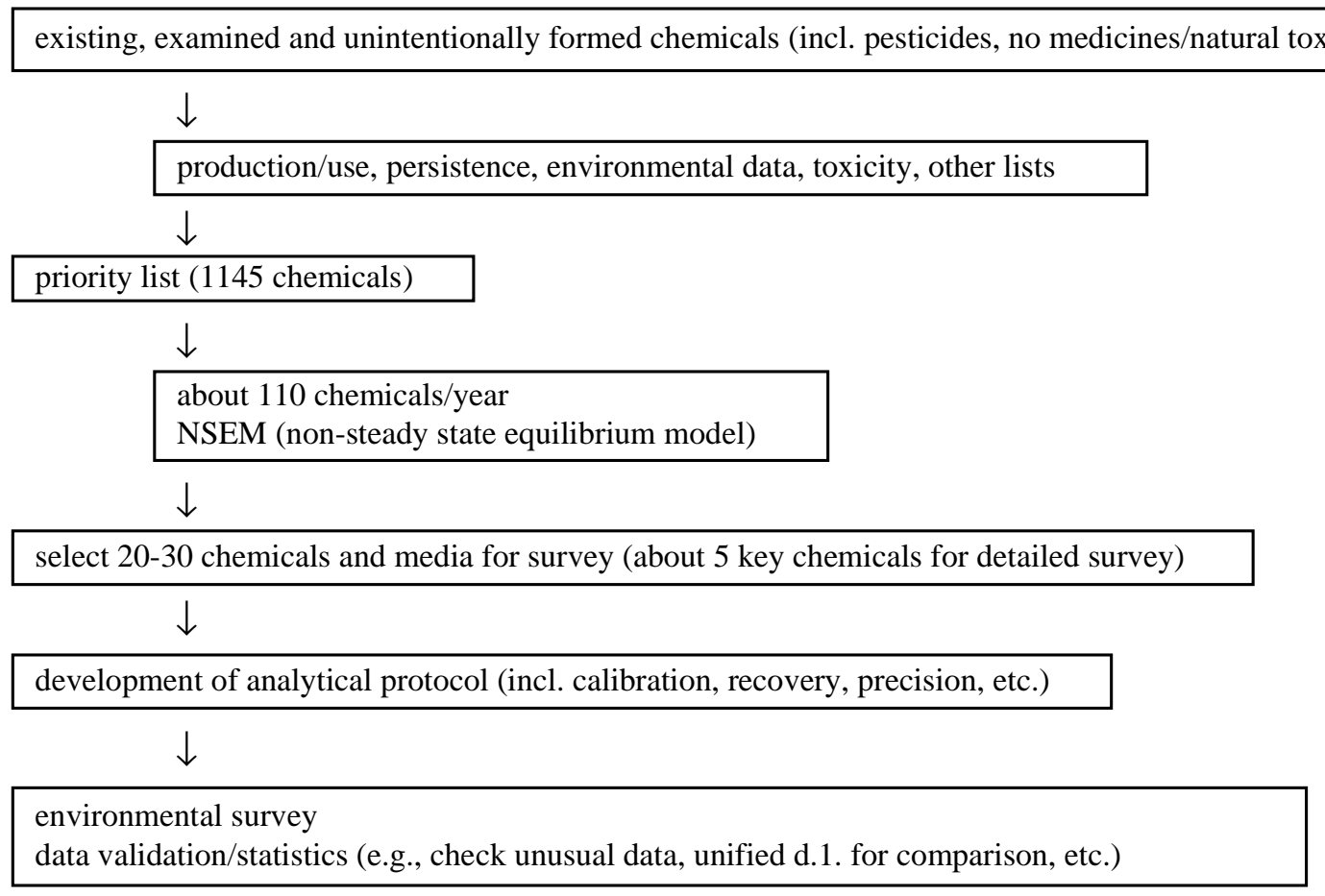

Figure 1. Outline of environmental survey on existing and examined chemicals

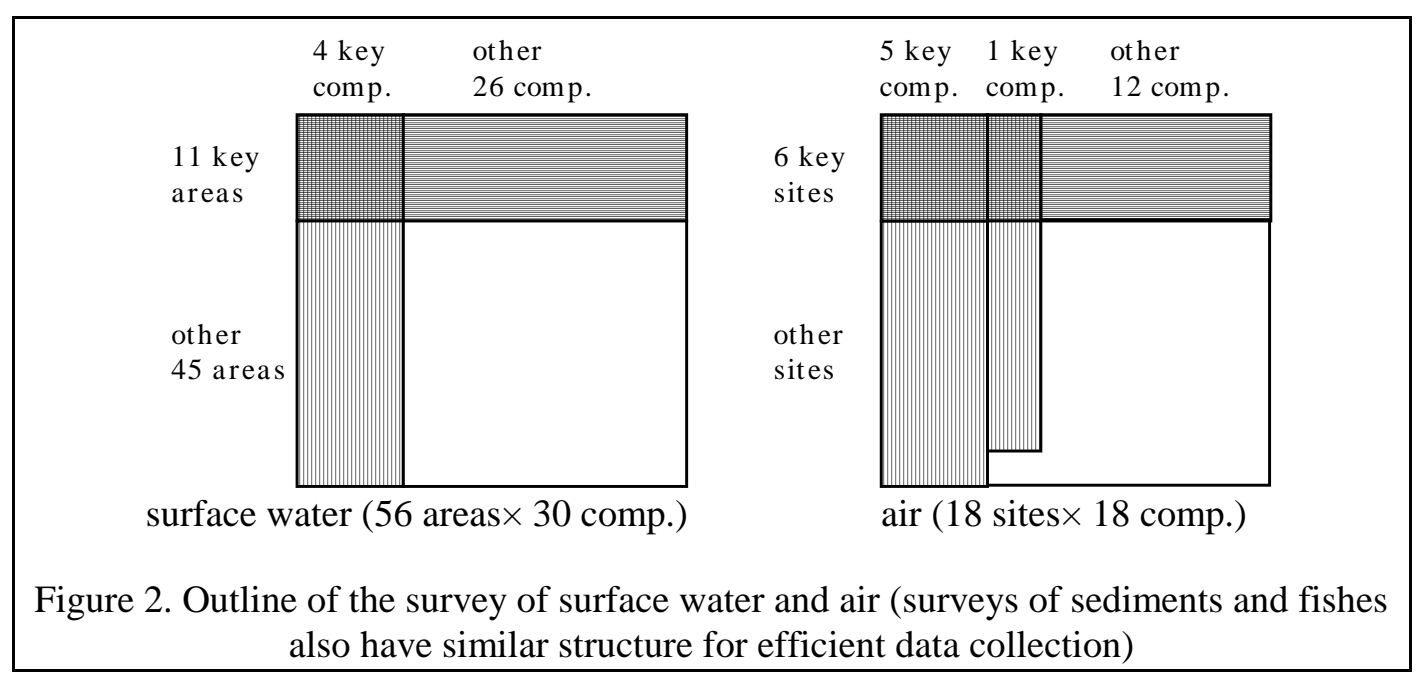




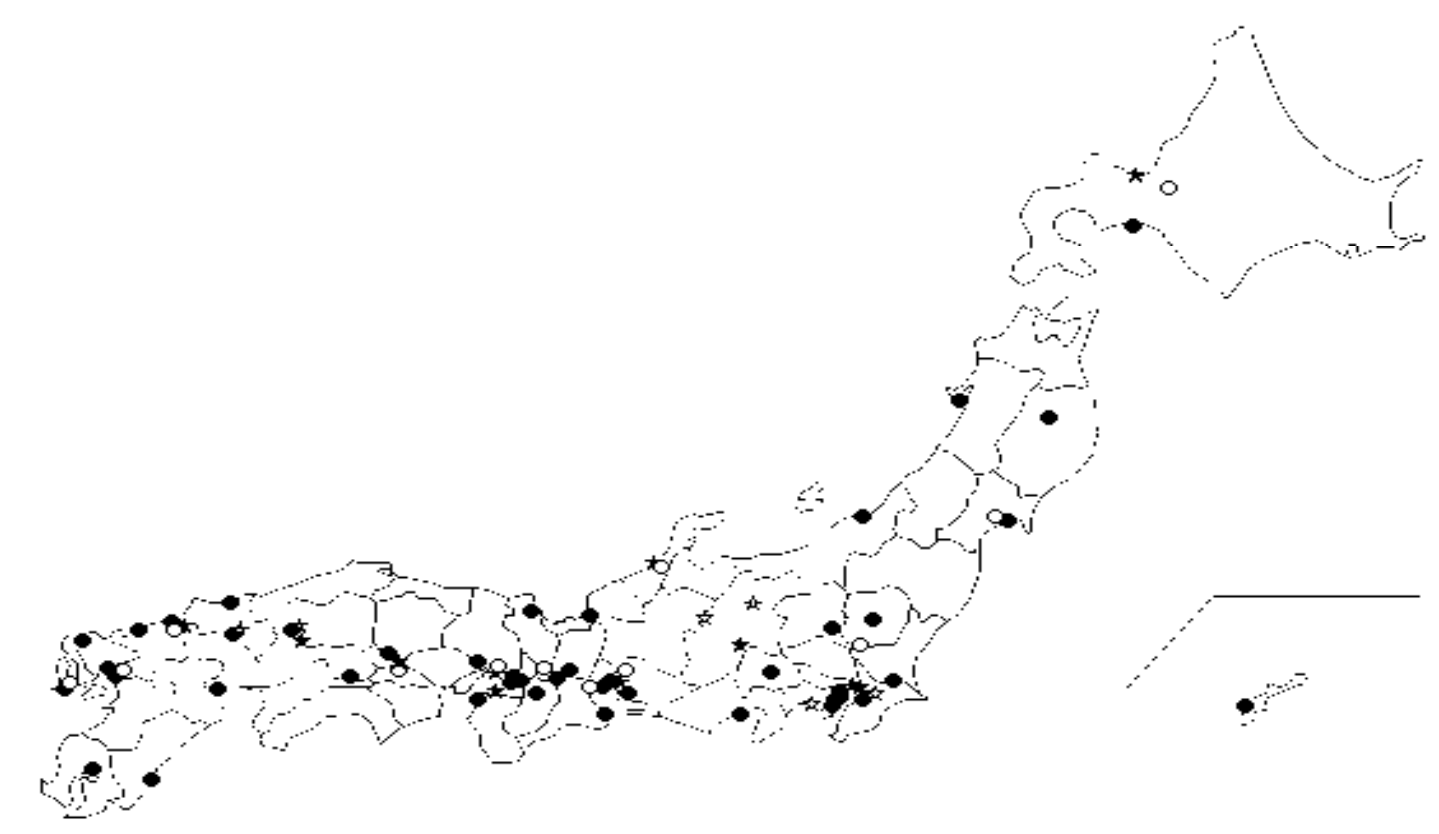

Figure 3. Sampling areas/sites for environmental survey

$\vec{v}, \bullet$ sampling areas for water, sediments and fishes consist of 11 key ( $\vec{t}), 14$ industrial, 16 residential/commercial, 1 agricultural and 14 mixed areas

is, O sampling sites for air include 6 key areas ( 3 )

Table 1 shows the numbers of detected and investigated chemicals in the survey from 1974 to 1995 . Media of interest are different by chemicals, so that the numbers are different by media. As overall, 287 chemicals have been detected from environment, where 752 chemicals have been investigated. The results have triggered various actions, such as detailed studies, classification and regulation under CSCL, regulations by responsible authorities under other laws, etc.

Table 1. Numbers of detected/investigated chemicals in environmental survey (1974 1995)

\begin{tabular}{llll}
\hline & detected(A) & Investigated(B) & $\mathrm{A} / \mathrm{B}(\%)$ \\
\hline water & 135 & 731 & 18.5 \\
sediment & 219 & 710 & 30.8 \\
fish & 87 & 226 & 38.5 \\
air & 104 & 174 & 59.8 \\
\hline total & 287 & 752 & 38.2 \\
\hline
\end{tabular}

\section{Monitoring of HAPs}

Recent years, chronic effects, especially carcinogenicity, of environmental chemicals have become public concern, which is encouraging government to establish new management systems for chemicals based on exposure/risk assessment. One of the systematic approaches, first one, is HAPs monitoring/management system under amended APCL enforced in 1997. The system has been designed following tiered structure of risk assessment/management shown in Figure 4. Based on screening level 
investigation, 234 HAPs which include various organics, inorganics, minerals, etc. were listed up. From the listed HAPs, 22 priority HAPs were selected based on semi-quantitative exposure/risk assessment by existing information such as temporal monitoring data (see Table 2). Four of 22, by which pollutions have been judged to cause unacceptable level risk, were designated to specified HAPs. Management of HAPs are mainly carried out by voluntary emission reductions by industries and regulations on specified HAPs based on environmental and emission standards.

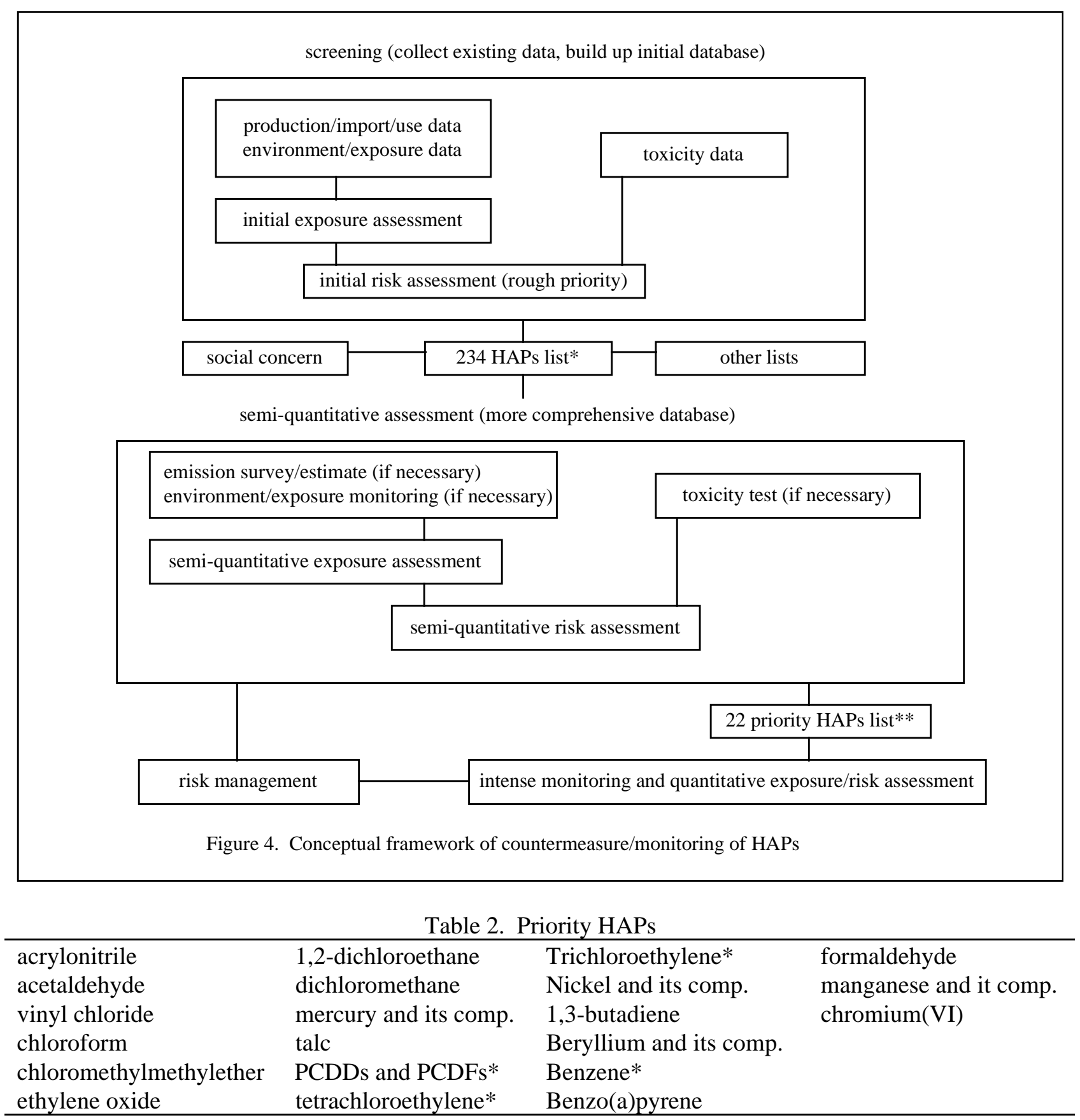

\footnotetext{
*: specified HAPs
} 
Monitoring of HAPs introduced under the amended APCL has two features corresponding to the tiered approach mentioned above. Main monitoring is intense one of 22 priority HAPs for quantitative exposure/risk assessment. Local authorities, all 47 prefectures and 78 big cities, are responsible to conduct this monitoring, and it is carried out at about 10 sites in each prefecture, i.e., nearby source sites, general environment sites and road side sites where people are actually living. One 24 hour data every month is to be taken to estimate yearly average. Overall, at about 400 sites $\times 12$ data/sites are collected every year. Monitoring methods are required to satisfy performance specifications, i.e., target determination limit corresponding to $10^{-6}$ risk level and $\pm 30 \%$ overall accuracy (recommended methods provided in manuals are normally used with analytical quality control). The results will be used to quantitative exposure/risk assessment, and effectiveness of voluntary emission reductions and legal regulations on 4 specified HAPs will be evaluated. The results also will be used to judge necessity of regulation on non-specified priority HAPs.

Monitoring of 234 listed HAPs are to be carried out by national government. On the process of listing and selection of priority HAPs, lack of environmental data caused big difficulty on quantitative evaluation of exposure/risk. National government selected about 10 sites to cover various types of environment such as huge city, remote area, etc. In 1997, 24 hour samples were corrected in summer and winter, and about 30 volatile organic compounds and 5 polycyclic aromatic hydrocarbons were analyzed by GC/MS and HPLC, respectively. The results of the monitoring will be used for semi-quantitative exposure/risk assessment of listed HAPs to judge necessity of further management. However, it is required to measure as many HAPs as possible, so that development of monitoring methods is required and studied.

\section{Other activities relating to chemical monitoring/management}

In the field of water pollution, similar approach to HAPs monitoring/management is now under discussion. Some chemicals, mainly pesticides, are already included in intense monitoring of water. About 300 hazardous water pollutants will be newly listed up, and screening level monitoring of these pollutants will be initiated in near future.

Relating to the improvements in chemical monitoring/management, which reflect public awareness on environmental pollution by chemicals, introduction of more systematic approach is also under consideration. One is construction of a database which includes basic information of chemicals such as physico-chemical properties, toxicities, environmental concentrations, regulatory information, etc. The database is expected to become both an output media of collected data and a start point of exposure/risk assessment and management.

Environmental models have not been used frequently in evaluation of chemical pollution. General Inspection Survey had started in 1974, and it has been working fine as is designed to be. HAPs monitoring is strongly connected to regulations, so that actual monitoring has to play an important role. However, good models for simulation have been developed recent years, and it is obvious that both monitorings and models may provide better understandings on environmental exposure with minimum costs/requirements. Actually, General Inspection Survey includes model prediction for selection of chemicals and environmental media. When the model was introduced, validation was carried out by using existing results of the survey addition to conventional parameter setting.

Further utilization of models is planned in a research. As shown in Figure 5, the system consists of good emission information provided by PRTR, various models, GIS with geographical/meteorological information, chemical database including toxicity information, population statistics, etc. is under construction. This system is expected to be used for 1) prediction of environmental pollutions by various chemicals, 2) exposure/risk evaluation and communication, 3) simulation of managements. Monitoring 
data will also be handled by the system for better and easy to understand evaluation as well as for comparison of model prediction and observed data.

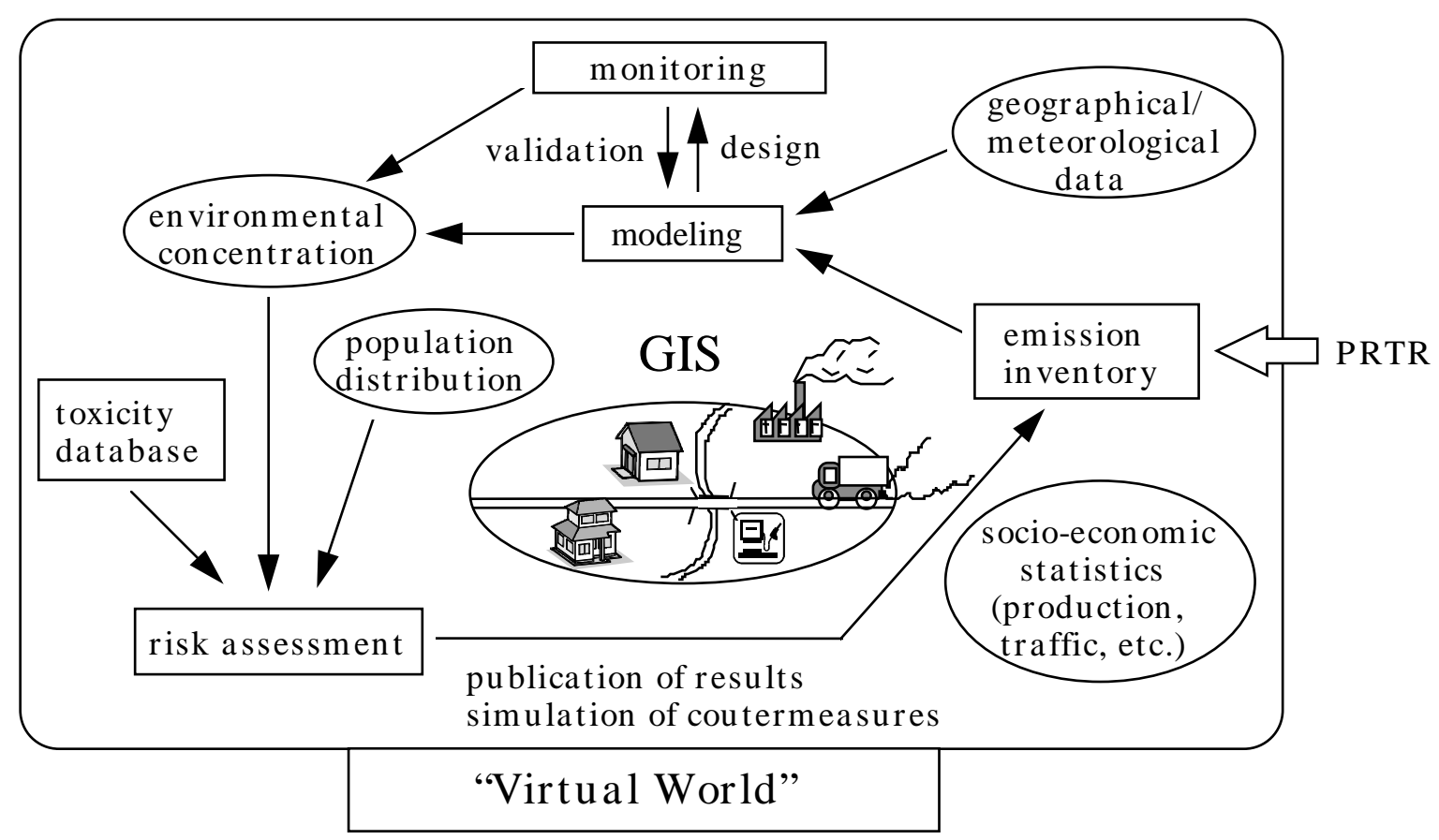

Figure 5. Conceptual framework of "Virtual World" system 


\title{
Monitoring Contaminants in the Hydrological Environment - A Multi Tiered Approach
}

\author{
By Larry B. Barber, United States Geological Survey, Boulder, Colorado
}

\section{Introduction}

Monitoring contaminants in the hydrologic environment is a broad concept with respect to both the type of environment to be considered (river, lake, aquifer) and the definition of contaminants (organic, inorganic, agricultural, industrial). The issue of scale (local, regional, global) also is of importance when conceptualizing a monitoring program. The United States Geological Survey (USGS) is the Federal agency charged with the mission of scientific evaluation of the natural resources of the United States (US). The USGS consists of four divisions, Geologic, Mapping, Biological Resources, and Water Resources, with offices distributed throughout the US that evaluate earth-science issues at the local, state, regional, and national scales. This paper describes several monitoring programs conducted by the USGS Water Resources Division to evaluate water quality related to the input of industrial, municipal, and agricultural chemicals. A conceptual approach for designing and implementing monitoring programs is presented.

\section{Basic Concepts}

A fundamental concept to consider when designing water-quality monitoring programs is defining the hydrological system. The system can be defined by addressing questions such as:

- $\quad$ is the system of interest surface or ground water

- $\quad$ where does the water come from and where does it go

- what are the rates and directions of flow and how do they change over time

- $\quad$ what is the quality of the native water

- what are the end uses of the water

Once the hydrological systems is defined, the potential effect of contaminants can be evaluated. Contaminants include a wide range of organic and inorganic chemicals introduced into the environment as the result of human activities such as agricultural practices, industrial discharges, urban runoff, and domestic and commercial chemical consumption. Factors related to contamination that must be considered include:

- land-use practices and population densities

- $\quad$ chemical use and disposal (sources)

- $\quad$ stream dilution factors

- $\quad$ environmental removal processes (sinks)

- $\quad$ formation of transformation byproducts

- bioavailability

- $\quad$ human effects

- $\quad$ ecosystem effects

Selection of the contaminants of interest also involves a number of considerations related to potential sources and adverse effects. Because of the vast numbers of chemicals in use, selection of specific compounds for monitoring is a difficult task. Successful monitoring programs use a hierarchy of 
analytical methodologies to identify not only target compounds but also to provide relevant information on a broad range of chemical characteristics of the water. This broad-spectrum chemical information can aid in identifying chemicals that may be of concern but are not on specific target lists. Monitoring programs are dependent on the analytical methodologies used and associated considerations such as:

- $\quad$ broad spectrum or highly specific analytical methods

- $\quad$ suitability of methods for different water matrices

- method detection limits relative to ambient environmental concentrations

- $\quad$ significance of individual compounds relative to total contaminant load

- $\quad$ ability to determine "difficult-to-measure" compounds

Finally, in order to evaluate the effects of contaminants on the hydrological environment it is necessary to define the geochemical framework. The geochemistry of natural waters is controlled by a complex continuum of physical, chemical, and biological processes. Superimposed on the natural hydrogeochemical system is the geochemistry of the contaminants of concern. Factors to consider include:

- $\quad$ inorganic solution chemistry of major ions, trace metals, and nutrients

- natural dissolved organic matter dynamics

- $\quad$ oxidation/reduction potential of the system

- biological communities

\section{Specific Monitoring Programs}

The following is a discussion of four USGS monitoring programs, which cover scales ranging from tens of $\mathrm{km}^{2}$ to more than one million $\mathrm{km}^{2}$.

\section{Toxic Substances Hydrology Program - Cape Cod Site}

The USGS Toxics Substances Hydrology Program was established to provide long-term detailed investigations of the fate of contaminants in the hydrological environment. One of the study sites for this program is located on Cape Cod, Massachusetts, where an aquifer has been contaminated by rapid infiltration disposal of secondary-treated sewage effluent. This site has been extensively studied for 15 years by a multidisciplinary team that includes hydrologists, organic and inorganic geochemists, and microbiologists (Morganwalp and Aronson, 1996). A variety of chemical constituents have been evaluated including volatile chlorinated solvents such as tetrachloroethene, detergent-derived chemicals such as linear alkylbenzenesulfonates (LAS) and alkylphenolpolyethoxylates (APEO), nutrients such as nitrogen and phosphorus species, and trace metals such as iron, manganese, lead, and zinc. Research at the site involves:

- $\quad$ large scale synoptic sampling of the $10 \mathrm{~km}$ long, $2 \mathrm{~km}$ wide, $1 \mathrm{~km}$ thick plume at 2 to 5 year intervals

- $\quad$ high resolution vertical sampling (0.1 m intervals) to define specific geochemical zones and their controlling processes

- $\quad$ small and large scale in situ tracer experiments to establish the nature and rates of transport and transformation processes under ambient environmental conditions 
Results from LAS tracer experiments (Krueger and others, 1998) show that:

- the longer-chain homologs and external isomers are selectively retarded during transport

- biodegradation in the sewage-contaminated aquifer is oxygen limited

- the longer-chain homologs and external isomers are selectively removed by biodegradation

- metabolites persist in the aquifer under low oxygen conditions

\section{Mississippi River Study}

The Mississippi River is the largest river in North America and drains about $41 \%$ of the conterminous United States. The basin consists of several major subbasins including the Ohio, Missouri, and Illinois Rivers and covers a broad range of land uses. Between 1987 and 1994 the USGS conducted an investigation of contaminants along the entire Mississippi River (Meade, 1995). This scale of investigation $(1800 \mathrm{~km}$ reach) required different methodologies than the localized and small-scale studies conducted at the Cape Cod site, although many of the concepts and analytical methods developed there were transferable to the larger scale Mississippi River study. For example, many of the trace-organic chemicals in the sewage effluent discharged into the aquifer are common in sewage effluents across the US as well as many other countries. For example, chemicals such as LAS, APEO, and ethylenediaminetetraacetic acid (EDTA), which have been extensively studied at the Cape Cod site, also are significant contaminants in the Mississippi River. However, different processes control the fate of these chemicals in the different hydrologic environments. These chemicals also illustrate another point, that being the usefulness of evaluating chemicals that are not regulated and therefore are not included in typical monitoring programs. In many instances the unregulated compounds are present at much higher concentrations than regulated contaminants such as polychlorinated biphenyls. Identifying compounds that are present at significant concentrations in natural waters is an important contribution that monitoring studies can provide to risk assessment studies. Some general conclusions from the Mississippi River study include:

- a wide range of organic and inorganic chemicals originating from agricultural, industrial, and urban practices are present throughout the Mississippi River system

- although non-point sources of contamination influence the water quality of the river, many chemicals can be traced to specific source reaches or land uses

- $\quad$ stream dilution factors control concentrations of contaminants in the river

- $\quad$ significant amounts of contaminants are in storage in the bed sediments

- a portion of organic contaminants are transported in the colloidal phase

\section{National Water Quality Assessment Program}

Assessing water-quality issues at the national scale involves a different conceptual approach than that utilized at the local scale and large river-basin scale studies. Because of the geographic and hydrologic diversity of the US, the USGS established the National Water Quality Assessment (NAWQA) program to provide a nationally consistent set of water-quality data (Hirsch and others, 1988). This program utilizes an approach based on the hydrological study unit for investigation with national-scale synthesis of the data. More than 50 study units scattered across the US have been selected for investigation, representing over one-half of the water use and covering all land-use types and hydrologic regimes. A variety of contaminants are being evaluated as part of the study unit investigations including pesticides, nutrients, and volatile organic compounds (VOC), all of which have undergone national synthesis of the data. The results from the VOC national synthesis are an example of the types of information gathered under the NAWQA program. As part of this effort, waters from across the US were analyzed for a suite of $60 \mathrm{VOC}$ compounds. The results show the relationship between large-scale changes 
in chemical use and ground water quality. In 1990 the US Environmental Protection Agency began requiring the use of fuel oxygenates to address air quality issues in a number of urban areas in the US. One of the most common oxygenates is methyl-t-butyl ether (MTBE), which has a chemical structure that imparts volatility, resistance to biological degradation, and high water solubility. The rapid introduction of MTBE into the atmosphere on a large geographic scale has resulted in a significant effect on ground-water resources in urban areas like Denver, Colorado, where about $80 \%$ of the shallow wells sampled had detectable MTBE concentrations (however, values were typically well below draft health advisory levels).

\section{National Stream Quality Accounting Network}

Since 1995 the National Stream Accounting Network (NASQAN) of the USGS has focused on monitoring the water quality of four of the largest rivers in the US -- the Mississippi, the Columbia, the Colorado, and the Rio Grande (Hooper and others, 1997). The basin size ranges from 600,000 to $3,000,000 \mathrm{~km}^{2}$, with sub-basin sizes ranging from 60,000 to $180,000 \mathrm{~km}^{2}$. The NASQAN program operates a network of 39 stations where concentrations of a range of chemicals including pesticides and trace elements are measured in conjunction with measurements of discharge. By sampling these stations under a variety of hydrologic regimes, the mass flux characteristics of contaminants within the basin can be determined. These data provide information on sources, transport, and delivery of chemicals derived from human activities that can be used to address a number of regional and national issues by:

- comparing yields of non-point source contaminants among large regional basins

- describing long-term trends in mass fluxes and concentrations of contaminants at key locations

- $\quad$ calculating contaminant loads to receiving waters

- $\quad$ establishing frameworks for more detailed assessments

- $\quad$ testing regional models relating land use to water quality

\section{Conclusions}

Water-quality monitoring studies benefit from a multidisciplinary approach that uses scientific expertise from a variety of disciplines such as hydrology, geochemistry, and microbiology. The issue of scale is an important factor for consideration, and many studies need information on a variety of scales. Considerable effort is required to generate consistent sets of data over large geographical areas while still maintaining the flexibility to explore nontraditional chemicals using innovative methods. Evaluation of critical water-quality issues related to chemical discharges requires knowledge of the hydrology of the system of interest as well as a broad understanding of the organic and inorganic geochemistry of the system. Because of the complexity of natural waters affected by contamination, it is necessary to develop highly specific and sensitive methods for target compounds. However, cost will limit the number of compounds that can be determined. Therefore, it also is important to perform a broad spectrum of analyses in order to evaluate potential contaminants that are not on target compound lists.

\section{References}

Hirsch, R.M., Alley, W.M., and Wilber, W.G., 1988, Concepts for a national water-quality assessment program: U.S. Geological Survey Circular 1021, 42 p.

Hooper, R.P, Goolsby, D.A., Rickert, D.A., and McKenzie, S.W., 1997, NASQAN - A program to monitor the water quality of the Nation's large rivers: U.S. Geological Survey Fact Sheet FS-055-97, 6 p. 
Krueger, C.J., Barber, L.B., Metge, D.W., and Field, J.A., 1998, Fate and transport of linear alkylbenzenesulfonate in a sewage contaminated aquifer - A comparison of natural-gradient pulsed tracer tests: Environmental Science and Technology, v. 32, p. 1134-1142.

Meade, R.H., 1995, Contaminants in the Mississippi River, 1987-92: U.S. Geological Survey, Circular $1133,140 \mathrm{p}$.

Morganwalp, D.W. and Aronson, D.A., 1996, U.S. Geological Survey Toxic Substances Hydrology Program - Proceedings of the Technical Meeting, Colorado Springs, Colorado, September 20-24, 1993, Volume 1: U.S. Geological Survey Water-Resources Investigations Report 94-4015, 621 p. (A complete listing of publications on the Cape Cod site can be found at:

http://toxics.usgs.gov/toxics/bib/bib-cape-cod.shtml

Squillace, P.J., Pope, D.A., and Price, C.V., 1995, Occurrence of the gasoline additive MTBE in shallow ground water in urban and agricultural areas: U.S. Geological Survey Fact Sheet FS-114-95, 4 p.

For more information on USGS Water Resources Division activities can be found at: http://h2o.usgs.gov 


\section{The European Environment Agency (EEA) and the monitoring of chemicals in Europe}

Bo Jansson, Stockholm University, EEA Scientific Committee

The EEA is a young institution and the headquarters in Copenhagen was set up during 1995. The aim of the Agency is to provide objective, reliable and comparable information for those concerned with framing and implementing European and national environmental policy, and for the public.

The work of the EEA is based on the activity of the European Environment Information and Observation Network (EIONET). The EIONET includes 9 European Topic Centres (ETCs), 18 National Focal Points (NFP), and a large number of Main Component Elements (some of which are National Reference Centres). The Agency further-more purchases expertise for projects from all over Europe, whenever necessary.

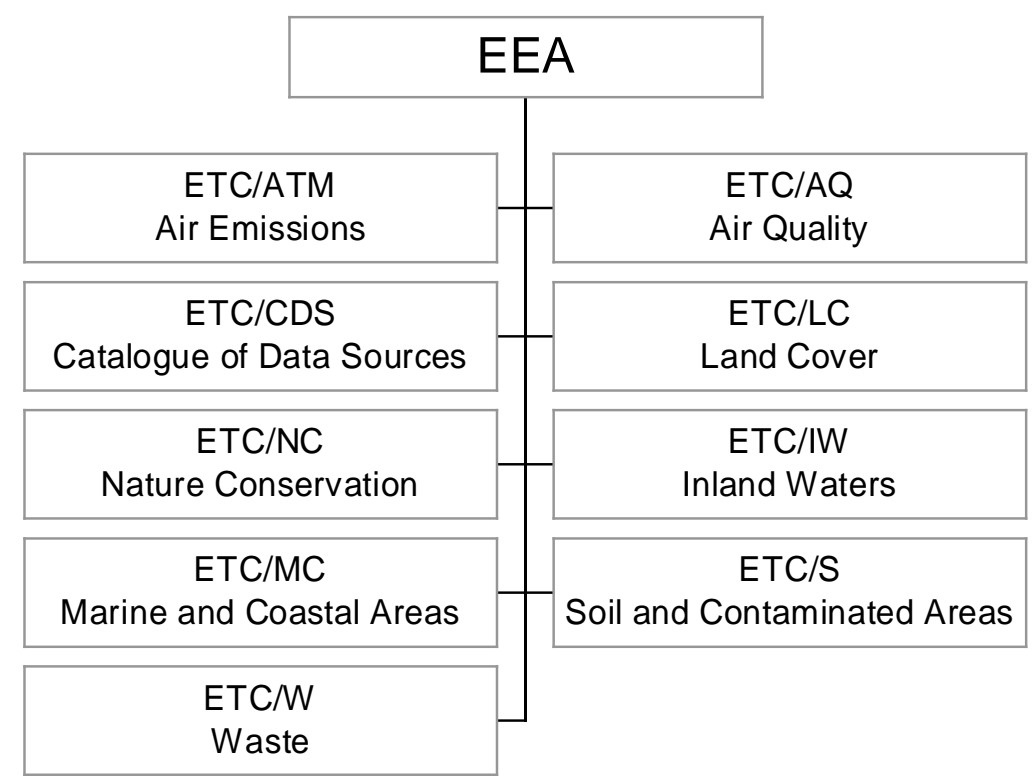

Figure 1. The EEA and its European Topic Centres (ETCs)

The gathering of monitoring data is mainly done by the ETCs (Figure 1 shows the presently operating ETCs). The origin of the data are mainly national monitoring programmes and international agreements, such as the conventions for the seas (HELCOM, MAP and OSPARCOM). The aim is to make the data available in data bases and the ETCs for air quality (ETC/AQ) and air emissions (ETC/ATM) have already working systems as these were planned before the EEA was born. Figure 2 shows the present status of the different data bases. 


\begin{tabular}{|l|c|l|l|}
\hline Topic & ETC & Database & Status \\
\hline Air quality & AQ & AIRBASE & Under development, some data available \\
\hline Water quality & IW & WATERBASE & $\begin{array}{l}\text { Under development, initially inland waters, } \\
\text { eventually marine }\end{array}$ \\
\hline State of soil & $\mathrm{S}$ & SOILBASE & Proposal to be finalised \\
\hline Atmospheric emissions & $\mathrm{AE}$ & CORINAIR & Available, being updated \\
\hline Chemical substances & $\mathrm{AE}$ & CORINAIR & Available for some heavy metals and POPs \\
\hline Waste & $\mathrm{W}$ & WASTEBASE & Under development \\
\hline
\end{tabular}

Figure 2. State of development of some EEA databases.

The ongoing monitoring programmes are mainly focussed on well known environmental pollutants. The levels of these are followed over long time to detect trends in order to see that the measures already taken gives the desired results. This has to be continued until it is clear that the risks have been reduced to acceptable levels.

In the coming years risk assessments have to be performed for a number of chemicals not included in the present monitoring programmes. Data that happens to be available from the open literature and other reports then have to constitute the bases for the exposure assessment. Experiences from this type of work are that there are in most cases a couple of critical exposure data missing. There is a need to find a way to support the risk assessors with this information.

The number of chemicals awaiting risk assessments is large and even if the exposure information needed for each of them is limited it will take some resources to produce these data. However, the widespread use and disposal of most chemicals makes the situations in different countries very alike. This means that the exposure data do not have to be produced for each country and this calls for an international co-operation. The data needed will vary from one chemical to another and the most critical data points have to be identified. This is probably best done by an expert panel and/or by modelling.

The EEA could be a co-ordinator of at least European efforts in this field. The extensive network (covering not only the EU as most European states are included today) should be very useful in the coordination of such a project. If the involved states took responsibility for one compound each annually that would cover a considerable fraction of the chemicals to be scrutinised. 


\title{
Development of a Geography referenced Regional Exposure Assessment Tool for European Rivers - GREAT-ER
}

\author{
Martin Holt and Tom Feijtel
}

\begin{abstract}
Summary
The objective of the GREAT-ER project is to develop and validate a powerful and accurate chemical exposure prediction tool for use within the EU environmental risk assessment schemes. Current techniques to estimate regional predicted environmental concentrations (PECs) use a generic multimedia 'unit world' approach and do not account for spatial or temporal variability in landscape characteristics, river flows and/or chemical emissions. The results are therefore merely applicable at a generic screening level because these models do not offer a realistic prediction of the actual steady-state background concentrations. Furthermore, the default EU generic regional environment assumes only $70 \%$ of the wastewater mass loading is treated in a sewage treated plant, leaving the other $30 \%$ to be released into the receiving environment untreated.
\end{abstract}

A new database, model and software system is being developed to calculate the distribution of PECs, both in space and time, of down the drain chemicals in European surface waters on a river and catchment area level. The system will use Geographical Information Systems (GIS) for data storage and visualisation, combined with simple mathematical models for prediction of chemical fate. Hydrological databases and models will be used to determine flow and dilution data.

A monitoring programme is being undertaken in both the Yorkshire region of the U.K and in the Lambro catchment in Italy to validate GREAT-ER. Linear alkylbenzene sulphonate (LAS) which undergoes both adsorption and biodegradation in rivers and boron, a conservative compound, have been chosen for model validation. Data on dissolved oxygen, biochemical oxygen demand and ammonia will be used to assess water quality and to provide data for calibration.

The refined exposure assessment tool should greatly enhance the accuracy of current local and regional exposure estimation methods, ultimately on a pan-European scale. This work is being carried out on behalf of ECETOC, and sponsored by the Environmental Risk Assessment Steering Committee (ERASM) of the Association Internationale de la Savonnerie, de la Détergence et des Produits d'Entretien (AISE) and the Comité Européen de Agents de Surface et Intermédiaires Organiques (CESIO) in co-operation with the UK Environment Agency.

\section{Introduction}

The assessment of whether a substance presents a risk to organisms in the environment is based on a comparison of the predicted environmental concentration (PEC) with the predicted no effect concentration (PNEC) to organisms in ecosystems. This assessment can be performed for different compartments (e.g. air, water and soil) and on different spatial scales (local, regional). This is further captured in a number of EU Commission documents (Technical Guidance Documents supporting the Commission Directive on Risk Assessment of New Chemicals (93/67/EEC) and Commission Regulation on Risk Assessment of Existing Substances (1488/94/EEC) in support of Existing Substances Regulation (793/93/EEC)) and computerized calculation model EUSES (European Uniform System for Evaluating Existing Substances, $[1,2,3])$. 
In the environmental exposure assessment, it is essential to define the primary target compartment of the exposure assessment - i.e. what is being exposed and how long (point-source versus diffuse and intermittent versus continuous) ? The exposure estimate may describe the exposure of the aquatic compartment close to the source of emission (e.g. wastewater effluent) and assess maximum exposure (i.e. "local" realistic worst-case estimates).

Alternatively, the exposure assessment may be developed taking into consideration the fate, transport and distribution of the chemical into different media (air, water, soil and biota) away from the source of emission (i.e. "regional" background estimates). In order to decrease the complexity inherent to "real" spatial/temporal environments, the use of "generic" or "evaluative" steady state environments with standard properties have been suggested and developed for chemical assessments. Mathematical distribution and fate models of the "Mackay level III" type are used for this purpose in the screening phases of the assessment (e.g. USES - RIVM VROM [4] \& WVC, 1994; HAZCHEM - ECETOC [5], 1994b; EUSES, DG-ECB, 1997 [3]).

Realism can only be further introduced by taking into account environmental specifications of the receiving environment, and by verifying each underlying assumption used in these exposure models as illustrated in Figure 1.

Figure 1: Refinement of Generic Regional Exposure Models by using actual discharge pathway, treatment and river flow data into account

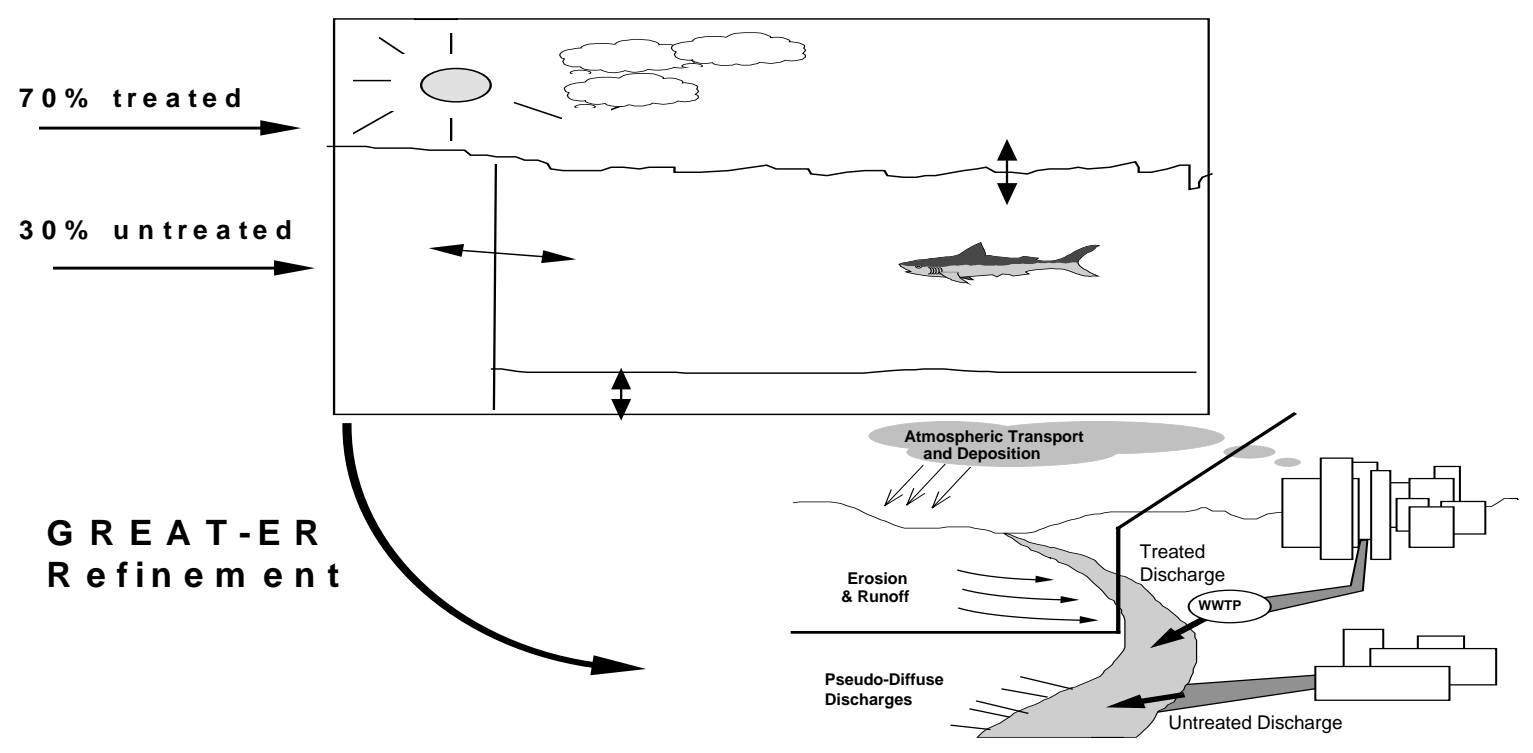

These PECs should be preferentially used in realistic environmental risk assessments in support of EU risk assessment legislation.

\section{Modular Approach}

The project will be approached in a modular way as described in detail in Feijtel et al. 1997 [6]. 


\subsection{GIS Data Manipulation}

In the data manipulation module, input data sourced from several data bases and from the hydrology module will be transformed into appropriate GIS formats. Geographical segmentation will also be performed in this module.

\subsection{Hydrology}

The hydrology module will combine several hydrological databases with a hydrological model. It will provide the GREAT-ER system with the required flow distributions and river characteristics.

\subsection{Waste Pathway and River Modelling}

This module is used for the prediction of chemical emission, of chemical transformation during conveyance and treatment, and of chemical fate in rivers.

\subsection{End-User Desktop GIS}

In this module, access to and visualization of the data banks and model results is achieved, as well as the linking of the models with the data banks.

The hydrological models and the ARC/INFO spatial data processing steps will not be integrated into the end-user software system. Data transfer between the GIS data banks and the models will be allowed only via a pre-defined format, which depends neither on the implemented model formulations, nor on the used GIS software. All data transfers will be arranged by a GIS / Model Interchange Server. This server program will have the GIS and the models as clients. It will use Model Object Descriptions (MOD) to determine which parameters and variables have to be written or read, and in which sequence.

A menu-oriented user interface will be developed as an 'easy-to-use' front-end between the user and the software system. It will allow the selection of catchments as well as the input of model and scenario parameters. 
Figure 2: Integration of the GREAT-ER Methodology

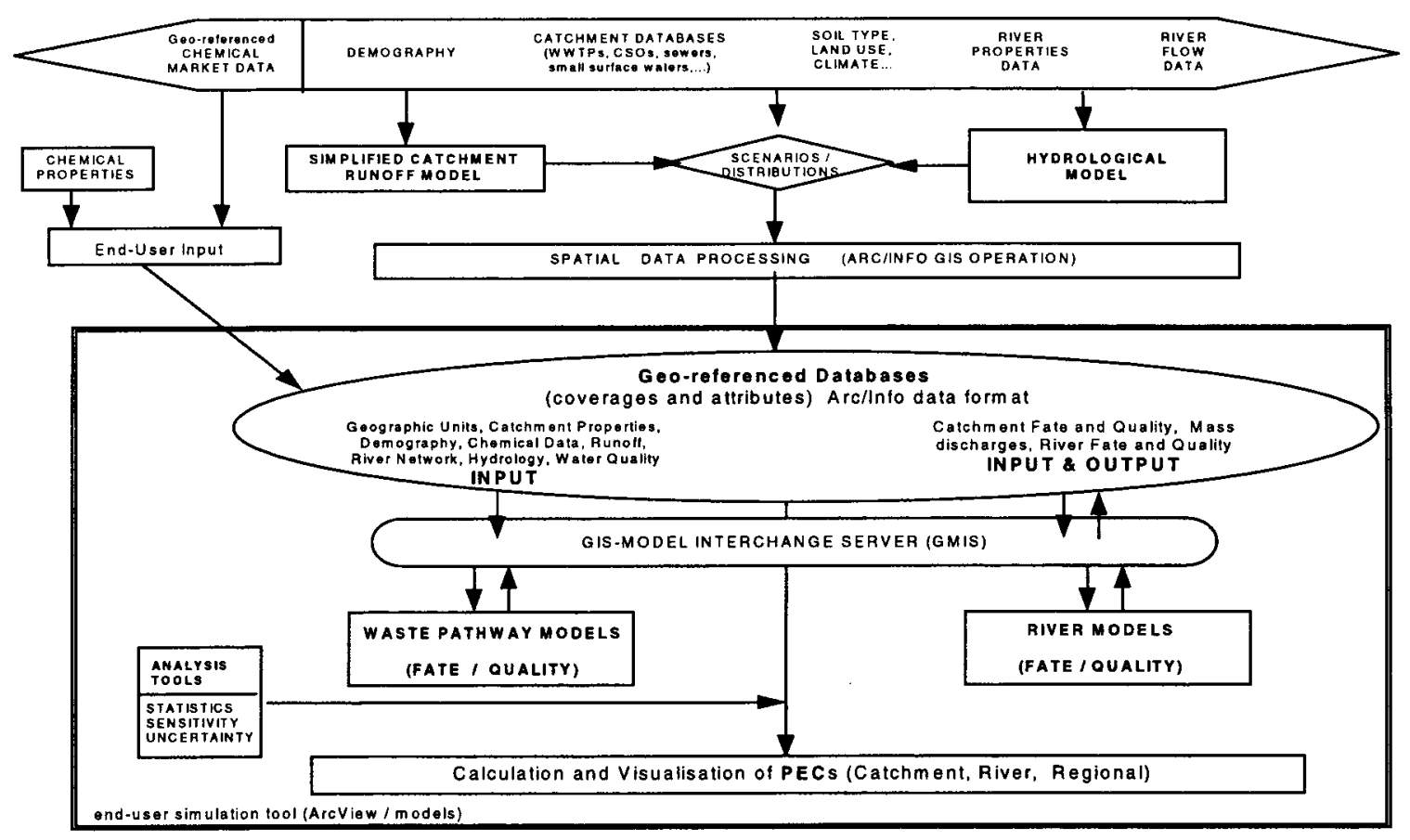

\section{Monitoring}

A series of monitoring programmes were set up to address the exposure requirements of the wastewater, river and fate models necessary to support the prediction of environmental concentrations of specific consumer chemicals with reference to their spatial location and seasonality.

The specific aims of the monitoring were:

- to establish a routine programme for river waters and sewage effluents, which would be statistically robust, in a number of catchments in the UK and Italy. These data will also be used to verify climatic and geographical transferability;

- to measure typical removal of LAS in trickling filter type sewage treatment works;

- to measure 'in stream' removal;

- to validate consumer usage.

Sampling sites were chosen based specifically on the study objectives but in all cases met the following criteria;

- pilot studies were carried out to adequately characterise the sites, confirm their 'representativeness' and establish the analytical feasibility;

- good historical databases existed;

- availability of 'on line' flow measurements at the sewage treatment plants; 
Sample collection criteria included:

- validated sample collection and preservation techniques;

- use of standard additions in the field.

Four catchments in the UK and one in Italy were chosen following discussions with the regulatory authorities and other interested parties and are being analysed for LAS, boron, $\mathrm{BOD}_{5}$ ammonia, nitrate, nitrite and suspended solids.

\subsection{UK monitoring}

\subsubsection{Catchment monitoring}

The four catchments monitored are the Aire, Calder, Don (all highly industrialised) and Went (predominantly rural). The river water and effluents sampling programme in the UK started in August 1996 and will continue for up to 24 months. River water samples are being collected monthly and sewage treatment effluents twice monthly at the regular Environment Agency monitoring sites. All samples ( total will be > 2500) are grab samples 
Figure 3 illustrates the extent of the sampling regime in the Calder catchment and the results to date are summarised in Table 1.

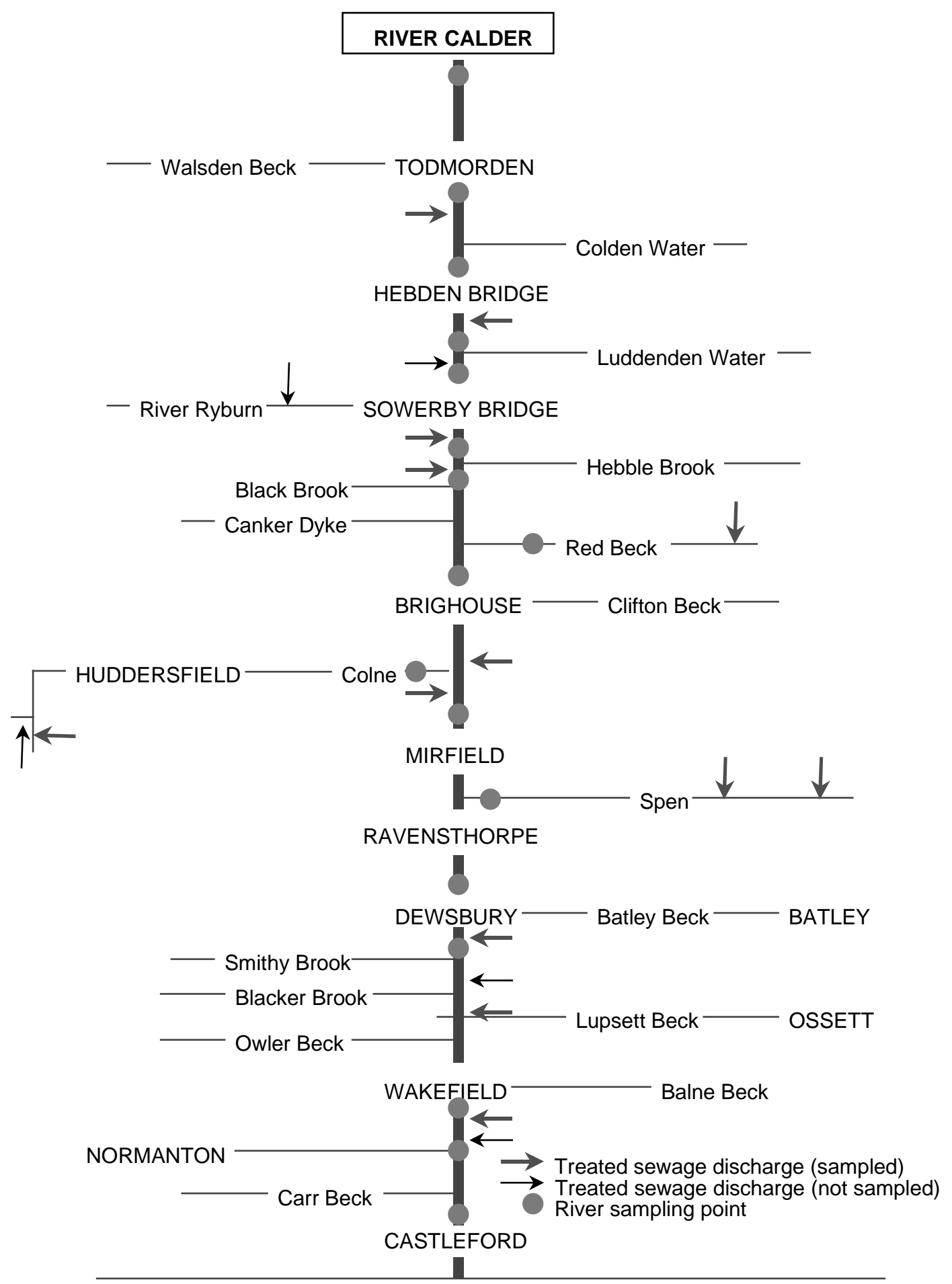


Table 1 River Calder Catchment Summary Data

\begin{tabular}{|c|c|c|c|c|c|}
\hline & Type of Plant & $\begin{array}{c}\text { Percentage } \\
\text { LAS } \\
\text { Removal }\end{array}$ & $\begin{array}{l}\mathrm{LAS} \\
(\mu \mathrm{g} / \mathrm{l})\end{array}$ & Boron $(\mathrm{mg} / \mathrm{l})$ & $\begin{array}{l}\text { Number } \\
\text { of } \\
\text { samples }\end{array}$ \\
\hline Site & Type of plant & Mean & Mean & Mean & \\
\hline Portsmouth & & & 2.5 & 28.0 & 17 \\
\hline $\begin{array}{l}\text { Eastwood Final } \\
\text { Effluent }\end{array}$ & $\begin{array}{l}\text { Trickling Filter } \\
(\mathrm{TF})\end{array}$ & 93.8 & 192 & 235 & 23 \\
\hline Heptonstall & & & 34.0 & 66.7 & 16 \\
\hline Hebden Bridge & & & 21.9 & 36.9 & 17 \\
\hline Redacre Final Effluent & Trickling Filter & 990.5 & 446 & 299 & 16 \\
\hline Brearley Weir & & & 28.9 & 42.5 & 17 \\
\hline $\begin{array}{l}\text { High Royd Final } \\
\text { Effluent }\end{array}$ & Trickling Filter & 97.5 & 144 & 351 & 3 \\
\hline Sowerby Bridge & & & 20.2 & 49.4 & 17 \\
\hline $\begin{array}{l}\text { Milner Royd Final } \\
\text { Effluent }\end{array}$ & $\begin{array}{l}\text { Activated Sludge } \\
\text { (AS) }\end{array}$ & 99.9 & 13.2 & 264 & 19 \\
\hline Copley Church & & & 24.5 & 55 & 17 \\
\hline Halifax Final Effluent & Activated Sludge & 99.1 & 58.5 & 650 & 26 \\
\hline North Dean & & & 27.5 & 159 & 17 \\
\hline $\begin{array}{l}\text { Shibden Head Final } \\
\text { Effluent }\end{array}$ & Trickling Filter & 94.6 & 481 & 490 & 19 \\
\hline Red Beck & & & 12.2 & 169 & 22 \\
\hline Rastrick & & & 21.1 & 171 & 16 \\
\hline $\begin{array}{l}\text { Brighouse Final } \\
\text { Effluent }\end{array}$ & Trickling Filter & 98.7 & 714 & 459 & 8 \\
\hline Cooper Bridge & & & 23.2 & 140 & 14 \\
\hline Neiley Final Effluent & Trickling Filter & 96.5 & 243.8 & 462 & 11 \\
\hline River Colne & & & 15.0 & 75 & 15 \\
\hline $\begin{array}{l}\text { Huddersfield Final } \\
\text { Effluent }\end{array}$ & $\mathrm{AS} / \mathrm{TF}$ & 96.9 & 167.5 & 423 & 14 \\
\hline Battyeford & & & 75.1 & 162 & 15 \\
\hline $\begin{array}{l}\text { North Brierley Final } \\
\text { Effluent }\end{array}$ & Tricklig Filter & 96.9 & 218.6 & 506 & 19 \\
\hline $\begin{array}{l}\text { Spenborough Final } \\
\text { Effluent }\end{array}$ & Trickling Filter & & 155 & 675 & 12 \\
\hline Dewsbury & & & 67.4 & 180 & 15 \\
\hline $\begin{array}{l}\text { Dewsbury Final } \\
\text { Effluent }\end{array}$ & $\mathrm{AS} / \mathrm{TF}$ & 92.6 & 519 & 1150 & 23 \\
\hline Horbury Bridge & & & 84.1 & 245 & 14 \\
\hline Horbury Final Effluent & Trickling Filter & 95.7 & 465 & 733 & 2 \\
\hline $\begin{array}{l}\text { Ossett Spa Final } \\
\text { Effluent }\end{array}$ & Trickling Filter & 96.0 & 368 & 697 & 15 \\
\hline Kirkgate & & & 62.7 & 252 & 15 \\
\hline $\begin{array}{l}\text { Caldervale Final } \\
\text { Effluent }\end{array}$ & Activated Sludge & 98.6 & 25.3 & 762 & 12 \\
\hline Stanley Ferry & & & 49.6 & 270 & 15 \\
\hline Methley Bridge & & & 38.8 & 279 & 17 \\
\hline
\end{tabular}




\subsubsection{Trickling filter plant monitoring}

Six trickling filter type plants were chosen in the Aire and Calder catchments having a range of industrial inputs from 0-33\%. The works treated population equivalents of between 2000 and 120,000 and were considered by the authorities to be representative of both the Yorkshire region and the UK in general.

Automatic samplers were used to collect samples of degritted raw sewage, primary settled and final effluent for 3 consecutive days. Daily time proportional composite samples were prepared from $24 \times 1$ hour grab samples for water quality measurements. Separate samplers were used to prepare 24 hour flow proportional composite samples for LAS analysis. The daily flow proportional samples were prepared from discrete 2 hourly samples (4 shots at 30 minute intervals), with proportions based on the measured flow into the plant.

The discrete 2 hourly samples were used to measure diurnal variations in both the influents and effluents at each site (see figures 4 and 5).

Figure 4: LAS diel influent concentrations at Marley

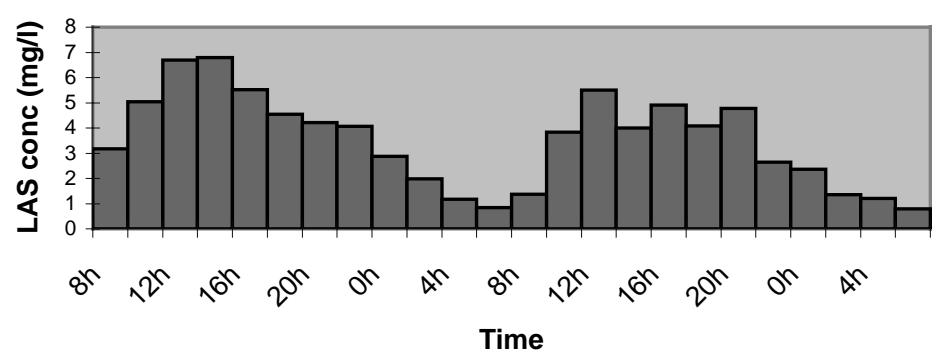

Figure 5: LAS variation in effluent concentration at Dowley

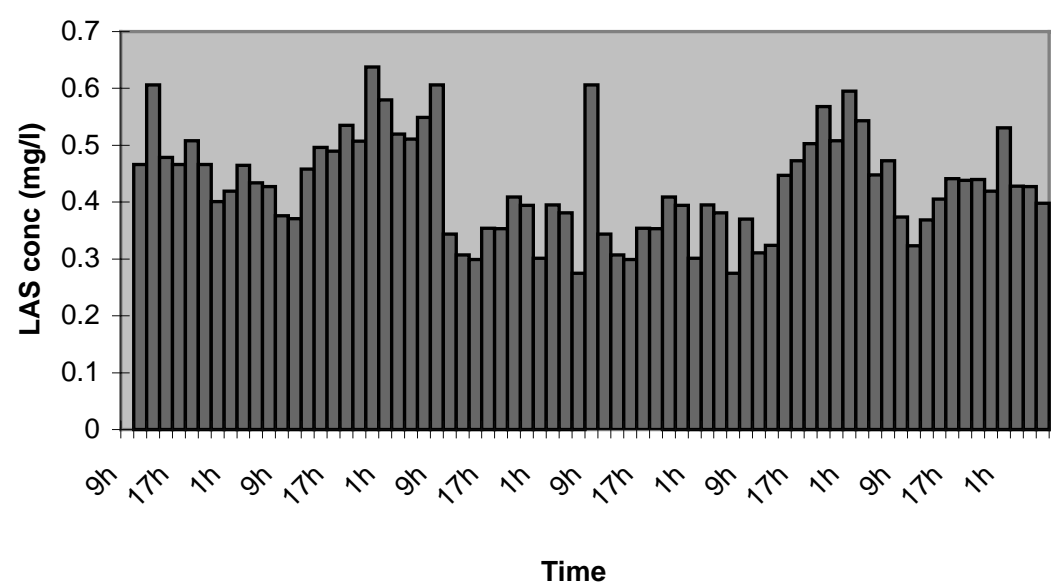




\subsection{3 'In stream' removal}

LAS removal has been studied in three rivers of varying depth and containing different initial concentrations of sewage effluent. For the two smaller rivers, final effluent was spiked with a fluorescent dye (Rhodamine WT). LAS and water quality measurements were made as the Rhodamine pulse passed down the river. River water samples were analysed periodically (2-5 minutes) at each site until the fluorescent dye was detected. Duplicate samples (one immediately preserved for LAS, one for water quality) were then collected at 2 minutes intervals. The first and last samples and samples around the centroid of the fluorescence curve were analysed. Dilution due to increased flow in the catchment was determined from flow measurements as well as boron and Rhodamine concentration data. For the larger river, conductivity and flow measurements were used to follow the effluent downstream, and LAS concentration was determined relative to the boron concentration.

\subsection{Italy}

The monitoring programme in the Lambro has been designed to address a rather different situation to that found in the UK. There are three activated sludge type sewage treatment plants in the monitoring zone (figure 6). One of the plants currently only has the capacity to treat approximately $60 \%$ of the daytime flow. The remaining $40 \%$ flows untreated into the Lambro. At night the flow into the plant falls to just below the treatment capacity and hence only treated effluent is discharged. This imposes a very strong diurnal variation in load upon the receiving water. The influence of the two other treatment plants discharging further down the catchment are almost negligible in comparison.

Sampling is carried out, at fortnightly intervals, at 4 sites downstream of Merone. Duplicate samples are collected every 20 minutes over 24 hours. Daily time proportional samples are prepared routinely and some discrete samples are being analysed to establish the diurnal variations. 
Figure 6: The Lambro Monitoring Study Area

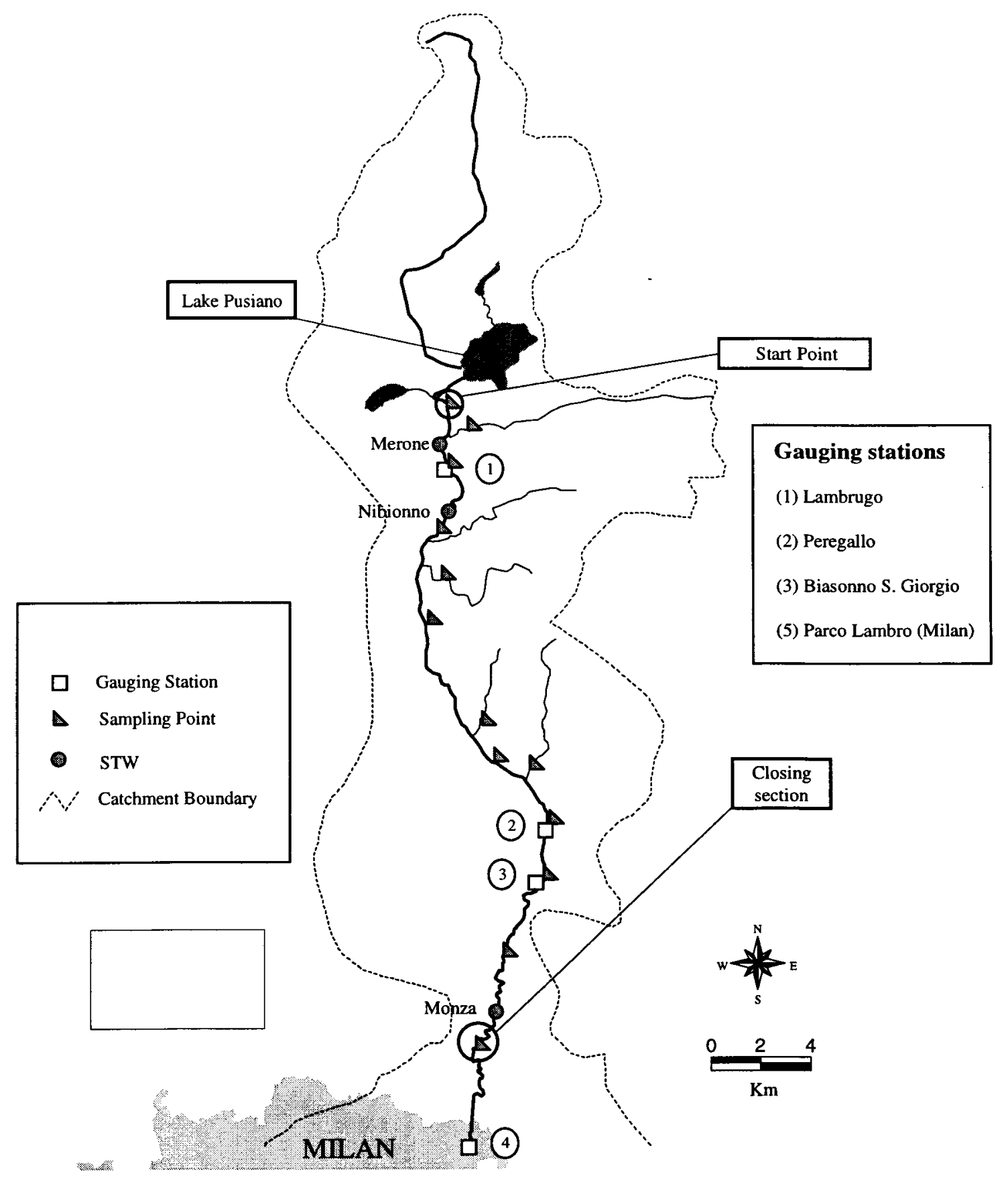




\section{Conclusions}

The chemical specific input data for the model are the physico-chemical and biochemical parameters together with geographical consumption patterns or market data and relevant environmental information will be taken from available geography linked databases.

A thorough understanding of the catchment is important for data interpretation and model validation.

The sampling regimes are very different and are specific to both the aims of the programmes and the characteristics of the catchments.

All sampling protocols use the same preservation, analytical methods and quality controls.

The quality monitoring programme described will ultimately contribute to the validation of the model.

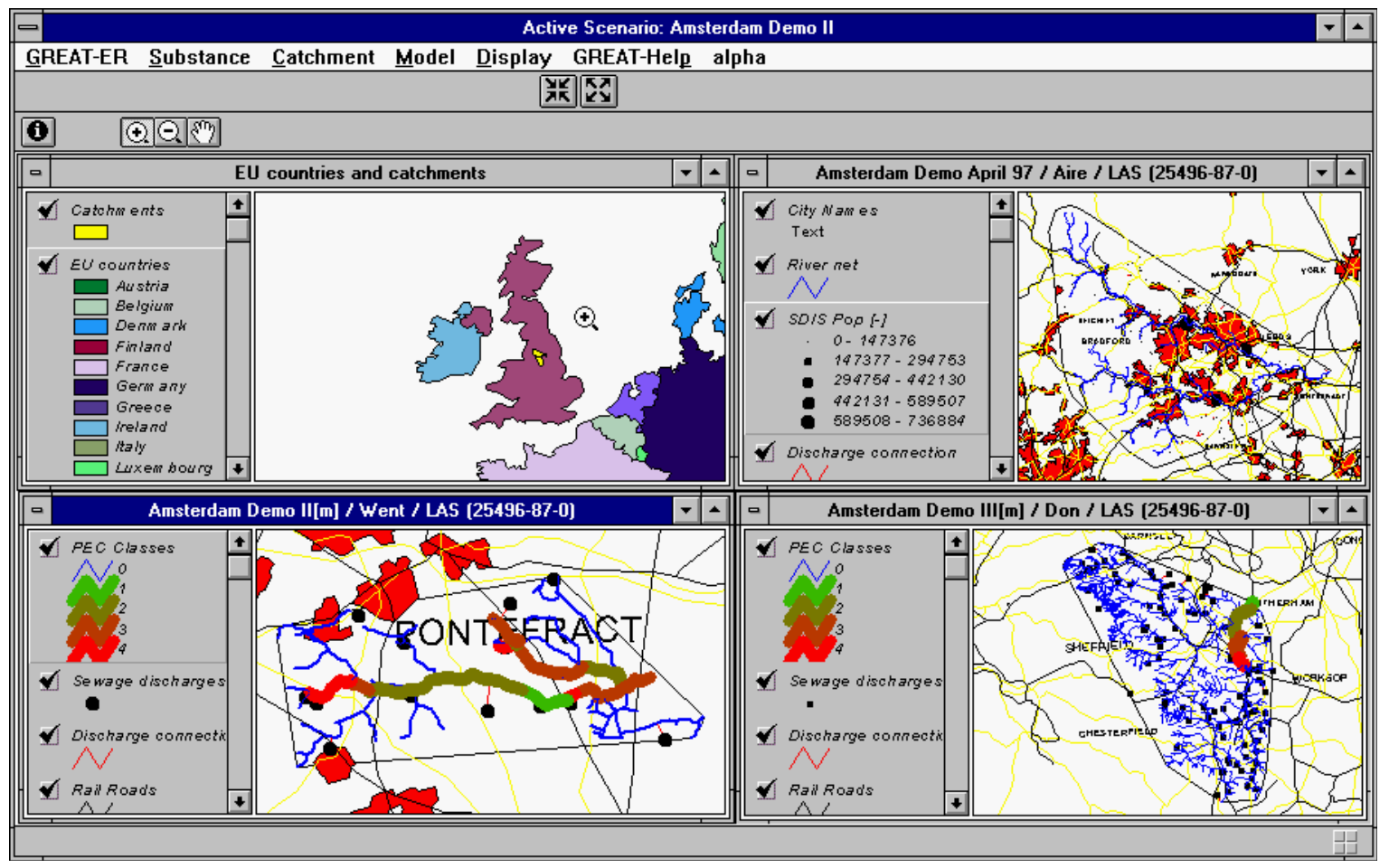

The output of GREAT-ER will be a distribution of a chemical's predicted aquatic environment concentration, throughout the geographical region of interest. An additional output will be standard water quality parameters.

\section{Acknowledgements}

The authors are reporting on behalf of the European Centre for Ecotoxicology and Toxicology of Chemicals (ECETOC) GREAT-ER project team of G. Cassani, K. Fox, V. Koch, E, Matthijs, R. Schroeder, D. Schowanek, R. Murray-Smith, G. Boeije, C. Gandolfi, M. Matthies, G. Morris, C. Heidorn and A. Young 


\section{References}

[1] EEC, 1993. Commission Directive 93/67/EEC of 20 July 1993 laying down the principles for assessment of risks to man and the environment of substances notified in accordance with Council Directive 67/458/EEC, Off. J. of the European Communities L 227/9 (1993).

[2] EEC, 1994. Commission Regulation of laying down the principles for the assessment of risks to man and the environment of existing substances in accordance with Council Regulation (EEC) No 793/93/EEC (1994).

[3] European Chemical Bureau, 1997. European Uniform system for the evaluation of substances (EUSES), version 1.0.

[4] RIVM, VROM \& WVC, Uniform system for the evaluation of substances (USES), version 1.0. National Institute of Public Health and Environmental Protection (RIVM), Ministry of Spatial Planning and the Environment (VROM), Ministry of Welfare, Health and Cultural Affairs (WVC). The Hague. Distribution No. 11144/150 (1994).

[5] ECETOC, 1994, HAZCHEM, a mathematical model for use in risk assessment of substances. Special Report, No. 8 (1994).

[6] Feijtel T.C.J., G. Boeije, M. Matthies, A. Young, G. Morris, C. Gandolfi, B. Hansen, K. Fox, M. Holt, V. Koch, R. Schroder, G. Cassani, D. Schowanek, J. Rosenblom and H. Niessen 1997. Development of a Geography-referenced Regional Exposure Assessment Tool for European Rivers - GREAT-ER. Contribution to GREAT-ER \#1. Chemosphere, 34, 2351-2374. 


\title{
Use of Existing Monitoring Data in Marine Risk Assessment
}

\author{
Prof. André Lecloux, EuroChlor, Brussels
}

\section{Summary}

This presentation is describing collation, evaluation and use of existing monitoring data in rivers, estuaries and seas to assess the exposure level in the marine environment. Practical examples are presented and discussed to assess the risk for the marine environment in the case of chlorinated organic compounds.

\section{Introduction}

Euro Chlor has voluntarily agreed to carry out risk assessments of more than 20 chlorine-based compounds, focusing on the marine environment. Data is collected and evaluated on the effects and environmental concentrations of these compounds. These products are on the lists of concern of European countries participating in the North Sea Conference. The risk assessments aim to explore whether these chlorine chemicals currently pose a risk to the marine environment, especially the North Sea.

Data sources - The effect data is derived from laboratory toxicity tests. All data come from validated, published worldwidesources. A primary source of data is the HEDSET file on each compound. Exposure data come from analytical monitoring programmes in Europe only Where necessary, the exposure data is backed up with calculated concentrations based on emission models.

Risk assessment methodology - For the voluntary risk assessments of more than20 chlorine-based compounds - aimed at evaluating the risks linked to given products - Euro Chlor has followed the EU guidelines (1488/94) published under the Existing Substances Regulation (793/93). The three steps used in all Euro Chlor risk assessments are:

1. Predicted no-effect concentration (PNEC) - An evaluation of the hazard based on (eco)toxicological characteristics. The use of this data to derive the PNEC, the level of chemical at which no effects on the environment would be expected. Three different levels in the marine food chain are examined: aquatic plants (primary producers), invertebrates (primary consumers) and fishes (secondary consumers).

2. Predicted environmental concentration (PEC) - An estimation of exposure of the marine aquatic environment based on real data from monitoring programmes. This will allow a PEC to be derived.

3. PEC/PNEC - A comparison between PNEC and the actual exposure level, expressed by the predicted environmental concentration (PEC). If PEC is lower than PNEC, the product poses no risk; if it is equal to or higher than PNEC, management measures have to be taken to reduce the exposure to an acceptable level.

Overall, a risk assessment can indicate that there is (i) a need for further information or testing; (ii) at present no need for further information or testing, or no need for risk reduction measures; or (iii) a need to limit the risks.

The exercise presented here is a regional risk assessment targeted on the marine environment, in paricular the North Sea. It is intended to extend the approach to other seas if monitoring data were available. 


\section{Monitoring data sources}

Ideally, the environmental concentrations should be measured (monitored) in the relevant environmental compartments according to a pre-planned sampling strategy. This is only possible for substances, which are released in quantities large enough to be detectable by appropriate analytical methods after dilution in the environment. In those cases where reliable high quality monitoring data are available - with proper statistical and temporal evaluation and adequate spatial representation- they should take precedence over the calculated PECs, based on model predictions.

If, in the case of local scenario, the choice of the monitoring site location seems to be straightforward, although many conditions should be fulfilled (see Feijtel and al. presentation at this workshop), a monitoring approach in the case of a regional scenario should be based not only on reliable and representative local measurements, but also on a representative set of sites, consistent with the goals of the monitoring programme.

In evaluating the risk for the marine environment, several difficulties appear which are linked to the high dilution factor within the seas. The actual concentrations are generally so low that the analytical methods are unable to provide reliable measured data, almost all measured values being under the detection limit. A reasonable worst case PEC value in therefore difficult to estimate. Moreover, in the case of substances which are persistent and liable to bioaccumulate, the estimation of a reasonable PNEC value is still a matter of discussion even if the actual environmental concentration is very low.

In order to solve these problems, EuroChlor is working on a methodology to be applied to a serie of more than 20 chlorinated organic compounds. The more volatile substances have been considered first and the procedure is progressively extended to other compounds with higher molecular weight. The consistency of the results obtained in such a way will be checked by using simple modelling approaches.

As it is almost impossible to get monitoring data in the seas, it has been decided to consider, as reasonable worst cases for the seas, the concentration values measured in coastal areas, estuaries and downstream in the rivers. This choice is justified by the fact that there is a further dilution effect in the seas, even if the mixing process is not alwaysvery efficient.

As far as they are available, existing monitoring data from the main rivers and estuaries related to the North Sea have been collated. Most of the locations are those chosen by the various national authorities to check the surface water quality. A list of the databases which are in principle available is given in enclosure 1. In practice, however, the accessibilityit of the data is relatively limited. In this study, only the most recent data available have been used (from 1990 to now). Temporal variations at a given site are taken into account.

In the present exercise, the objective is not to carry out a meaningful in-depth analysis of spatial trends within the Noth Sea area, that would be biased towards a relatively small number of major sites, but to give an overview of the existing situation at representative sites of this geographical regio, in order to assess the potential risk for the marine environment. It would also be important, that some attempt is made to consider water bodies of different kinds, for example, rivers in industrial catchments and rivers from unpopulated areas. This would certainly give a better global image. It is however obvious that most of the monitoring programmes are linked to industrial activities. This last remark reinforces the « worst case aspect » of the approach presented here. 


\section{Two practical examples}

To illustrate the process used in assessing the risk for the marine environment, two practical examples are presented hereafter.

\section{Application to 1,2-dichloroethane}

The main use of 1,2-dichloroethane (EDC) - currently accounting for more than $95 \%$ of production - is to make vinyl chloride monomer (VCM) on which PVC is based.The remaining EDC production (under 5\%) is used in three areas: as a raw material for manufacture of ethyleneamines, trichloroethylene and perchloroethylene; as an extraction and cleaning solvent; and as a lead scavenger for petrol.

\section{Evaluation of environmental risk}

For EDC, the evaluation of toxicity was based on 7 sets of data for algae (primary producers), 16 for invertebrates (primary consumers) and 21 for fish (secondary consumers) in both marine and freshwater media. These were assessed using the environmental quality criteria recommended by the European authorities. Both acute and chronic toxicity studies were taken into account, and the appropriate assessment factors were used to define a final Predicted No-Effect Concentration (PNEC) value of 1100 $\mu \mathrm{g} / \mathrm{litre}$.

All North Sea monitoring data show a progressive decrease in surface water concentrations of 1,2dichloroethane. Measurements were taken in the UK (wide range of river estuaries), the Netherlands (North Sea coasts and open ocean, Rhine estuary, various rivers), France (Seine estuary) and Germany (Elbe and Weser estuaries, Rhine). The map presented in Fig. 1 gives an overall pattern of the situation.

The most recent data (1991-95) support a typical PEC of $0.5 \mu \mathrm{g}$ EDC/l water and a worst case PEC of 6.4 $\mu \mathrm{g} / \mathrm{l}$ water. Data on persistence of EDC show a half-life in water of a few hours or days, and negligible bioaccumulation in aquatic organisms. EDC is not a substance which should be considered as being persistent, toxic and liable to bioaccumulate (PTB) in the environment.

\section{Conclusion}

When the environmental concentration of EDC in rivers and coastal waters/estuaries is compared with the predicted no-effect level to give the PEC/PNEC ratio, there is a safety margin of 170-2200 between actual exposure and the level at which no effect on the environment would be expected. This calculation takes no account of any further dilution within the sea, which would increase these safety margins.

Current use of 1,2-dichloroethane does not, therefore, represent a risk to the marine environment as summarized in Table 1. 
ENV/JM/MONO(2000)2

Table 1 :Risk Assessment Conclusion for 1,2-Dichloroethane

\begin{tabular}{|l|c|c|}
\hline Type of water & $\begin{array}{c}\text { Predicted environmental } \\
\text { concentration (PEC) }\end{array}$ & $\begin{array}{c}\text { PEC/PNEC } \\
\text { (PNEC=1100 } \mu \mathrm{g} / \mathbf{l})\end{array}$ \\
\hline Coastal waters/estuaries & & \\
- Worst case & $6.4 \mu \mathrm{g} / \mathrm{l}$ & 0.0058 \\
- Typical water & $0.5 \mu \mathrm{g} / \mathrm{l}$ & 0.00045 \\
\hline River waters & & \\
- Worst case & $5 \mu \mathrm{g} / \mathrm{l}$ & 0.0045 \\
- Typical water & $0.5 \mu \mathrm{g} / 1$ & 0.00045 \\
\hline
\end{tabular}


Fig. 1 :North Sea monitoring data on 1,2-dichloroethane

JULY 1996

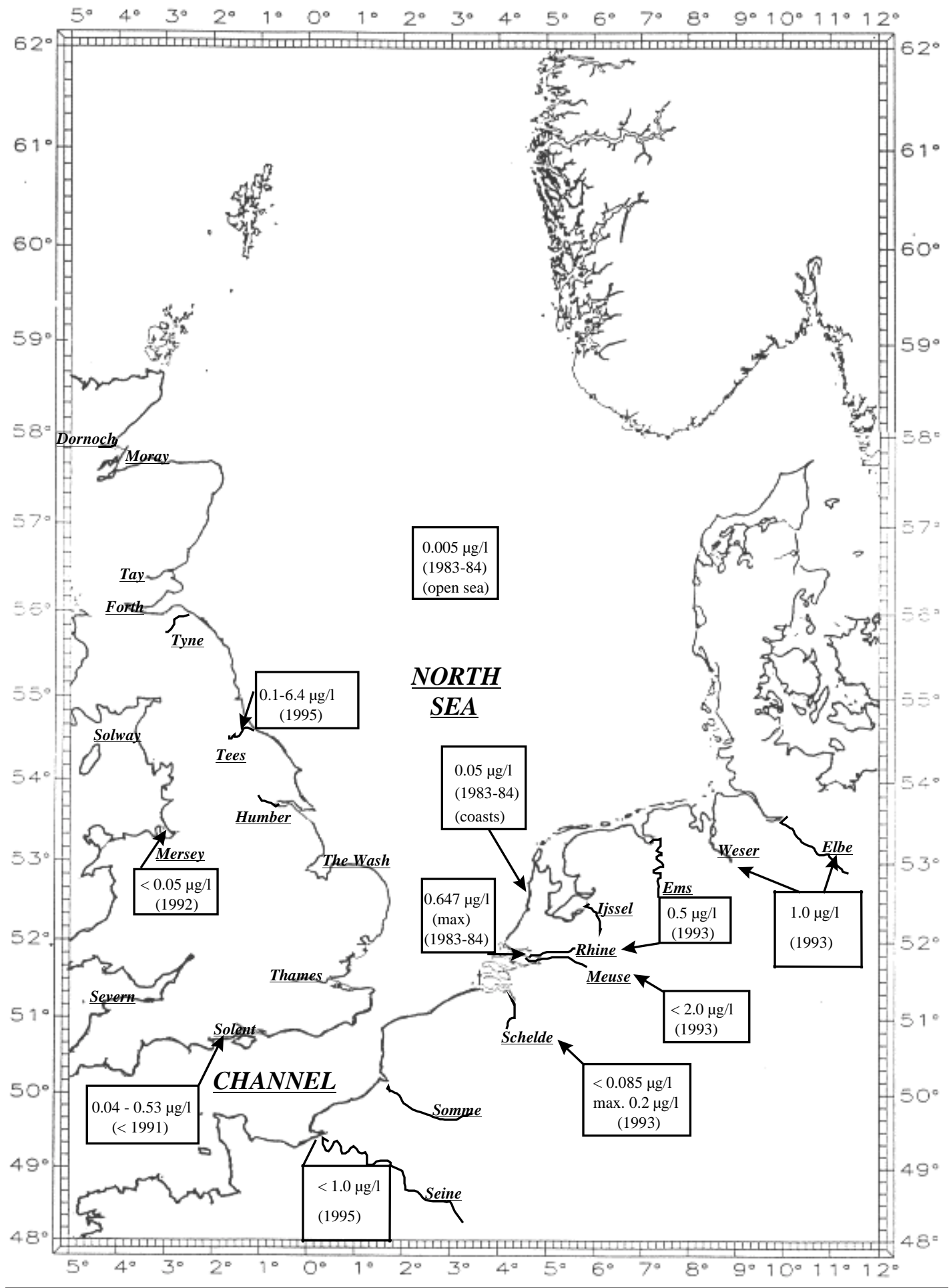




\section{Application to tetrachloroethylene}

In 1994, 164,000 tonnes of tetrachloroethylene was produced by six companies in the EU. Sales totalled 78,000 tonnes and exports, 20,000 tonnes. The remainder was used by the chemical industry as an intermediate. EU production and use of the product fell from 340,800 tonnes in 1986 to 164,000 tonnes in 1994.

The main uses of tetrachloroethylene are dry cleaning (some 60,000 tonnes were used in 1991 by about 60,000 dry-cleaning shops), metal cleaning \& degreasing, chemical synthesis (raw material for production of the CFC substitutes, HFCs and HCFCs), and some other minor applications (paint removers, printing inks, adhesives).

Tetrachloroethylene is mainly produced jointly with trichloroethylene by the so-called "TRI/PER" process. This is based on chlorination or oxychlorination of the light fractions of residues from vinyl chloride monomer (VCM) manufacture.

\section{Evaluation of environmental risk}

For tetrachloroethylene, the evaluation of toxicity was based on eight sets of data for algae (primary producers), 13 for invertebrates (primary consumers) and 18 for fish (secondary consumers) in both marine and freshwater media. These were assessed using the environmental quality criteria recommended by the European authorities. Both acute and chronic toxicity studies were taken into account, and the appropriate assessment factors were used to define a final Predicted No-Effect Concentration (PNEC) value of $50 \mu \mathrm{g} / \mathrm{litre}$.

All North Sea monitoring data shows a progressive decrease in surface water concentrations of tetrachloroethylene. Measurements were taken in Germany (Elbe and Weser estuaries, coastal water), the Netherlands (Rhine estuary, Maas), the German/Dutch border (Rhine), the Belgian/Dutch border (Maas, Meuse), Schelde estuary, the UK (Mersey \& other river estuaries) and France (Seine estuary). The map presented in Fig. 2 gives an overall pattern of the situation.

The most recent data (1991-95) support a typical PEC of $0.5 \mu \mathrm{g}$ tetrachloroethylene/l water and a worst case PEC of $2.5 \mu \mathrm{g} / \mathrm{l}$ water. Data on persistence of tetrachloroethylene indicate a half-life in water of a few hours or days, and negligible bioaccumulation in aquatic organisms. It is not a substance which should be considered as being persistent, toxic and liable to bioaccumulate (PTB) in the environment.

\section{Conclusion}

When the environmental concentration of tetrachloroethylene in rivers and coastal waters/estuaries is compared with the predicted no-effect level to give the PEC/PNEC ratio, there is a safety margin of 20250 between actual exposure and the level at which no effect on the environment would be expected. This calculation takes no account of any further dilution within the sea, which would increase these safety margins. 
Current use of tetrachloroethylene does not, therefore, represent a risk to the marine environment as summarized in Table2.

\begin{tabular}{|c|c|c|}
\hline \multicolumn{3}{|c|}{ Table2 :Risk assessment conclusion for Tetrachloroethylene } \\
\hline Type of water & $\begin{array}{l}\text { Predicted environmental } \\
\text { concentration (PEC) }\end{array}$ & $\begin{array}{c}\text { PEC/PNEC } \\
(\mathrm{PNEC}=50 \mu \mathrm{g} / \mathrm{l})\end{array}$ \\
\hline $\begin{array}{l}\text { Coastal waters/estuarie. } \\
\text { - Worst case } \\
\text { - Typical water }\end{array}$ & $\begin{array}{ll}0.87 & \mu \mathrm{g} / 1 \\
0.2 & \mu \mathrm{g} / 1\end{array}$ & $\begin{array}{l}0.017 \\
0.004\end{array}$ \\
\hline $\begin{array}{l}\text { River waters } \\
\text { - Worst case } \\
\text { - Typical water }\end{array}$ & $\begin{array}{ll}2.5 & \mu \mathrm{g} / 1 \\
0.5 & \mu \mathrm{g} / 1\end{array}$ & $\begin{array}{l}0.049 \\
0.009\end{array}$ \\
\hline
\end{tabular}

\section{Further work}

EuroChlor recently asked WRc to carry out a research to collate and evaluate existing monitoring data in water compartment in Europe for the same serie of chlorinated compounds. These data will be used to update the evaluation of the PEC regional values for the North Sea.

A comparison between these estimates and those obtained through modelling will also be made by deriving a correlation factor between the two sets of values for the same serie of chlorinated compounds. Normally a high correlation coefficent should be observed. This would be a good indication of consistency within both data sets and any outliers should be justified in a reasonable way.

Moreover, a statistical analysis of the temporal trends observed in monitoring data will be made whenever possible. It already appears that the statistical significance of these trends greatly depends on the geographical scale considered within Europe as well as on water type (coastal, estuarine, marine, freshwater).

Finally, for the heaviest and more bioaccumulative products, temporal trends in sediments and various biota will be compared and analysed in order to develop a better risk estimation for the environment.

\section{Conclusion}

The chlor-alkali industry is keen to carry out valuable risk assessments to the marine environment for its products. A serie of studies is carried out on more than 20 chlorinated compounds. The first five full reports will appear very soon in the scientific literature in the form of peer reviewed papers. An other set of eight compounds is at final draft stage. As indicated, further work is going on to collate and analyse existing monitoring data in Europe to input the risk assessment process.

Even if the work presented here could be subject to improvement, its essential merit is the demonstration that such an approach is possible provided that a co-ordinated Europe-wide monitoring data base could be developed and could be freely accessible to third parties. 


\section{Acknowledgments}

This work has been made possible thanks the positive contributions from the scientists from the EuroChlor member companies and from Dr. V. Garny from the EuroChlor Staff. Many thanks to all of them.

Fig. 2 :North Sea monitoring data on tetrachloroethylene

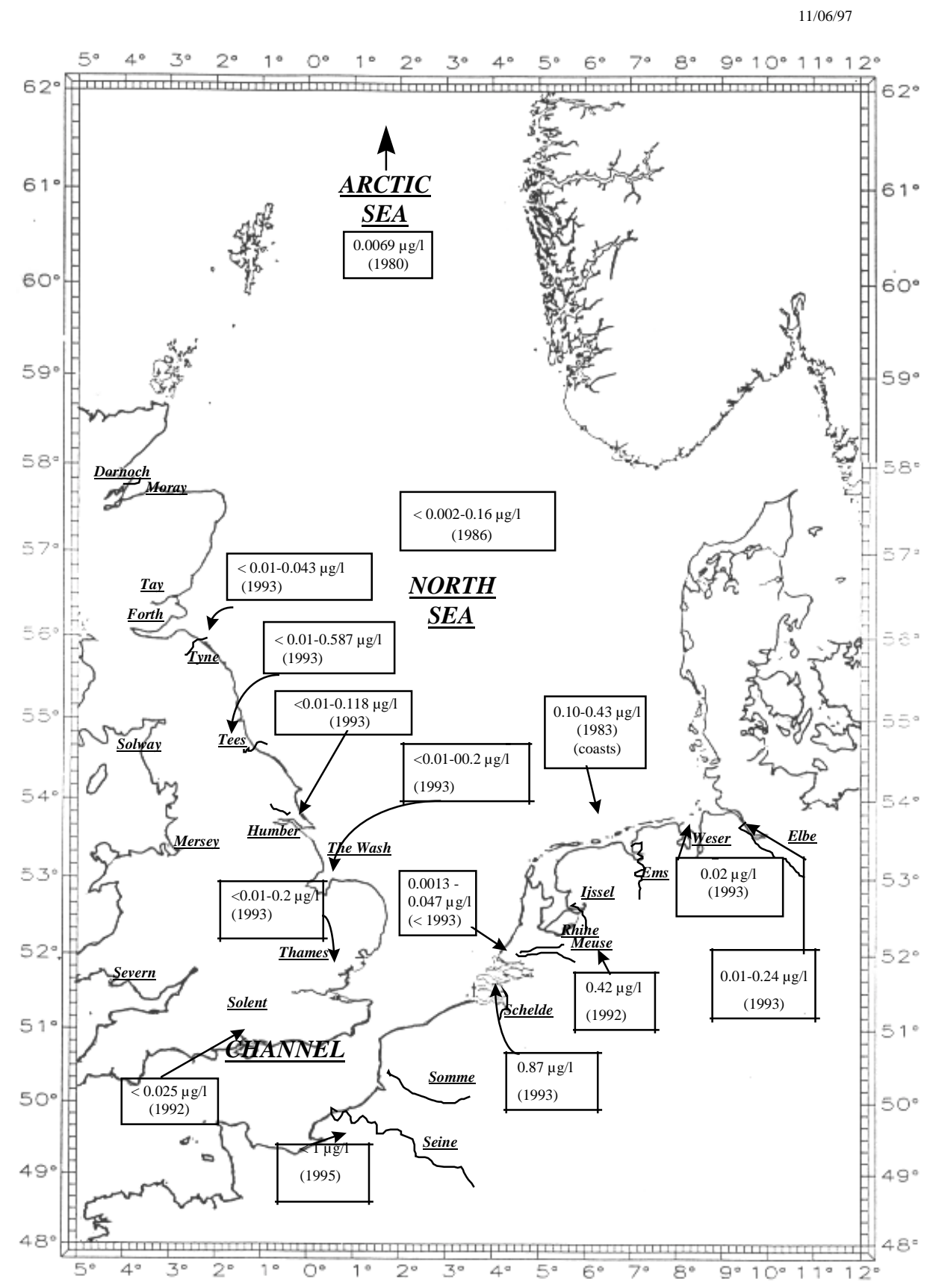




\section{ENCLOSURE 1 : Source reports and databases available}

- AMAP (Arctic Pollution Issues) - 1997 (Oslo)

- The Danube - 1993

- The Finnish Environment - Trends in the Finnish Environment - 1997

- The Future of the Finnish Environment - 1996

- Northern Ireland - Regional Report of the National Monitoring Programme Marine Pollution Monitoring Management Group, IRTU, 1995

- Aquatic Environment Monitoring Report, No. 22, 36, 44, 47, 40. Monitoring \& Surveillance of Non-Radioactive Contaminants in the Aquatic Environment \& Activities Regulating the Disposal of Wastes at Sea.

- NRA - National Coastal Baseline Survey Results: 1992-1993.

- Regional Seas - Technical annexes to the report on the state of the marine environment, UNEP Regional Seas Reports \& Studies No. 114/1, 1990.

- Oslo and Paris Commissions - Monitoring and Assessment - 1992

- $\quad$ North Sea Quality Status Report 1993

- State of the Environment in Austria 1997

- State of the Environment in Ireland 1996

- Daten zur Umwelt 1992/3, Umweltbundesamt

- Zahlentafeln der physikalisch-chemischen Unterschungen 1994

- Zahlentafeln der physikalisch-chemischen Unterschungen des Rhinewassers und des schwebstoffs 1994

- Milieu-en natuurrapport Vlaanderen 1996. Leren om te keren

- Waterkwaliteit 1995, Jaarverslag meetnet oppervlaktewater, Vlaamse Milieumaatschappij

- Flanders - Facts \& Figures, The government of Flanders, 1996

- Jaarverslag meetnet oppervlaktewater 1991, Vlaamse Milieumaatschappij, Bestuur Meetnetten en Planninng

- Jaarverslag meetnet oppervlaktewater 1994, Vlaamse Milieumaatschappij, Bestuur Meetnetten en Onderzoek Dienst Water.

- Jaarverslag meetnet oppervlaktewater 1993, Vlaamse Milieumaatschappij, Bestuur Meetnetten en Onderzoek Dienst Water.

- Collaborative UK Marine Mammal Project: summary of data produced 1988-1992 (R Law compiler), MAFF Technical Report No. 97, Directorate of Fisheries Research, Lowestoft, 1994.

- Impact of Directive 76/464/EEC \& its Daughter Directives on the Most Important Surface Waters in the Community, 1997.

- Evaluation of Directive 76/464/EEC Regarding ListII Substances on the Quality of the Most Important Surface Waters in the Community, 1997.

- Institut Francais De L'environnement (IFEN), Agriculture et environnement : les indicateurs : edition 1997-1998, 1998

- French Institute For The Environment (IFEN) The environment in France : Key facts and figures : 1994-1995 edition, 1994

- Agences De L'eau/ Ministere De L'environnement, River quality assessment in France, 1997. 


\section{Annex 4 \\ Composition of the Working Groups \\ Working Group A \\ Chairperson \\ Jos TIMMERMAN, RIZA, the Netherlands \\ $\underline{\text { Rapporteurs }}$}

Alf LUNDGREN, National Chemicals Inspectorate(KemI), Sweden

David BROOKE, Building Research Establishment, UK

\section{Members}

Larry BARBER, Unites States Geological Survey, US

Ole Christian HANSEN, Danish Technological Institute, Denmark

Hana CULÍKOVÁ, Ministry of Environment, Czech Republic

Michael KLEIN, Environmental Information and Evaluation Systems, Germany

Jack HOLLAND, Environment Australia, Australia

Martin HOLT, ECETOC

André LECLOUX, EuroChlor

Beryl C. NYGREEN, Norwegian Pollution Control Authority, Norway

Roland SCHRÖDER, Henkel KGaA, BIAC

Klaus VOGT, Landesumweltamt Nordrhein-Westfalen, Germany

\section{Working Group B}

\section{Chairperson}

Patrick DOYLE, Environment Canada, Canada

Rapporteurs

Robert DIDERICH, Ministère de l'Environnement, France

Stanislaw TARKOWSKI, The Nofer Institute of Occupational Medicine, Poland

\section{Members}

Marc BABUT, Agence de l'eau Rhine-Meuse, France

Karlheiz BALLSCHMITER, Center of Technology Assessment in Baden-Wuerttemberg, Germany

Tessa BEULSHAUSEN, Umweltbundesamt, Germany

Alessandro DI DOMENICO, Comparataed Ecotossicologia, Italy

Britta HEDLUND, Swedish Environmental Protection Agency, Sweden

Heike HERATA, Helsinki Commision (HELCOM)

Bo JANSSON, Stockholm University, EEA

Takao KOWATA, Ministry of International Trade and Industry, Japan

Arto KULTAMAA, Finnish Environmental Institute, Finland

Slavko LAPAJNE, Inštitut za varstvo okolja, Slovenia

Ralph G. STAHL, Jr., E.I. DuPont de Nemours \& Company, BIAC

Christof STUDER, Swiss Agency for the Environment, Forests and Landscape, Switzerland

Sten-Åke SVENSSON, KemI, Sweden

Burkhard WAGNER, Umweltbundesamt, Germany 


\title{
Working Group C
}

\author{
Chairperson \\ Michael MATTHIES, University of Osnabrück, Germany \\ Rapporteurs \\ Tom FEIJTEL, Proctor \& Gamble, ECETOC \\ Kiyoshi TANABE, National Institute for Environmental Studies, Japan \\ Members \\ Marc BABUT, Agence de l'eau Rhine-Meuse, France \\ Aline BERTHOLD, Federal Environment Agency, Austria \\ W. Eberhard FALCK, Consultant to EEA \\ Katharine K. FOX, UNILEVER RESEARCH, ECETOC \\ Hartmut HEINRICH, Bundesamt für Seeschiffahrt und Hydrographie - M5, Germany \\ Jouko KINNUNEN, NESTE, Environmental and Industrial Hygiene, ECETOC \\ Yves DE LAFONTAINE, Environment Canada, Canada \\ Ivar LUNDBERGH, KemI, Sweden \\ Liviu N. POPESCU, Environmental Programme for Danube River Basin (EPDRB) \\ Janusz SWIATCZAK, Nofer Institute of Occupational Medicine, Poland
}

Peter RONCAK, UNECE

\section{Working Group D}

\section{Chairperson}

Walter GIGER, Swiss Federal Institute for Environmental Science and Technology, Switzerland

\section{Rapporteur}

Christina E. COWAN, Proctor \& Gamble Company, BIAC

Henrik Søren LARSEN, Environmental Protection Agency, Denmark

\section{Members}

Charles BODAR, RIVM, the Netrherlands

Andrew FRASER, GEMS/Water Programme Manager

Britta HEDLUND, Swedish Environmental Protection Agency, Sweden

Ferdinand KASER, European Chemicals Bureau, EC

Patrick KENNEDY, U.S. Environmental Protection Agency, US (Rapporteur for the Plenary

Sessions)

Jürgen MÜLLER, Umweltbundesamt, Pilotstation Frankfurt, Germany

Richard MURRAY-SMITH, ZENECA, Environmental Laboratories, ECETOC

Colin NEAL, Institute of Hydrology, UK

Milan TATARA, Institute of Preventive and Clinical Medicine, Slovak Republic 


\begin{abstract}
Annex 5
Report of Working Group A

Chairperson: Mr J. TIMMERMAN, RIZA, the Netherlands

Rapporteurs: Mr Alf LUNDGREN, Swedish National Chemicals Inspectorate, Sweden

Mr David BROOKE, Building Research Establishment, UK
\end{abstract}

\title{
Issue 1: Criteria for quality and representativeness of monitoring data
}

The starting point for discussions was to look at criteria to judge if existing monitoring data can be used in exposure assessment. The outcome of the discussions are summarised in Table 1, redrawn from a survey by ECETOC.

It was agreed that the criteria in this table should be considered in a flexible way. Data should not be automatically rejected simply because some criteria are not fully met, particularly for the minimum set. The assessor should decide on a case by case basis if the information is sufficient. It was recognised that the more criteria that can be met, the more confidence the assessor can have in the data.

A question was raised regarding whether the assessor should use the latest monitoring data or older ones. In many instances it will be recommended to use the most recent monitoring data in doing environmental exposure assessment, but there is also benefit from looking at trends of concentrations of chemicals in the environment.

If the assessor decides to use data that do not meet the minimum criteria and finds out that these data are crucial to the assessment, he should review the decision or try to obtain additional information.

For applying monitoring data for exposure assessment, it is easier to decide if the data are applicable to a local or continental scale. It may, however, be difficult to make a distinction between the regional and the continental scale. Traditional monitoring programmes, such as monitoring looking at water quality, try to avoid too much influence from point sources, and hence monitoring results are more applicable to the regional scale. Much of the available data may be of this type. Data suitable for the local scale are more likely to come from specific studies, although monitoring maybe useful in this respect.

Improvement of data accessibility was also discussed as it was considered to be an important element. It was proposed that accessibility of data from monitoring databases may be facilitated by introducing a high-order code as presented in the next example.

\begin{tabular}{|l|l|l|}
\hline Analyte 1 & Biota II & Sediment III \\
\hline Water I & Method C & Method E \\
\hline Method A & Method D & Method F \\
\hline Method B
\end{tabular}

Note: In this example, a high order code is "I(analytes)/ II(media)/ III (methods)".

Likewise, a code linking actual sampling to river reach is necessary to sort through the vast amount of available data.

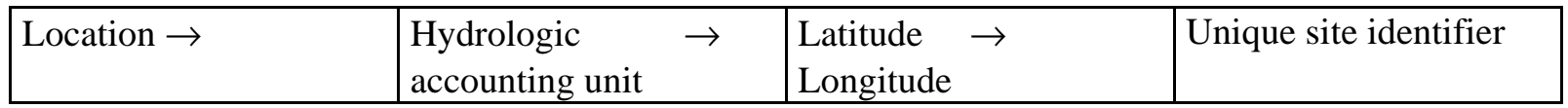


Table : Minimum Information to Justify Use of Existing Ambient Monitoring Data

\begin{tabular}{|c|c|c|}
\hline Criteria & Ideal Set & $\begin{array}{c}\text { Minimum Set for } \\
\text { Exposure Assessment }\end{array}$ \\
\hline Objective of the programme & $\checkmark$ & \\
\hline What has been analysed ? ${ }^{1)}$ (e.g., pore water, bulk, water column) & $\checkmark$ & $\checkmark$ \\
\hline Analytical method $^{2)}$ & $\checkmark$ & $\checkmark$ \\
\hline Unit & $\checkmark$ & $\checkmark$ \\
\hline Limit of quantification (LOQ) $)^{3)}$ & $\checkmark$ & $\checkmark$ \\
\hline Blank concentration $^{4)}$ & $\checkmark$ & \\
\hline Recovery $^{5)}$ & $\checkmark$ & \\
\hline Accuracy ${ }^{6}$ & $\checkmark$ & \\
\hline Reproducibility $^{7}$ & $\checkmark$ & \\
\hline $\begin{array}{l}\text { Sampling protocol (e.g., grab samples, continuous sampling, } \\
\text { duration, filtered/unfiltered, sampling frequency and pattern }{ }^{8} \text { ) }\end{array}$ & $\checkmark$ & $\begin{array}{l}\text { (see statistical evaluation } \\
\text { below) }\end{array}$ \\
\hline One shot or mean ${ }^{9)}$ & & $\checkmark$ \\
\hline Location $^{10)}$ & $\checkmark$ & $\checkmark$ \\
\hline Date $\mathrm{dd} / \mathrm{mm} / \mathrm{yy}^{11)}$ & $\checkmark$ & $\begin{array}{c}\text { Minimum is } \\
\text { Knowledge of year }\end{array}$ \\
\hline Time & $\checkmark$ & \\
\hline $\begin{array}{l}\text { Matrix characteristics (e.g., OC-content, size and age of } \\
\text { organisms) }\end{array}$ & $\checkmark$ & \\
\hline Proximity and influence of sources ${ }^{12)}$ & $\checkmark$ & $\checkmark$ \\
\hline Discharge emission pattern and volume ${ }^{13)}$ & $\checkmark$ & \\
\hline Flow and dilution or application rate of water body sampled & $\checkmark$ & $\checkmark$ \\
\hline Explanation of value assigned to non-detects if used in a mean & $\checkmark$ & $\checkmark$ \\
\hline Description of statistical evaluation of results & $\checkmark$ & $\begin{array}{l}\text { Minimum required is whether } \\
\text { one-shot or mean }\end{array}$ \\
\hline
\end{tabular}

Notes

1. Precisely what has been analysed should be clear. Details of the sample preparation, including for example whether the analysis was of the dissolved fraction, the suspended matter (i.e. adsorbed fraction) or the total (aqueous and adsorbed) should be given.

2. The analytical method should be given in detail or the scientific publication (e.g. the relevant ISO/DIN method or standard operating procedure) should be referenced.

3. The limit of detection (LOD) and details of possible interfering substances should be quoted. There is normally a fixed relation between LOD and LOQ, so LOQ may be calculated from the LOD.

4. Concentrations in system blanks should be given to support the minimum level of detection.

5. Recovery of laboratory and field standard additions (spikes) should be quoted.

6. The relationship between the measured concentration and the LOD should be given. Results of analysis of standard "reference samples", containing a known quantity if the substance. Accuracy is connected to analytical method and the matrix.

7. The degree of confidence and standard deviation in the results from repeat analyses should be given. Reproducibility is also connected to analytical method and the matrix.

8. Whether the sampling frequency and pattern relate to the emission pattern, or whether they allow for effects such seasonal variations need to be considered.

9. The assessor needs to know how the data have been treated, e.g. are the values reported single values, means, 90\%-ile, etc.

10. The monitoring site should be representative of the location and scenario chosen. If data represent temporal means, the time over which concentrations were averaged should be given too.

11. The time, day, month and year may all be important depending upon the release pattern of the chemicals. For some modelling and trend analysis, the year of sampling will be the minimum requirement.

12. For the aqueous environment, detailed information on the distance from and influence of other sources in addition to qualitative information on flow and dilution (see "Flow and dilution or application rate of water body sampled") are needed.

13. Whether there is a constant and continuous discharge, or whether the chemical under study is released as a discontinuous emission showing variations in both volume and concentration with time need to be considered. 


\section{Issue 2: Improvements on the design of monitoring programmes}

Rather than consider changes to existing monitoring programmes, the group discussed how to bring monitoring into a tiered approach to risk assessment. Considering the large number of substances in use, it is necessary to set priorities for substances that may be of large influence. High priority substances should then be investigated with the use of a survey, for instance along the lines of the Japanese example (see paper by Kiyoshi Tanabe in Annex 3).

Prioritisation may be done on the basis of:

- potential hazard, such as ecotoxicity information

- potential exposure, based on production, use pattern and physical-chemical properties including degradation

Preparation of a survey may be done on the basis of:

- potential geographic areas of concern, based on location of production plants and use pattern, preferably covering local, regional and continental scale. Identification of such areas may be done with the use of geo-reference models.

- opportunity of combined analyses for similar substances. Adding further substances that can be analysed in the same way/method as the selected substances.

A similar approach has been developed and is in use in some pilot projects within the framework of the evaluation of the Guidelines on Water Quality Monitoring of Transboundary Rivers by the UN/ECE Task Force on Monitoring and Assessment.

Since, for many substances, no analytical methods are available, the burden of developing analytical methods should be shared to avoid duplicative work. Analysis of a similar kind of substances could be concentrated in one laboratory, so that different laboratories can specialise and accumulate knowledge and experience with specific substances. The benefit would be that all analyses are comparable.

The outcome of the surveys can be:

- no immediate concern

- further monitoring is needed

- accelerated risk management

The surveys could be repeated after a period of time e.g., because of a change in situation.

The group felt that the geographic areas of concern may be catchments. These would contain point sources which would be surveyed to get local concentrations. In addition, monitoring upstream of these sources could be used to give an indication of the regional concentration. These values could be compared between the different catchments studied in order to get an idea of variability on a regional scale. 


\section{Recommendations}

- To evaluate if data are suitable for use, criteria as mentioned in Table 1 should be applied.

- The EEA should extend the coverage of its meta-database of monitoring data to incorporate non-EU sources if possible. (US NWIS may be an appropriate model for this.)

- OECD should investigate the feasibility of incorporating a systematic use of surveys into risk assessment along the lines of the Japanese example.

- OECD should continue efforts to improve accessibility to data from government institutions, industry, etc.

- For risk assessment purposes, data are welcomed in an aggregated form rather than many basic data. Aggregation should contain mean, 90\%-ile, number of samples and range of data.

- Geo-reference models should be developed to support identification of potential areas of concern with respect to specific chemical substances.

- In order to facilitate accessibility to chemical information from existing and new monitoring databases, a common high-order code that integrates analytes/media/methods may be useful. 


\begin{abstract}
Annex 6
Report of Working Group B

Chairperson: Mr Patrick DOYLE, Environment Canada, Canada

Rapporteurs: Mr Robert DIDERICH, Ministère de l'Environnement, France

Mr Stanislaw TARKOWSKI, The Nofer Institute of Occupational Medicine, Poland
\end{abstract}

\title{
General
}

In order to find a common discussion ground, the objectives of risk assessment and quality monitoring needed to be clarified:

For risk assessors, the goal is to find out whether there is a risk to the environment due to the release of a chemical into the environment. They need to know the concentration of a chemical substance on a local (vicinity of the industrial or other site where the chemical is produced, formulated, used or recycled) and regional scale during emissions. The results have to cover intermittent release and areas containing sensitive targets.

On the other hand, the objective of most national monitoring programs is assessment/control of the quality of a medium. The sampling locations are chosen according to the configuration of rivers and out of the direct influence of discharges. Longer-term trends are determined.

Both groups need to identify and quantify the sources of chemicals in the environment, and both want additional data on effluent monitoring made available.

\section{Issue 1: Criteria for quality and representativeness of monitoring data for exposure assessment purposes}

The following items should be reported from a monitoring program for an efficient use in risk assessment:

- description of medium (e.g., for sediment whether it is a pore water or a bulk sample, for water whether it is a surface or bottom water sample, for biota their size and age )

- sampling frequency and pattern/number of samples

- location (long./lat.)

- relationship to sources

- sampling protocol (e.g., grab samples, continuous sampling, duration, filtered/unfiltered)

- analytical protocol (e.g., spike/recovery analysis)

- limit of quantification

- unit

- statistical evaluation (i.e., summary) of results

The priorities for information for a risk assessment regarding different compartments and different spatial situations are:

\begin{tabular}{|l|l|l|l|}
\hline & Local & regional & continental \\
\hline $\begin{array}{l}\text { Water/suspended } \\
\text { sediment }\end{array}$ & +++ & ++ & ++ \\
\hline Air & +++ & +++ & +++ \\
\hline Soil & +++ & ++ & + \\
\hline Biota & +++ & ++ & + \\
\hline
\end{tabular}

Note: +++ high; ++ medium; + low 
By comparing the objectives of risk assessors and most national monitoring programs, it can be concluded that the results from the monitoring programs can be used directly for the estimation of a regional concentration. They are usually not suitable for a local assessment.

\section{Issue 2: Improvements to the design of monitoring programs}

The following recommendations to the monitoring community to increase utility of existing programs were made:

- information listed under Issue 1 should be reported

- decrease monitoring activities for banned or severely restricted chemicals - especially when concentrations are below levels of concern, and have been steadily falling in recent years.

- include some other chemicals - preferably priority chemicals after preliminary fate and release assessment in a screening program

- re-evaluate as required, old analytical records (e.g., chromatograph traces) to quantify, to the extent possible, previous unidentified chemicals

- report data for parameters that can influence bioavailability (e.g., organic carbon, pH)

- programs should be flexible and allow for rapid integration of other (non-routine) chemicals

- $\quad$ report maximum and minimum concentrations, and percentiles (e.g., $10^{\text {th }}, 25^{\text {th }}, 50^{\text {th }}, 75^{\text {th }}, 90^{\text {th }}$, $95^{\text {th }}$ etc.), reflecting spatial and temporal variation.

- when a new list of priority chemicals is announced, arrange meetings between the risk assessment and monitoring communities, to explain why chemicals are on the list for risk assessment, and to identify existing data

- risk assessors and the monitoring community should also meet to discuss and compare methods for priority setting and methods for deriving quality objectives and PNECs

- in general - an effort should be made to establish a sustainable dialogue between the risk assessment and monitoring communities

There is generally a lack of information regarding concentrations in the vicinity of industrial sites, for continuous releases as well as for intermittent ones.

Because of the diversity of the scenarios, it is not useful to give detailed requirements for monitoring in the vicinity of industrial releases, e.g., it is not possible to define a priori the number of locations, distance from emitter, sampling regime, number of samples, evaluation of results. General recommendations or prerequisites include:

- early dialogue between risk assessors and the monitoring community (include decision makers)

- consideration of fate and behaviour of a chemical in the compartment of concern as well as the use of chemicals concerned have to be known in advance

- description of site, emission controls in place, dilution of discharge

- measurement during both low flow and high flow of receiving water

To ensure better communication of existing monitoring data, the following suggestions were made:

- Internet publication of existing reports

- including a code on your home page that would identify the presence of monitoring data, to facilitate searching

- preferably publishing contact points for existing data (maybe OECD can be focal point) 


\section{ENV/JM/MONO(2000)2}

- increasing details in reports from monitoring programs (e.g., results of analyses for all samples)

- risk assessors should contact monitoring authorities directly (e.g., EIONET via EEA home page, gives contact points of monitoring authorities)

- better communication with monitoring data that are already flowing towards OECD.

- better reporting of existing monitoring data to EXICHEM 


\title{
Annex 7
}

\section{Report of Working Group C}

\author{
Chairperson: Mr Michael MATTHIES, University of Osnabrück, Germany \\ Rapporteurs: Mr Tom FEIJTEL, Procter \& Gamble, ECETOC \\ Mr Kiyoshi TANABE, National Institute for Environmental Studies, Japan
}

\section{ISSUE 3: MODEL CALIBRATION AND VALIDATION}

\section{Develop guidance on which monitoring data can be used to calibrate and validate models}

How are monitoring data most often used (surveillance, early detection/early warning, calibration, validation, biomonitoring etc.)? Rank experience with each potential application of monitoring data.

- Monitoring started as surveillance and data are more and more used to extend or stretch the goals to increase understanding of the system and/or for setting environmental quality objectives.

- Monitoring data in the UK are used for setting of consents for industrial emissions. Statistical distribution of effluent/flow is used for the model development using statistical fitting with decay constants which is only valid for the specific catchment (i.e., stochastic model). However, this black box approach does not allow transferability - due to lack of process and mechanistic based understanding.

- A transnational network for surveillance of the Danube river is now providing data for a diagnostic evaluation of the Danube using DELWAQ model - developed by Delft. The data are now used for calibration and validation. Data set contains information on 70 chemicals, and meteorological and hydrological data. The model is now used to increase understanding of the river system processes.

- Marine monitoring and modelling is looking at biological and physical processes, and is more focused at processes like eutrophication.

- Transboundary rivers - increasing number of fields studies have been made or are planned to improve the understanding of fate and distribution of chemicals - i.e., process understanding.

What problems are encountered with using monitoring data for model parameterization, calibration and validation (e.g., model parameter missing incomplete data set of environmental concentrations)?

- Issue is to ensure geographical, meteorological and demographic representativeness and ensure environmental relevance. Spatial representativeness of monitoring data must be ensured.

- Another key issue is to relate the monitoring data, to 'reliable' emissions data for the specific area of interest.

- Two approaches are used in regional modelling: top-down (e.g., EUSES and regional models) and bottom-up(e.g., GREAT-ER).

- Expectation of the accuracy and precision of modelling results should be different for mechanistic models on a small or local scale vs. box or multi-media models on a continental or regional scale.

- $\quad$ Time constant of the processes at regional and continental scale are long, and we may need very long monitoring data sets for validation. Time-response needs to be accounted for. 
What is the state of validation of models for regulatory purposes, e.g., EUSES models? Which type of models (exposure, fate, emission/source models) were most often used for calibration and validation (e.g., multimedia, aquatic, air, soil)?

- New EUSES Working Group has been funded by the EU to remove the errors or blacklist mistakes in the EUSES models - i.e., verification or structural validity

- $\quad$ RIVM is providing verification (and sensitivity analysis) of individual modules using several chemicals.

- A new validation project of EUSES models funded by UBA to use monitoring data for a specific environment and for 8 different chemicals, and then apply the models with these specific environmental characteristics to compare predictions with monitoring data.

- Mostly process based models and fate models are used for calibration and validation.

What type of monitoring data have been used to calibrate and validate emission/source models and which type of emission/source models?

- Key issue is to have emission data for the chemical of interest. This data is often confidential. Consents are publicly available but generally does not provide the chemical specific release (mostly BOD/COD and metals with upper limits). Data in Canada is public, but not always reliable.

- Emission scenarios - 8 use categories (e.g., intermediates, textile dyes, household, paints, lacquers) are available, and others are in development.

- Toxic release inventories, e.g., Pollutant Release and Transfer Register and/or inventory of point sources - over 10 countries are developing this and/or have introduced this system for exposure assessment.

- EU consultants has delivered a report for providing a common basis for the European Pollutant Emission Register (EPER).

- Similar activities are ongoing in CEE for pesticide use.

- Statistical distribution of PECs for empirical emission/source models are currently developed (e.g., leather processing)

- Mass balance preferably expanded to material flow analysis would be one way to validate emission/source models

- Links should be made to Life-cycle inventory for data sharing.

How does the environmental scenario used for validation differ from that used in model calibration?

- Question is what is representative, and to what extent can or may the scenarios differ. EUSES does not pretend to be representative.

- EUSES and regional SIMPLE BOX models are, on purpose, generic and fictive.

- Spatial aggregation has its limits, and the relevance of continental and regional multi-media modelling is questioned.

What methods are used for model calibration and validation (e.g., hand-tuning, computer routine)? What type of environmental characteristics and release characteristics from monitoring are used in calibration and validation? Are these sufficient for model calibration and validation?

- $\quad$ Published data of industry is used and compared with monitoring data. All production and manufacturing and use must be accounted for to have all possible inputs. Quality control is essential not to miss a key emitter. Hand-tuning is important. 
- $\quad$ GREAT-ER has similar issues with background levels of boron, which must be accounted for (e.g., groundwater/sediment).

- Use of similar models using same inputs and ensure similar outputs, and/or use models with analytical solutions

How do the assessment endpoints affect the calibration and validation (different averaging times, health vs. ecological endpoints)?

- The effect assessment endpoint will determine the exposure endpoint. Chronic vs. acute endpoints need different exposure endpoints. The effects assessment and risk endpoint drives the type and extent of averaging exposure concentration over time.

\section{Develop guidance on how data gaps can be filled}

What data are needed for running a model for calibration and validation? How are data gaps filled?

- Chemical data

- Physico-chemical data are easy to obtain.

- QSAR are increasingly being used to fill data gaps.

- Variation in sorption, degradation and other fate processes due to influence of climate, environment and other are needed.

- Need to distinguish total vs. dissolved/particulate phases.

- Environmental data

- Environmental data are not ready available.

- They are also very heterogeneous and highly variable.

- Environmental data has 'copyright' issues and are not freely available.

- They affect 'removal' data, e.g., suspended solids(amount and quality) and also hydrometry, substrate, biota, etc.

- Need to build process and mechanistic understanding.

- Develop databases on the controlling variables (i.e., $\mathrm{pH}$ for hydrolysis rate and sorption).

- Data collected with public money should be publicly available (e.g., hydrogeology, soil and landuse maps).

- Data should be ready accessible.

- On European scale, this becomes very difficult.

- Biological and ecological database with biotic index mapping is desirable.

- Emission/Source data

- Emission/Source data are confidential.

- PRTR is a source of emission data. Emission scenario documents need to be developed by industry in pursuit of Integrated Pollution Prevention Control (IPPC).

- Strategy

- Stimulate and develop EU initiatives for integration of data (e.g., Corine).

- Collect and centralize production data.

- Institutionalize data centers at local level and regional levels.

- Stimulate data sharing at Pan-European level.

- Intermediate solution could be to inventarize data holding institutions and collect necessary data for exposure and risk assessment (Possibly share via virtual Internet links.). 
What monitoring data are needed for calibrating or validating a model?

- Location and characteristics of sampling and discharge points

- Statistical parameters of observations (mean, variance, median)

- Time series of measurements

- Spatial representativeness

Note: Enough data are not always available for use in modelling. It is important to know what model is, what are its objectives and which scale and temporal resolution are expected. Historical data of the site may also be needed.

\section{Identify criteria that can be used to decide if a model has been calibrated or validated}

How are the criteria set for determining if a model is calibrated? What are the criteria (e.g., qualitative and/or quantitative)?

- Compare actual measured vs. predicted for each point, plot dataset, and determine goodness of fit with least squares; or

- Compare measured concentration range vs. single fixed predicted value, and check qualitatively how accurate the prediction is or can be. (Qualitative approach)

- Type of calibration depends on model and intended or needed accuracy.

What elements need to be taken into consideration?

- Objectives of the model and which variable can be changed (e.g., soil permeability, clay content) and resources that are available.

- Need to watch out whether there is an unique solution and whether too many variables.

- Individual mechanisms/processes need to be calibrated. Same it true for verification/validation.

- Cost of fine-tuning may be prohibitive and not be worth the benefit.

- Target accuracy of about one order of magnitude would be seen as very satisfactory for emission and regional multi-media modelling.

- $\quad$ River and hydrological models are looking for 20-30\% accuracy.

How are the criteria set for determining if a model is validated? What are the criteria (e.g., qualitative and/or quantitative)?

- Calibration/validation ratio will depend on the model, chemical and environment. Target accuracy should be in principle be the same, but in practice is often less.

How are ranges in environmental concentrations obtained in the monitoring programmes used (only average or geometric mean, stochastic variability also included)? Is the uncertainty of model predictions determined (e.g., by Monte Carlo)? What is the current state of applied methods?

- Monte Carlo distribution is used, but distribution (e.g., shape, width, mean) of variable and input parameters is often not known.

- Extended Kalman filtration (iterative methods) are increasing being used for calibration. 
- For sensitivity analysis, normal distribution (mean+SD) can be used, but this should be done with care for uncertainty modelling. It helps to identify the key parameters.

- Ideally, one should collect the frequency distribution of the variables (e.g., suspended solids distribution in rivers) for an uncertainty analysis.

\section{Develop guidance on what to do when monitoring data and model predictions are different}

What is the "degree of conservation" in model assumption? Reduce over-conservative as well as underconservative assumptions. Worst-case vs. realistic assumptions.

- Data and assumptions must be separated from the process/mechanistic descriptions. The conceptual description of the processes can be tackled differently, and may be in one case conservative, while in the other case not.

- Assumption about fraction connected to sewage, default degradation rate constants, and input parameters may affect the degree of conservatism.

What is done if the monitoring data and model predictions do not agree within the criteria?

- $\quad$ Check monitoring data.

- Check model parameters.

- Check model assumptions.

- Accept difference.

- Change criteria.

Consensus is :

- pragmatic and clear on the set criteria, and investigate if the model did incorporate the key processes that could explain the discrepancy. This should be an iterative process using expert judgement.

\section{ISSUE 4: $\quad$ USE OF MODELS IN THE DESIGN OF NEW MONITORING INITIATIVES}

Recommend and give examples of how risk and exposure assessment models could be used to help design new monitoring initiatives

What is experience with using environmental fate models to design monitoring programmes? What type of monitoring programme? Capture experience and identify any gaps.

- Use of surveillance monitoring data in Japan in combination with non-steady multi-media models (NSEM) for priority setting, and allow the selection of the right compartments and/or media. The monitoring data is used to validate the model predictions. The accuracy is within one order of magnitude.

- Expert judgement is mostly used, but is not always comprehensive. The combination with use and release pathways and the interaction between fate processes will help to elucidate the fate and distribution.

- Fugacity (level 1,2,3,4) provides insight on which processes are important to assess generic understanding of the substance and distribution on global scales.

- Modelling helps us also to understand which parts of the environment to monitor (e.g., fish, suspended solids, air) 
For what purpose(s) have environmental fate models been used to help in designing monitoring programmes (e.g., which compartments to focus monitoring in, what detection levels are required, placement of samples in space and time)?

a) What types of models have been used to design monitoring programmes (e.g., multi-media models, media-specific models, site-specific models that have been developed and calibrated for site)?

- "TALuft" is used for location identification.

- "HAZARD" for priority setting criteria and monitoring of sediment

- River models can be used to determine the dispersion coefficient or length of mixing and where to set your sampling locations

- Models can help to select the number and type of substances which need to be monitored, by providing transparent predictions on fate and exposure of protection targets (man).

- Models can be used to discriminate among geographical areas and allow optimization of the allocation/use of resources

b) Has the modelling data then been used in model calibration/validation?

- When data becomes available, it will be further used for calibration/validation.

c) Have environmental fate models ever been used to determine the sources of chemicals? How has this related to monitoring programmes and use of monitoring data?

- Yes. Environmental fate models can be used for prospecting (e.g., metals) and location/strength of the sources (e.g., industrial activity)

- Multimedia models are also used for global distillation and source identification of POPs and (S)VOCs.

Discuss the possibility of models in helping estimating the level of detection needed for analytical techniques and the concentrations of chemicals in case of analytical techniques are not available

What is the accuracy of predicted concentrations compared to analytical monitoring programmes?

- Models with one order of magnitude accuracy are mostly not used for setting analytical targets.

Can models help to estimate the level of detection needed for analytical techniques?

- Models are used to estimate expected concentrations in the different compartments.

- Sampling technique and analytical detectability needs to be combined in order to solve detectability.

Can models help to estimate concentrations if analytical techniques give only poor accuracy, e.g., at low levels or in difficult-to-analyse media such as solids and sediments.

- Yes. Models enhance understanding and help to understand where it will partition (e.g., air, plant)

- Models are used for the design of laboratory experiments. 


\section{RECOMMENDED FURTHER WORK FOR THE OECD AND/OR OTHERS}

Its is recommended:

- to start a process which identifies suitable monitoring databases and characterizes, interprets and digests the data in such a way that the information can be shared according to the necessary quality assurance criteria (action: initiate and facilitate: OECD; also possibly longterm support)

- to identify environmental data sets (e.g., hydrological, meteorological, topographic, demographic, geomophological, land-use and soil type), data holders and contact points (action: OECD/Eurostat)

- to provide information about the type, quality and structure of the available databases and inform about data interchange format and ensure free and transparent access (action: EEA and GEMS for monitoring data sets, others).

- to initiate the development of geo-referenced information about mass of chemicals released during the life-cycle of the chemical and/or product - using a common methodological approach. Develop release inventories such as Pollutant Release and Transfer register; International Pollution Prevention Control data and geo-referenced inventories of point sources of wastewater treatment plants. Control data and geo-referenced inventories of point sources of wastewater treatment plants.

- to integrate geo-referenced database and link with fate and distribution models to increase transparent access to and visualization of the data banks and model results.

- to initiate validation programmes for models covering a wide range of chemicals and systems. Apply the existing criteria for calibration and validation of the individual process, underlying data and assumptions. (action: OECD;DGXI; CA;...)

- to develop guidance to optimize existing monitoring studies so that newly collected data can be used for risk assessment purposes (action: OECD, DGXI; taking into account UN-ECE Task Force on monitoring of transboundary waters)

- to install an expert advisory group, comprising of monitoring/modelling/risk assessment people, which could develop and design new monitoring studies.

- Strategy for filling data gaps could consist of integrating regulatory needs for water quality and chemical risk assessment and exchange monitoring, chemical and biological information. 


\author{
Annex 8 \\ Report of Working Group D \\ Chairperson: Mr Walter GIGER, Swiss Federal Institute for Environmental Science \\ Technology, Switzerland \\ Rapporteur: Ms Christina E. COWAN, Procter \& Gamble, BIAC \\ Mr Henrik Søren LARSEN, Danish Environmental Protection Agency
}

\title{
ISSUE 3: MODEL CALIBRATION AND VALIDATION
}

\section{Develop guidance on which monitoring data can be used to calibrate and validate models}

Can monitoring data be used to develop or expand the basic understanding of processes for risk assessment, model development and/or validation (e.g., GREAT-ER) ?

- Monitoring programs have been developed to look at and in some cases used to test for underlying physicochemical understanding (e.g., in acid deposition research). Most often monitoring programs are used to detect excursions from ambient conditions/quality, to study trends over time, and to provide baseline information for pristine places (e.g., upstream of anthropogenic input into the system).

- Models, however, usually require information for input or parameterization that is more research focused (i.e., on detailed process descriptions) and this type of information is not generally available from monitoring programs.

- If large sets of monitoring data are available, then these can potentially be interrogated to obtain an idea of the importance of various basic functions of the catchment's hydrochemical processes.

- Monitoring data are very biased because most programs focus on problem areas; therefore, there are not much data, if any, on pristine conditions which may be needed for model development and validation.

- Research activities and monitoring need to interact as this helps both the identification of the processes and widens the role of monitoring data.

Describe problems that are encountered when using monitoring data for model parameterization, calibration and validation (e.g., model parameter missing, incomplete data set of environmental concentrations).

- Typically the monitoring programmes do not provide data for model parameterization of rates and detailed characterisation of process.

- These process oriented parameters are usually determined in laboratory experiments and confirmed in research oriented field programmes.

- In model calibration, there is a need to ensure that final parameter values are both reasonable and give accurate results (i.e., the model predictions agree with the monitoring data). If the parameter values that give accurate results are not reasonable, then this could indicate the need to look for another set of parameter values and/or to include other processes in the model.

- Monitoring data can potentially be used to look at overall validation of whether the model behaves correctly or not. 
- There may be several sets of parameter values/processes that can simulate the monitoring results but typically monitoring programs do not provide the data required to discriminate among these options.

- When using monitoring data for calibration, less-than-detection-limit values can not be used because problems arise when running statistical tests on these data to estimate the parameters and/or the exact value of input parameters. However, less-than-detection-limit values can be used for model validation.

- It is important to keep a record of the detection limit for a particular data set because as time progresses, the detection limits become lower and lower; therefore in future work a concentration may be measured.

- There is considerable danger in reporting less than detection limit values as 0 concentration and therefore, this activity should be discouraged. This would also result in a bias in the parameter estimates obtained from these data.

- Model validation is much easier on a local scale than a regional scale because there is generally more control over and understanding of the local site. For regional scale, as defined by EU, validation is potentially much more difficult because of the large number of sources and longer time-frame of data required. This is especially true when trying to obtain data for validating a fugacity/box model which estimates average concentration for a chosen average environment. In addition, there is a need to determine if the monitoring data is representative of the regional exposure scenario that is the focus of the model.

What is the state of validation of models for regulatory purposes, e.g., EUSES models?

- For EUSES there has been ad hoc verification for selected compounds looking at reasonableness of results as part of EU risk assessment process.

- The Netherlands and Germany are looking at the internal logic and verification of components of the EUSES model.

- Since EUSES is such a complex model, agreement between the output of the model with monitoring data would not necessarily mean that the model is validated.

- Status of other regulatory models in unknown but probably similar to that of EUSES.

What sorts of considerations are needed in choosing monitoring data (e.g., environmental characteristics, emissions and environmental concentrations) to use in calibration and validation of environmental exposure and emission/source models?

- Monitoring data can give input and output concentrations/data but does not provide information on processes that are acting in the system.

- Data from single monitoring points or variance in the monitoring data from multiple monitoring points can be used to look at reasonableness of model predictions and by inference the underlying parameters and processes; however, these data can't confirm the processes that are operative.

- In some situations, it may be possible to use monitoring data to quantify the disappearance of a particular chemical in the field; however, generally the detailed data are not available to identify which processes are responsible for the observed disappearance. To quantify this disappearance, the monitoring study will need multiple sites along the river and/or data on a conservative tracer. These data on the conservative tracer may also help discriminate among removal process; however, these type of data are not normally collected in monitoring programmes.

- For river models, the hydrograph is a vital piece of information and it cannot be obtained from monthly or weekly flow data. Gauging stations are required to measure the instantaneous responses that are required to construct the hydrograph. 
- Loading is also a critical parameter for these models. However, caution must be used when calculating loads as there are 5 or 6 major methods which can be used to calculate the load and which can give values that differ by an order of magnitude or more.

- There is a need to understand and identify which parameters have the most impact on the outcome of a model. The data collection and determination can focus on these parameters.

- The modeler and risk assessor need to "understand the data", especially the uncertainty. Different analysts, and different analytical methods can effect the data; however, it is not practical to expect all analyses to be done in the same way. Instead work is needed to better understand the magnitude of and basis for these differences. For example, in Great Britain, acid available metals on particles are measured using several methods which give different values with different levels of uncertainty.

- Physical/chemical/degradation properties of the substance effect the number and distribution of sites required in the monitoring program for model calibration and validation. For example, if a substance is rapidly degraded then there is a need for more detailed and closely distributed monitoring data to understand the substance's distribution and the processes that effect this distribution.

- Under certain circumstances, non-traditional factors need to be included in the monitoring program. For example, temperature, $\mathrm{pH}$, redox potential, and $\mathrm{O}_{2}$ can significantly effect the chemical's distribution and interpretation of monitoring data as well as validation. For example, if there is a $\mathrm{pH}$ drop then $\mathrm{Al}$ may be released from sediments, as is $\mathrm{P}, \mathrm{Fe}$, or $\mathrm{Mn}$ if anoxic conditions occur in the sediments. If these data are not included in the monitoring program and/or these processes not considered in the model then the model can not be validated.

- Metal speciation, especially formation within solution of inorganic and organic complexes, including organo-metals formed by bacteria, and solid dissolution need to be understood and monitored before these data can be used in model calibration or validation.

- It is critical to understand and differentiate between the dissolved and particulate phases of a chemical. But the common definition (i.e., the dissolved fraction is defined as that which passes through a $0.45 \mu \mathrm{m}$ filter) is an operational definition. Depending on the technique that is used significant differences in this measurement can be found. This information is important because research into and models developed to predict the role of particulates in the transport of toxic substances in the environment depends on these type of data and understanding.

- It is important to understand the time-averaging of the sample. For example, are the monitoring data from a single grab sample or a $24 \mathrm{hr}$ composite sample?

Describe how the assessment endpoint affects the calibration and validation (e.g., different averaging times, health vs. ecological endpoints).

- For some health endpoints it is important to look at short averaging times to get peak concentrations and this should impact which data are collected and how these data are used in model calibration and validation.

- Generally the calibration and validation should focus on using exposure time-frames that are consistent with the duration of the long or short term toxicity studies that are used for the effects endpoint.

- However, it is important to recognise that in the field the fish move and can avoid high concentration area of chemical, and thus it is harder to extrapolate into and predict these situations.

- It is most useful to have both the complete time series of data as well as different summaries (e.g., running averages over time). 


\section{Develop guidance on how data gaps can be filled}

What are the particularly important data, which are usually not available, in conducting calibration and validation of models?

- Anything that may effect the sample and data interpretation needs to be captured. One option is to compile a metafile on the characteristics of the site and what is upstream of the site.

- There is a need to develop and use a common system for referencing location. Locations that have been recorded historically may be inaccurate and new methods using hand-held GPS are not compatible with older approaches

Discuss how data gaps can be filled.

- When filling in missing data, these data need to be flagged. Also, before using the data the investigator should consider how many parameters were estimated relative to how many are measured. Chemical stoichiometry and the hydrograph can often be used to estimate missing chemical and flow parameters. However, micro-organic concentrations in low lands are not tied into hydrology because sources may be intermittent. Such substances require a much more intense monitoring program than is typical. There is also a very significant cost involved in micro-organic determinations because they are time-consuming and expensive.

- There is a need to collate all available information on the sites (e.g., other types of studies in that area) and conduct literature searches to locate information on what has already been done. However, it should be recognised that there are major limitations in the databases used for literature search especially regarding the limited time period of references that they contain. Furthermore, basic data is not always published and is being rapidly lost due to retirements (e.g., early retirement) and down-sizing of staff.

- Information of relevance to the model calibration and validation may also be housed in university archives, including information on the pristine environment. However, these data are very difficult to find and these data tend to be focused on addressing different questions from those of standard monitoring studies.

- When potential sources of data are located, it is important to have a dialogue with the keeper and collator of the data to build credibility with them and to better understand the data and its limitations.

\section{Identify criteria that can be used to decide if a model has been calibrated or validated}

What should be noted in considering criteria for calibration and validation?

- There is an ASTM initiative for developing guidance on environmental model validation and the report is available. The title of the document is "Standard Practice for Evaluating Mathematical Models for the Environmental Fate of Chemicals"(Designation: E978-92). Information on how to obtain copies of ASTM standards can be found at http://www.astm.org.

- Because many of the environmental processes are non-linear, individual values may behave differently from average values. Difference between average and time series must be recognised in evaluating calibration or validation.

Describe criteria for determining if a model is calibrated or validated.

- Parameter values for calibration should be within reasonable bounds for the process but setting these bounds are not always easy. Some options are to use within 1 SD or within $10 \%$ of the initial value as these are reasonable bounds. 
- The scale of resolution for validation of the model will depend on the use of the model. It is also important to understand the modeler's perception of the model's accuracy. For example, the model developers believed that for the EUSES model an accuracy within an order of magnitude would be adequate.

- When comparing model predictions with measured concentrations in the lower concentration ranges, it is important to recognise that a larger difference in these data is not as critical as is the same difference in predictions in the higher concentration range. Therefore, the required accuracy will depend on the concentration range of the model predictions.

- Confidence intervals for the model predictions should be quantified.

- Also it is important to define all sources of potential model uncertainty. Even if a formal uncertainty analysis is conducted, the uncertainty in the assumptions and the underlying processes which can not be quantified can have greater impact on the model results. Several models representing different representations of the fate processes can be used to look at differences in these model outputs which will give a crude estimate of the structural (model) uncertainty.

\section{Develop guidance on what to do when monitoring data and model predictions are different}

What should be done if the monitoring data and model predictions do not agree within the criteria?

- First, it is mandatory to check the monitoring data, model parameters, and model assumptions for any errors.

- Depending on the substance, the substance's mass balance may need to consider to determine if all processes have been considered. For example, water concentration may agree but the other concentrations like those in sediment may not agree because different processes are important in each media.

- It is important to recognise that the same model may not be valid for different chemicals because different processes are operational.

- Separate processes must be studied in the laboratory because in the environment there are a lot of interactions among the processes. But in the field every compartment and process is part of something else and loss of these links may result in artefacts in the laboratory. Usually it is very hard to take components apart and not loose some critical interactions.

- The more one looks inside systems, the more complicated the system seems to become; therefore, the greater the amount of descriptive knowledge and information on the system and processes that must be obtained.

- Emission sources can sometimes be missed especially in the case of diffuse sources and transport across boundaries.

- It is difficult to determine if all the appropriate processes are included in the model and also the impact of the model's scale on the results. Different models can be used to determine which processes to include and if scale is important.

- If the range of concentrations predicted is low compared to toxicity then agreement with monitoring data is less important.

- Acceptable agreement is dependent on what you plan to do with the model results.

- It is important to remember that one can not repeat the monitoring but can monitor again.

- Sometimes, the number of information points available is less than expected or required for statistical comparison of the model and monitoring data. In these cases, a judgement must be made as to whether the difference can be accepted. 
Discuss the significance of the "degree of conservatism" of the model.

- If highly toxic substances are being considered, and consequently large impact can occur then the degree of conservatism should be higher than for less important, less impactful substances.

\section{ISSUE 4: $\quad$ USE OF MODELS IN THE DESIGN OF NEW MONITORING INITIATIVES}

Recommend and give examples of how risk and exposure assessment models could be used to help design new monitoring initiatives

Describe any experience with using environmental fate models to design monitoring programmes.

- Based on the responses to the survey questionnaire, models are rarely used in the design stage and where one was used, it was only to identify the target compartment but even this experience is very limited. In reality, problems are usually identified from monitoring data first. Models are not the front-line.

- The people who are setting up the program may not be aware that the models exist and could be useful.

- If a substance of concern is identified with models, then this is added to the monitoring program. But this also depends on the type of substance, the degree of concern and the availability and cost of analytical measurement methods. Ideally, models would be used to conduct initial screening assessments and if a risk is predicted, then monitoring would be used to confirm or refute this concern.

- There are several algorithms which could be viewed as simple models used to design monitoring programs. If the acceptable variance in space and time are defined, then these algorithms can be used to indicate how many stations are required, where they should be located and the frequency of monitoring.

- One participant, Walter Giger, described a case where a lake model that connected hydrology and chemical fate was used to reduce the number of samplings done through the year for a substance with regular constant releases. Note that this method would not work for spiked or intermittent releases.

- Another participant (Richard Murray-Smith) described a case where a site specific model was used to determine spatial design for biological monitoring for biological effects close to an outfall.

- Participants also noted that there is no single way to conduct all the monitoring programs because the environment is not the same everywhere (Monitoring Tailor-made Workshop (WHO Geneva)).

Discuss the possibility of models in helping estimating the level of detection needed for analytical techniques and the concentrations of chemicals in case of analytical techniques are not available

Can models be used to set level of detection?

- If carcinogenic substances are being modelled, then the detection limit is set as low as possible.

- Otherwise, models could potentially be used this way, but there was no experience in the group. 


\section{CONCLUSION AND RECOMMENDATIONS}

Improve the flexibility of monitoring programs by providing the ability to add process-oriented research activities that are focused on gaining greater and more complete understanding of the system. This interaction of research and monitoring can provide feedback to both projects. Also, need to provide flexibility to explore a particular aspect of the system in more depth for refining risk assessments.

Large amounts of monitoring and ancillary data exist and can be used to gain insights into particular processes. There is a need to identify and/or develop a system for increasing communication about what data are needed and what data are available (e.g., conference on computer as a first step).

There is a need for harmonisation of terminology for monitoring and modelling. The draft of definitions with modifications recommendations in this workshop could form the basis for this activity by OECD. (Note; need to add uncertainty, parameter, structure, data)

Existing monitoring data are probably better suited for validating emission/source models (for point sources, there is a potential here; however, there is a concern with the different units (i.e., $\mathrm{mg} / \mathrm{d} \mathrm{vs} . \mathrm{mg} / \mathrm{l}$ ) that are used) than for exposure assessment models which require a complete understanding of the processes that effect the chemical's fate.

Monitoring data can be used far more easily for initial and endpoint concentrations but in most cases can not currently be used to identify steps/processes. This must be done in laboratory or controlled field tests. These could be added in a research survey.

More validation of regulatory models are needed. Each component of the model needs to be validated, not just overall results as these could give a false sense of validation.

OECD should look at development of a meta-database on monitoring programs for people to get information on which programs have occurred or are ongoing what is in the database and contact information (e.g., Background Document 2). But this document is just the first step and there is a need to expand to additional sources.

Distributed database rather than a single collected database is recommended. These databases could use password protection to limit access when necessary. Prototype of this type of database is being developed for selected EU countries. Sweden also has a system for agencies and some of these data are accessible to the public.

Need to identify exactly what are the impediments/limitations to sharing data (e.g., personal ownership, concerns about how the data are used, legal restrictions, costs for access, form that it is available) so that strategies can be developed that could work in each case.

Collect information on statistical and other quantitative techniques that have been developed for calibration and validation of models. 


\section{Annex 9}

\section{Members of the Working Group on Environmental Exposure Assessment}

(as of May 1998)

\begin{tabular}{|c|c|c|}
\hline \multicolumn{3}{|l|}{ CANADA } \\
\hline Mr. Patrick DOYLE & $\begin{array}{l}\text { Environment Canada } \\
\text { Commercial Chemicals Evaluation } \\
\text { Branch } \\
\text { 14th Floor } \\
\text { 351 St. Joseph Blvd. } \\
\text { Hull, Quebec, K1A 0H3 }\end{array}$ & $\begin{array}{l}\text { tel: } 18199531590 \\
\text { fax: } 18199534936 \\
\text { e-mail: pat.doyle@ec.gc.ca }\end{array}$ \\
\hline \multicolumn{3}{|l|}{ DENMARK } \\
\hline $\begin{array}{l}\text { Mr. Henrik Søren } \\
\text { LARSEN }\end{array}$ & $\begin{array}{l}\text { Danish Environmental Protection Agency } \\
\text { Chemicals Division } \\
\text { Strandgade } 29 \\
\text { DK-1401 Copenhagen }\end{array}$ & $\begin{array}{l}\text { tel: } 4532660100 \\
\text { fax: } 4532660479 \\
\text { e-mail: hel@ mst.dk }\end{array}$ \\
\hline \multicolumn{3}{|l|}{ FRANCE } \\
\hline Mr. Robert DIDERICH & $\begin{array}{l}\text { Institut National de l'Environnement } \\
\text { Industrial et des Risques (INERIS) } \\
\text { Parc Technologique ALATA - BP } 2 \\
\text { F-60550 Verneuil-en-Halatte }\end{array}$ & $\begin{array}{l}\text { tel: } 33344556216 \\
\text { fax: } 33344556767 \\
\text { e-mail: robert.diderich@ineris.fr }\end{array}$ \\
\hline \multicolumn{3}{|l|}{ GERMANY } \\
\hline Mr. Burkhard WAGNER & $\begin{array}{l}\text { Umweltbundesamt } \\
\text { Environmental Exposure Assessment } \\
\text { Postfach } 330022 \\
\text { D-14191 Berlin }\end{array}$ & $\begin{array}{l}\text { tel: } 493089033220 \\
\text { fax: } 493089033900 \\
\text { e-mail: } \\
\text { burkhard.wagner@uba.de }\end{array}$ \\
\hline \multicolumn{3}{|l|}{ JAPAN } \\
\hline Mr. Mineo TAKATSUKI & $\begin{array}{l}\text { Deputy Director } \\
\text { Chemicals Inspection \& Testing Institute } \\
\text { Chemicals Assessment Center } \\
\text { Technical Division } \\
\text { 5-6-21 Kameido, Kotu-ku } \\
\text { Tokyo } 136\end{array}$ & $\begin{array}{l}\text { tel: } 81336388847 \\
\text { fax: } 81336388840 \\
\text { e-mail: takatsuki@ citi.or.jp }\end{array}$ \\
\hline Mr. Kiyoshi TANABE & $\begin{array}{l}\text { National Institute for Environmental } \\
\text { Studies } \\
\text { Regional Environment Division } \\
\text { 16-2, Onogawa, Tsukuba } \\
\text { Ibaraki, 305 }\end{array}$ & $\begin{array}{l}\text { tel: } 81298502478 \\
\text { fax: } 81298502570 \\
\text { e-mail: tanabe@ @nies.go.jp }\end{array}$ \\
\hline \multicolumn{3}{|c|}{ THE NETHERLANDS } \\
\hline $\begin{array}{l}\text { Mr. Peter VAN DER } \\
\text { ZANDT }\end{array}$ & $\begin{array}{l}\text { RIVM } \\
\text { Centre for Substances \& Risk Assessment } \\
\text { P.O. Box } 1 \\
\text { NL-3720 BA Bilthoven } \\
\end{array}$ & $\begin{array}{l}\text { tel: } 31302744082 \\
\text { fax: } 31302744401 \\
\text { e-mail: } \\
\text { peter.van.der.zandt@ rivm.nl }\end{array}$ \\
\hline
\end{tabular}




\begin{tabular}{|c|c|c|}
\hline \multicolumn{3}{|l|}{ SWEDEN } \\
\hline Mr. Alf LUNDGREN & $\begin{array}{l}\text { Swedish National Chemicals Inspectorate } \\
\text { Hazard and Risk Assessment Division } \\
\text { P.O. Box } 1384 \\
\text { S-171 } 27 \text { Solna }\end{array}$ & $\begin{array}{l}\text { tel: } 4687306742 \\
\text { fax: } 4687356798 \\
\text { e-mail: alfl@kemi.se }\end{array}$ \\
\hline \multicolumn{3}{|c|}{ UNITED KINGDOM } \\
\hline Mr. David BROOKE & $\begin{array}{l}\text { Building Research Establishment } \\
\text { Bucknalls Lane, Garston } \\
\text { GB-Watford WD2 7RJ }\end{array}$ & $\begin{array}{l}\text { tel: } 441923664862 \\
\text { fax: } 441923664609 \\
\text { e-mail: brookedn@bre.co.uk }\end{array}$ \\
\hline \multicolumn{3}{|l|}{ UNITED STATES } \\
\hline Mr. Patrick KENNEDY & $\begin{array}{l}\text { US EPA } \\
\text { Office of Pollution, Prevention \& } \\
\text { Toxics (7406), } \\
\text { Economics, Exposure, and Technology } \\
\text { Division, } \\
\text { Exposure Assessment Branch } \\
\text { 401 M Street SW } \\
\text { Washington, D.C. } 20460\end{array}$ & $\begin{array}{l}\text { tel: } 12022603916 \\
\text { fax: } 12022600981 \\
\text { e-mail: } \\
\text { kennedy.patrick@epamail.epa.gov }\end{array}$ \\
\hline \multicolumn{3}{|c|}{ EUROPEAN COMMISSION } \\
\hline Mr. Ferdinand KASER & $\begin{array}{l}\text { European Commission } \\
\text { European Chemicals Bureau } \\
\text { Environment Institute - JRC } \\
\text { I-21020 Ispra (VA) } \\
\text { Italy }\end{array}$ & $\begin{array}{l}\text { tel: } 39332789088 \\
\text { fax: } 39332789963 \\
\text { e-mail: ferdinand.kaser@jrc.it }\end{array}$ \\
\hline \multicolumn{3}{|l|}{ BIAC/ECETOC } \\
\hline $\begin{array}{l}\text { Ms. Christina E. } \\
\text { COWAN }\end{array}$ & $\begin{array}{l}\text { Proctor \& Gamble Company } \\
\text { Environmental Sciences Department } \\
5299 \text { Spring Grove Ave. } \\
\text { Cincinnati, Ohio } 45217 \\
\text { United States }\end{array}$ & $\begin{array}{l}\text { tel: } 15136278216 \\
\text { fax: } 15136275526 \\
\text { e-mail: cowan.ce@pg.com }\end{array}$ \\
\hline Mr. Tom FEIJTEL & $\begin{array}{l}\text { Proctor \& Gamble } \\
\text { European Technical Center } \\
\text { Temselaan } 100 \\
\text { B-1820 Strombeek-Bever } \\
\text { Belgium }\end{array}$ & $\begin{array}{l}\text { tel: } 3224562329 \\
\text { fax: } 3224562845 \\
\text { e-mail: feijtelt@pg.com }\end{array}$ \\
\hline
\end{tabular}




\section{Annex 10}

\section{Members of the Steering Group for the Workshop}

\begin{tabular}{|c|c|}
\hline ALLEMAGNE & GERMANY \\
\hline $\begin{array}{l}\text { Mr Burkhard WAGNER } \\
\text { Environmental Exposure Assessment } \\
\text { Umweltbundesamt } \\
\text { Postfach } 330022 \\
14191 \text { Berlin } \\
\end{array}$ & $\begin{array}{r}\text { Tel: 49-3089033220 } \\
\text { Fax: 49-3089033900 } \\
\text { E-mail: burkhard.wagner@uba.de }\end{array}$ \\
\hline ETATS-UNIS & UNITED STATES \\
\hline $\begin{array}{l}\text { Mr John L. SCHAUM } \\
\text { Chief } \\
\text { Exp. Analysis \& Risk Characterization Group } \\
\text { Nat'l Center for Environmental Assessment } \\
\text { US EPA } \\
\text { Office of Research \& Development (8623) } \\
401 \text { M Street NW } \\
\text { Washington, DC } 20460 \\
\end{array}$ & $\begin{array}{r}\text { Tel: 1-202 } 2605988 \\
\text { Fax: 1-202 } 2606370 \\
\text { E-mail: schaum.john@epamail.epa.gov }\end{array}$ \\
\hline JAPON & JAPAN \\
\hline $\begin{array}{l}\text { Mr Kiyoshi TANABE } \\
\text { Regional Environment Division } \\
\text { National Institute for Environmental Studies } \\
\text { 16-2 Onogawa } \\
\text { Tsukuba-shi } \\
\text { Ibaragi 305 }\end{array}$ & $\begin{array}{r}\text { Tel: } 81-298502478 \\
\text { Fax: } 81-298502570 \\
\text { E-mail: tanabe@ @nies.go.jp }\end{array}$ \\
\hline PAYS BAS & $\begin{array}{l}\text { NETHERLANDS } \\
\end{array}$ \\
\hline $\begin{array}{l}\text { Mr Cees VAN DE GUCHTE } \\
\text { Head of the Ecotoxicological Division } \\
\text { RIZA (Institute of Inland Water Management) } \\
\text { Postbus } 17 \\
\text { 8200 AA Lelystad } \\
\end{array}$ & $\begin{array}{r}\text { Tel: } 31-320298411 / 742 \\
31-6-52828158 \\
\text { Fax: } 31-320249218 \\
\text { E-mail: c.vdguchte@ riza.rws.minvenw.nl }\end{array}$ \\
\hline POLOGNE & $\begin{array}{l}\text { POLAND } \\
\end{array}$ \\
\hline $\begin{array}{l}\text { Mr Stanislaw TARKOWSKI } \\
\text { Head, Department of Environmental Health Hazards } \\
\text { The Nofer Institute of Occupational Medicine } \\
8 \text { Sw. Teresy Str. } \\
\text { PO Box } 199 \\
\text { 90-950 Lodz }\end{array}$ & $\begin{array}{r}\text { Tel: } 48-42314842 \\
\text { Fax: 48-42 } 568331 \\
\text { E-mail: tarko@porta.imp.lodz.pl }\end{array}$ \\
\hline
\end{tabular}




\begin{tabular}{|c|c|}
\hline SUEDE & $\underline{\text { SWEDEN }}$ \\
\hline $\begin{array}{l}\text { Mr Alf LUNDGREN } \\
\text { Hazard and Risk Assessment Division } \\
\text { Swedish National Chemicals Inspectorate } \\
\text { PO Box } 1384 \\
\text { S-171 } 27 \text { Solna } \\
\end{array}$ & $\begin{array}{r}\text { Tel: 46-8 } 7305700 \\
\text { Fax: 46-8 } 7357698 \\
\text { E-mail: alfl@kemi.se }\end{array}$ \\
\hline SUISSE & SWITZERLAND \\
\hline $\begin{array}{l}\text { Mr Walter GIGER } \\
\text { Swiss Federal Institute for Water Resources } \\
\text { and Water Pollution Control } \\
\text { Überlandstrasse } 133 \\
\text { CH-8600 Dübendorf }\end{array}$ & $\begin{array}{r}\text { Tel: 41-1 } 8235475 \\
\text { Fax: 41-1 } 8235028 \\
\text { E-mail: giger@eawag.ch }\end{array}$ \\
\hline \multicolumn{2}{|c|}{$\begin{array}{ll}\text { EUROPEAN COMMISSION } \\
\end{array}$} \\
\hline $\begin{array}{l}\text { Mr Bjorn HANSEN } \\
\text { European Chemicals Bureau } \\
\text { European Commission } \\
\text { Environment Institute - JRC } \\
\text { I-21020 Ispra, Italie } \\
\end{array}$ & $\begin{array}{r}\text { Tel: } 39-332785884 \\
\text { Fax: 39-33 } 2789963 \\
\text { E-mail: bjorn.hansen @jrc.i }\end{array}$ \\
\hline \multicolumn{2}{|c|}{ BIAC/ECETOC } \\
\hline $\begin{array}{l}\text { Mr Tom FEIJTEL } \\
\text { European Technical Center } \\
\text { Procter \& Gamble } \\
\text { Temselaan } 100 \\
\text { B-1820 Strombeek-Bever, Belgique } \\
\end{array}$ & $\begin{array}{r}\text { Tel: } 32-24562329 \\
\text { Fax: } 32-24562845 \\
\text { E-mail: feijtelt@pg.com }\end{array}$ \\
\hline $\begin{array}{l}\text { Ms Christina E. COWAN } \\
\text { Environmental Sciences Department } \\
\text { Procter \& Gamble Company } \\
5299 \text { Spring Grove Ave. } \\
\text { Cincinnati, Ohio 45217, Etats-Unis } \\
\end{array}$ & $\begin{array}{r}\text { Tel: } 1-5136278216 \\
\text { Fax: } 1-5136275526 \\
\text { E-mail: cowan.ce@pg.com }\end{array}$ \\
\hline
\end{tabular}




\section{Annex 11}

\section{References}

UN/ECE, 1996. Protection of Transboundary Waters. Guidance for Policy- and Decision-Making. Water Series No.3. ECE/CEP/11. ISBN 92-1-116658-6. New York

UN/ECE Task Force on Monitoring \& Assessment, 1996. Vol. 5: Sate of the Art on Monitoring and Assessment of Rivers. ISBN 9036945968. Lelystad, The Netherlands

Villars, M.T, 1995. Monitoring water quality in the future, Executive summary. ISBN 90-802637-6-1. Ministry of Housing, Spatial Planning and the Environment. Delft, The Netherlands

Adriaanse M., H.A.G. Niederländer, P.B.M. Stortelder, 1995. Monitoring water quality in the future, Vol.1: Chemical monitoring. ISBN 90-802637-1-0. Institute for Inland Water Management and Waste Water Treatment (RIZA), Lelystad and International Centre of Water Studies (ICWS), Amsterdam, The Netherlands

Nixon, S.C., Rees, Y.J., Gendebien, A. and Ashley, S.J., 1996. Requirements for water monitoring. EEA topic report 1 - inland waters. Copenhagen

Nixon, S.C., 1996. European freshwater monitoring network design. EEA topic report 10 - inland waters. Copenhagen

ECETOC, 1999. Monitoring and modelling of industrial organic chemicals, with particular reference to aquatic risk assessment. Technical report No.76. Brussels

OECD. 1999. Environmental Exposure Assessment Strategies for Existing Industrial Chemicals in OECD Member Countries, OECD Environmental Health and Safety Publications Series on Testing and Assessment No. 17. Paris 